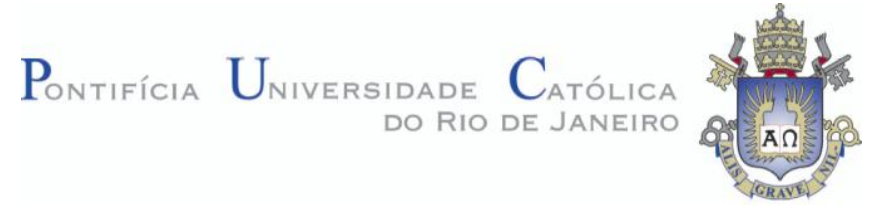

Raphael Guimarães Duarte Pinto

Simulação de uma Caldeira de Recuperação de Calor em uma usina de Ciclo Combinado

Dissertação de Mestrado

Dissertação apresentada como requisito parcial para obtenção do título de Mestre pelo Programa de PósGraduação em Engenharia Mecânica da PUC-Rio.

Orientador: Prof. Sergio Leal Braga Co-orientador: Dr. Sandro Barros Ferreira 
Raphael Guimarães Duarte Pinto

\section{Simulação de uma Caldeira de Recuperação de Calor em uma usina de Ciclo Combinado}

Dissertação apresentada como requisito parcial para obtenção do título de Mestre pelo Programa de PósGraduação em Engenharia Mecânica da PUC-Rio. Aprovada pela Comissão Examinadora abaixo assinada.

Prof. Sergio Leal Braga

Orientador

Pontifícia Universidade Católica do Rio de Janeiro - PUC-Rio

Dr. Sandro Barros Ferreira

Co-orientador

GT2 Energia

Prof. José Alberto dos Reis Parise

Pontifícia Universidade Católica do Rio de Janeiro - PUC-Rio

Prof. Carlos Valois Maciel Braga

Pontifícia Universidade Católica do Rio de Janeiro - PUC-Rio

Prof. José Eugenio Leal

Coordenador(a) Setorial do Centro Técnico Científico - PUC-Rio

Rio de Janeiro, 25 de maio de 2012. 
Todos os direitos reservados. É proibida a reprodução total ou parcial do trabalho sem autorização da universidade, do autor e do orientador.

\section{Raphael Guimarães Duarte Pinto}

Graduou-se em Engenharia Mecânica e Engenharia de Controle e Automação pela Pontifícia Universidade Católica do Rio de Janeiro - PUC-Rio, em 2009. Candidato ao título de mestre no Departamento de Engenharia Mecânica da PUC-Rio.

Ficha Catalográfica

\section{Pinto, Raphael Guimarães Duarte}

Simulação de uma caldeira de recuperação de calor em uma usina de ciclo combinado / Raphael Guimarães Duarte Pinto ; orientador: Sergio Leal Braga. $-2012$.

82 f. : il. (color.) ; $30 \mathrm{~cm}$

Dissertação(mestrado)-Pontifícia Universidade Católica do Rio de Janeiro, Departamento de Engenharia Mecânica, 2012.

Inclui bibliografia

1. Engenharia mecânica - Teses. 2. Algoritmos genéticos. 3. Caldeiras de recuperação de calor. 4. Ciclo combinado. 5. Diagnóstico. 6. Simulação off-design. I. Braga, Sergio Leal. II. Pontifícia Universidade Católica do Rio de Janeiro. Departamento de Engenharia Mecânica. III. Título. 


\section{Agradecimentos}

Agradeço a Sandro Barros Ferreira e Rafael Silvério Barbosa pela grande oportunidade e confiança ao me incorporarem nesse projeto, e, principalmente, por toda a orientação por eles concedida.

Agradeço à minha família,

Ao meu avós Moacyr e Eurides, pela honra.

À minha mãe Teresinha, pela vida.

Ao meu pai Élcio, pelo sonho.

Ao meu padrinho Luiz, pela ciência.

Ao meu mestre Ian, pelo caminho.

Aos meus amigos Skeli, Beto e Gunzo, pelo que não posso contar.

À minha irmã Raquell, pela cumplicidade, apoio e carinho.

À minha namorada Bárbara, pelo amor e a certeza. 


\section{Resumo}

Pinto, Raphael Guimarães Duarte; Braga, Sergio Leal. Simulação de uma Caldeira de Recuperação de Calor em uma usina de Ciclo Combinado. Rio de Janeiro, 2012. 82p. Dissertação de Mestrado - Departamento de Engenharia Mecânica, Pontifícia Universidade Católica do Rio de Janeiro.

A evolução das turbinas a gás industriais resultou em um processo de combustão mais eficiente que permitiu a elevação da temperatura dos gases na exaustão dessa máquina. Assim, caldeiras de recuperação de calor cada vez mais complexas foram desenvolvidas com o intuito de aproveitar ao máximo o potencial energético na exaustão das turbinas. Dessa forma, modelos computacionais capazes de prever as condições de operação do equipamento se mostraram necessários de maneira a analisar o comportamento da máquina em diferentes situações, visando à máxima eficiência do processo. Esta dissertação descreve um modelo computacional capaz de simular o funcionamento fora do ponto de projeto, em regime permanente, de uma caldeira de recuperação de calor operando em uma usina de ciclo combinado, enfatizando sua utilização em sistemas de diagnóstico. As rotinas foram desenvolvidas em FORTRAN e os trocadores de calor presentes na HRSG foram modelados individualmente e calibrados através de um sistema de otimização utilizando algoritmos genéticos, responsável por minimizar o desvio do modelo. O programa desenvolvido foi validado contra dados de operação de uma usina real e mostrou resultados satisfatórios, que confirmam a robustez e fidelidade do modelo de simulação.

\section{Palavras-chave}

Algoritmos Genéticos; Caldeiras de Recuperação de Calor; Ciclo Combinado; Diagnóstico; Simulação off-design. 


\section{Abstract}

Pinto, Raphael Guimarães Duarte; Braga, Sergio Leal (Advisor). Simulation of Heat Recovery Steam Generator Operating in a Combined Cycle Plant. Rio de Janeiro, 2012. 82p. MSc. Dissertation Departamento de Engenharia Mecânica, Pontifícia Universidade Católica do Rio de Janeiro.

The heavy duty gas turbines evolution and, consequently, a more efficient combustion process, allowed the temperature rising of the machines' exhaust gases. Thus, more complex heat recovery steam generators were developed in order to maximize the use of that energy potential. Therefore, computational models capable to predict the operational conditions of the equipment may be needed in order to analyze the machine's behavior for different situations, in a way to maximize the process efficiency. This thesis describes a computational model able to simulate the off-design behavior of a heat recovery steam generator operation in a combined cycle plant, emphasizing its utilization in diagnostics systems. The routines were developed using FORTRAN, each heat exchanger inside the Heat Recovery Steam Generator (HRSG) was designed individually and the calibration was done by a genetic algorithm responsible for minimizing the model's deviations. The developed program was validated against operational data from a real plant and showed satisfactory results, confirming the robustness and fidelity of this simulation model.

\section{Keywords}

Combined Cycle; Diagnostics; Genetic Algorithm; Heat Recovery Steam Generators; Off-design Simulation. 


\section{Sumário}

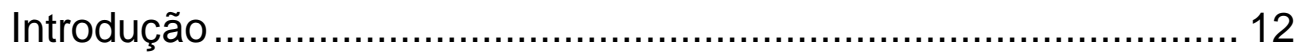

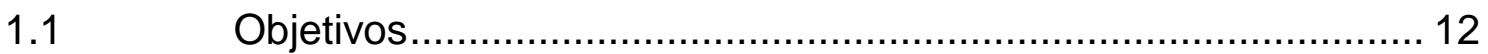

$1.2 \quad$ Estrutura da Dissertação ...................................................... 13

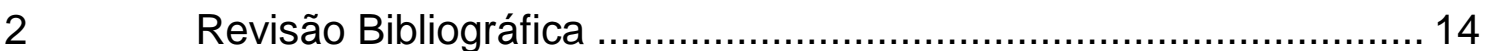

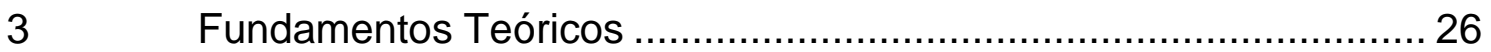

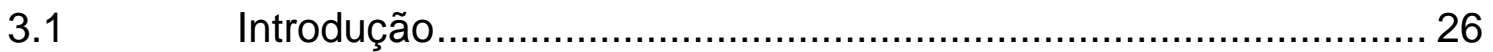

3.1.1 Ciclo Combinado ......................................................... 26

3.1.2 Caldeiras de Recuperação de Calor ................................ 27

3.1.3 Modelo Matemático - Ponto de Projeto ............................. 30

3.1.4 Modelo Matemático - Off-design ................................. 40

$4 \quad$ Algoritmos Genéticos ....................................................... 46

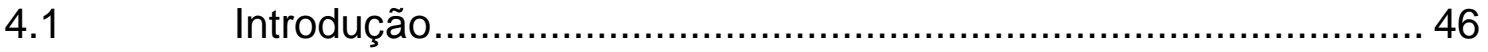

4.2 Aplicação ao Caso Estudado................................................ 48

4.2.1 O processo de Otimização ................................................ 48

4.2.2 Resultados Obtidos .................................................... 51

5 Simulação de uma Caldeira de Recuperação de Calor em uma usina de Ciclo Combinado ........................................................... 53

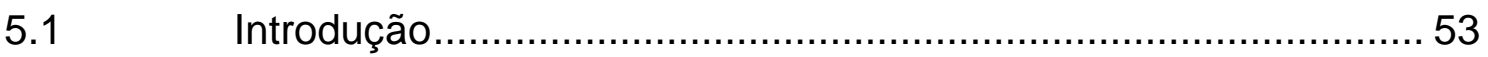

5.1.1 Duto de Transição da Admissão .................................... 55

5.1.2 Reaquecedor \#2 / Superaquecedor HP \#2 .......................... 55

5.1.3 Reaquecedor \#1 / Superaquecedor HP \#1 .......................... 55

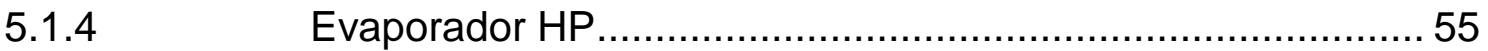

Economizador HP \#2 …............................................... 55

5.1.6 Superaquecedor LP / Superaquecedor IP / Evaporador IP .... 56

5.1.7 Economizador HP \#1 / Economizador IP \#1 /

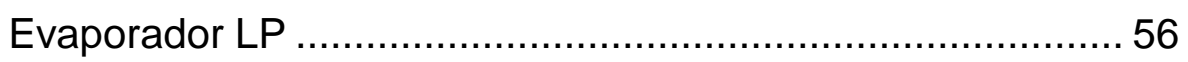

5.1.8 Preaquecedor........................................................ 56 


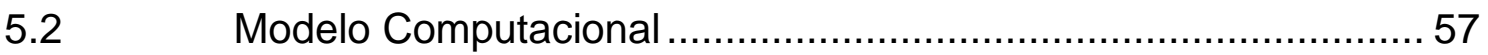

5.2.1 Metodologia Geral para o Cálculo dos Trocadores de Calor . 60

5.2.2 Metodologia de Cálculo para os Trocadores de Calor Paralelos (ECON HP\#1 e EVAP IP) .................................... 63

5.2.3 Organização do Modelo Computacional da Caldeira de

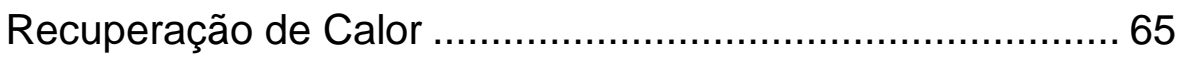

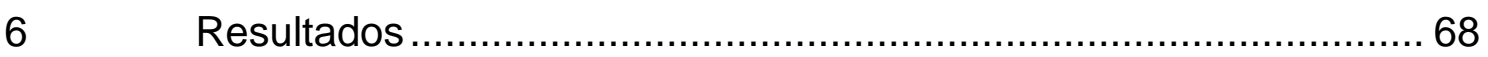

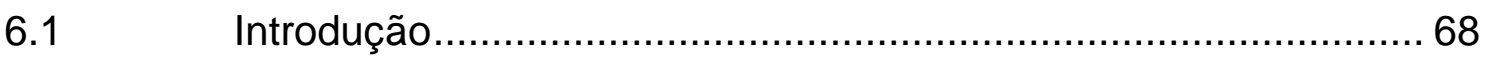

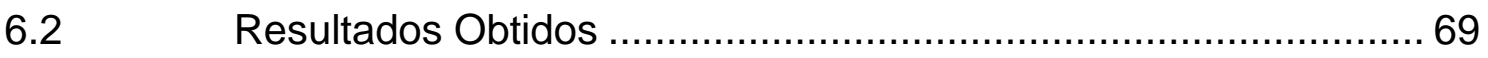

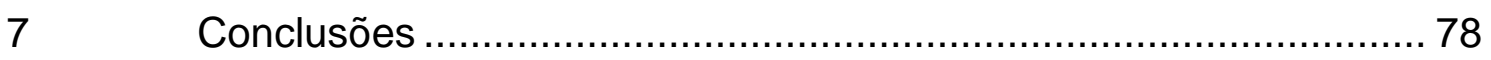

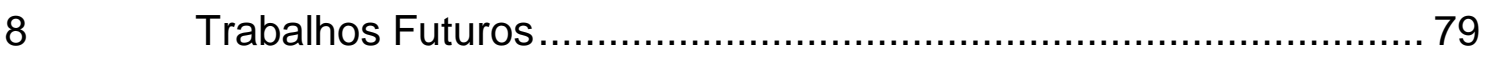

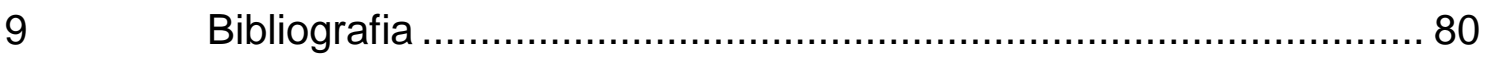




\section{Lista de Figuras}

Figura 1 - Comparação entre o Gás Natural e o Gás de coque para diferentes condições de operação [5].

Figura 2 - Influência da variação da temperatura ambiente na potência produzida por um ciclo combinado [5]. 15

Figura 3 - Comparação dos resultados obtidos com os dados de operação para diferentes pontos de operação (Turbina a gás com 75\% da carga total) [6]. 16

Figura 4 - Variação da condição do gás de exaustão de uma turbina a gás durante a partida [8]. 18

Figura 5 - Elementos do HRSG [9]. 18

Figura 6 - Variação com o tempo da temperatura dos gases quentes no evaporador a alta pressão. [9]. 19

Figura 7 - Diagrama do sistema bottoming de dois níveis de pressão [10] ...... 19 Figura 8 - Condição dos gases de exaustão na entrada da caldeira de recuperação. [10] 20

Figura 9 - Variações nas condições de vapor em HP e LP:

(a) sem controle de potência; (b) com controle de potência [10] 21

Figura 10 - Variações nas taxas nas taxas da vazão de água de alimentação, nível do tubulão e vazão em massa na entrada e saída do evaporador (de baixa e alta pressão): (a) sem controle de potência;

(b) com controle de potência [10]. 21

Figura 11 - Variação na potência da turbina a vapor (HP e LP):

(a) sem controle de potência de eixo; (b) com controle de potência [10]. 21

Figura 12 - Escoamento em massa dos gases quente em função do tempo [11]. 22

Figura 13 - Temperatura dos gases no sistema de alta pressão [11]. 22

Figura 14 - Temperatura dos gases no sistema de pressão intermediária [11]. 
Figura 15 - Temperaturas do vapor de saída do evaporador e superaquecedor de alta e média pressão [11]. ............................................. 23

Figura 16 - Pressões do vapor no tubulão nos sistemas de HP e IP [11]. ....... 23

Figura 17 - Vazões de vapor nos evaporadores dos sistemas de HP e IP [11].

Figura 18 - Temperatura do metal do superaquecedor e dos gases

quentes de saída [11]. 24

Figura 19 - Distribuição do fluxo de calor no superaquecedor $\left(\mathrm{kW} / \mathrm{m}^{2}\right)$ [13].... 25

Figura 20 - Exemplo de ciclo combinado (Brayton/Rankine) para

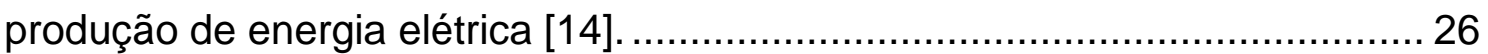

Figura 21 - Esquema do funcionamento de uma OTSG ................................ 29

Figura 22: Esquema do superaquecedor utilizado para fins de cálculo. .......... 30

Figura 23: Esquema do evaporador utilizado para fins de cálculo ................... 35

Figura 24: Esquema do economizador utilizado para fins de cálculo ................ 37

Figura 25 - Estrutura do programa de otimização dos expoentes de

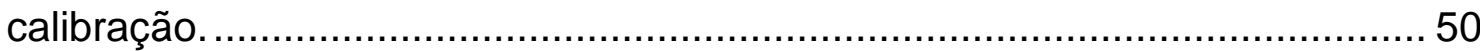

Figura 26 - Configuração da caldeira de recuperação de calor modelada ....... 54

Figura 27 - Exemplo de um componente operando como trocador de calor. ... 57

Figura 28 - Fluxo de informações no modelo computacional ...........................58

Figura 29 - Método de cálculo do trocador de calor .......................................... 61

Figura 30 - Trocadores de calor em paralelo ............................................... 63

Figura 31 - Diagrama do modelo computacional da caldeira de recuperação de calor

Figura 32 - Desvios obtidos para a temperatura do vapor na saída do reaquecedor de IP \#2.

Figura 33 - Desvios obtidos para a pressão do vapor na saída

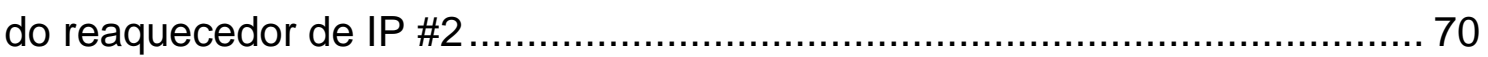

Figura 34 - Desvios obtidos para a vazão na superaquecedor de HP \#2 ........ 70

Figura 35 - Desvios obtidos para a temperatura do vapor na saída do superaquecedor de HP \#2

Figura 36 - Desvios obtidos para a pressão do vapor na saída do superaquecedor de HP \#2 71

Figura 37 - Desvios obtidos para a pressão do vapor na saída do evaporador de HP 72 
Figura 38 - Desvios obtidos para a pressão do vapor na saída do evaporador de IP

Figura 39 - Desvios obtidos para a vazão de vapor no superaquecedor de LP

Figura 40 - Desvios obtidos para a temperatura do vapor na saída do

superaquecedor de LP

Figura 41 - Desvios obtidos para a pressão do vapor na saída do

superaquecedor de LP 74

Figura 42 - Desvios obtidos para a temperatura do vapor na saída do superaquecedor de IP 75

Figura 43 - Desvios obtidos para a pressão do vapor na saída do superaquecedor de IP 75

Figura 44 - Desvios obtidos para a vazão de vapor no

superaquecedor de IP 75

Figura 45 - Desvios obtidos para a temperatura dos gases de exaustão na entrada do reaquecedor de IP \#2. 76

Figura 46 - Desvios obtidos para a pressão dos gases de exaustão na entrada do reaquecedor de IP \#2 


\section{Introdução}

O número de usinas Termelétricas no Brasil aumentou consideravelmente devido à implantação do Plano Prioritário de Termelétricas em 2000, decorrente da crise energética. Consequentemente, o número de caldeiras de recuperação de calor instaladas no território nacional também cresceu significantemente, uma vez que grande parte desses empreendimentos opera em ciclo combinado, devido à sua maior eficiência energética.

O monitoramento dos principais equipamentos presentes em um ciclo combinado é vital para a segurança do mesmo, bem como para estimar a necessidade de paradas para manutenção das máquinas, uma vez que esse período ocioso é convertido em um prejuízo financeiro considerável para a usina.

Logo, ferramentas de diagnóstico são importantes instrumentos para predizer o comportamento dos equipamentos e facilitar a tomada de decisões técnicas sem comprometer a integridade das máquinas e trocadores de calor, garantindo uma operação segura e eficiente.

\subsection{Objetivos}

Essa dissertação consistiu em desenvolver um programa computacional para a simulação de caldeiras de recuperação que calor que pode ser usado para sistemas de diagnóstico de tal equipamento.

Basicamente, o programa é composto pelos modelos individuais de cada trocador de calor (superaquecedores, reaquecedores, evaporadores e economizadores), gerenciados por um programa principal. Cada trocador de calor é modelado em seu ponto de projeto, sendo esse um modelo auxiliar no cálculo do offdesign. 


\subsection{Estrutura da Dissertação}

A dissertação se encontra dividida em oito capítulos, após a introdução, tem-se:

- Capítulo 2 - Revisão Bibliográfica: Estudos de simulação de caldeiras, em regime transitório e permanente.

- Capítulo 3 - Fundamentos Teóricos: Introdução sobre ciclo combinado com foco em caldeiras de recuperação de calor e descrição detalhada do modelo matemático dos trocadores de calor;

- Capítulo 4 - Algoritmos Genéticos: Introdução ao conceito de otimização utilizando algoritmos genéticos e como a teoria foi aplicada ao caso em questão;

- Capítulo 5 - Simulação de uma Caldeira de Recuperação em Ciclo Combinado: Descrição detalhada do modelo computacional utilizado para o cálculo;

- Capítulo 6 - Resultados: Apresentação dos resultados obtidos pelo modelo computacional;

- Capítulo 7 - Conclusões: Comentários sobre os resultados;

- Capítulo 8 - Trabalhos Futuros: Sugestões de pesquisas futuras baseadas no estudo dessa dissertação;

- Capítulo 9 - Referências Bibliográficas: Lista de trabalhos citados ao longo do texto. 


\section{2 Revisão Bibliográfica}

Neste capítulo é apresentada a revisão bibliográfica relativa aos estudos sobre a análise de desempenho de caldeiras de recuperação de calor.

Diversos estudos sobre o cálculo das condições de operação das Caldeiras de Recuperação de Calor em ponto de projeto e off-design foram realizados. Pode-se dar maior ênfase aos estudos de Ganapathy, V. Em seu livro [1], Ganapathy faz um amplo estudo dos aspectos termodinâmicos das HRSGs, exibindo uma grande variedade de problemas de operação e de projeto, além disso, o equacionamento termodinâmico para análise do desempenho dos principais tipos de evaporadores, superaquecedores e economizadores é mostrado pelo autor. Segundo Ganapathy, em [2], a simulação de caldeiras de recuperação de calor auxilia projetistas no momento de concepção do equipamento e também operadores para tomadas de decisões.

Em [3], Ganapathy, V. apresenta programas de interesse a projetistas de plantas operando com vapor, operadores e consultores. Em uma primeira etapa o autor aborda o desenvolvimento de programas para a análise do combustível (líquido, sólido e gasoso), da combustão e eficiências de caldeiras recuperadoras de calor. Posteriormente, rotinas para a determinação das quedas de pressão nas tubulações dos trocadores de calor são descritas, seguidas pelos cálculos de troca de calor propriamente ditos, isto é, determinação de coeficientes de troca em diversas configurações, cálculos de temperatura do metal e perdas de calor. Posteriormente, Ganapahty foca no comportamento do vapor e suas características. Finalmente, uma análise da performance dos equipamentos de troca de calor é descrita, bem como rotinas computacionais para realização dessa tarefa.

Ganapathy, no artigo [4], menciona a importância de um modelo capaz de prever as condições de operação da HRSG fora do seu ponto de projeto, pois a variação dos perfis de temperatura do gás de exaustão afetam diretamente o vapor, alterando toda a performance do equipamento. $\mathrm{O}$ autor mostra como prever tais condições através de um modelo simplificado, o qual independe da inserção de parâmetros geométricos muito detalhados da caldeira, tais como diâmetro, comprimento, número de tubos, densidade de aletas, etc. Utilizando dados relativos à condição de operação em ponto do projeto, o desempenho em cargas parciais pode ser obtido através de uma rápida convergência iterativa. 
Shi, An, Chen e Zhang em [5], seguiram uma linha de semelhante à de Ganapathy em [4]. Fazendo uso das características de operação no ponto de projeto para determinar o comportamento em off-design. Relações capazes de correlacionar a troca de calor e queda de pressão do ponto de projeto com as cargas parciais são utilizadas pelo autor. O desempenho da caldeira de recuperação no ciclo combinado foi avaliado e os resultados obtidos mostram uma comparação entre o ciclo combinado queimando gás natural e gás de coque em diferentes condições de operação (Figura 1).

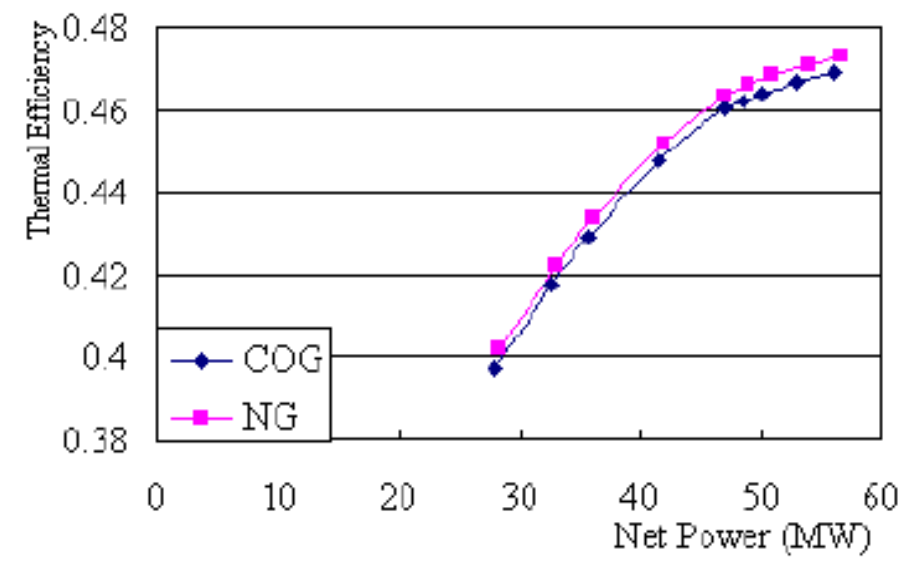

Figura 1 - Comparação entre o Gás Natural e o Gás de coque para diferentes condições de operação [5].

Um estudo da influência da variação da temperatura ambiente e suas consequências na potência global do ciclo também foi realizado e seus resultados são exibidos na Figura 2.

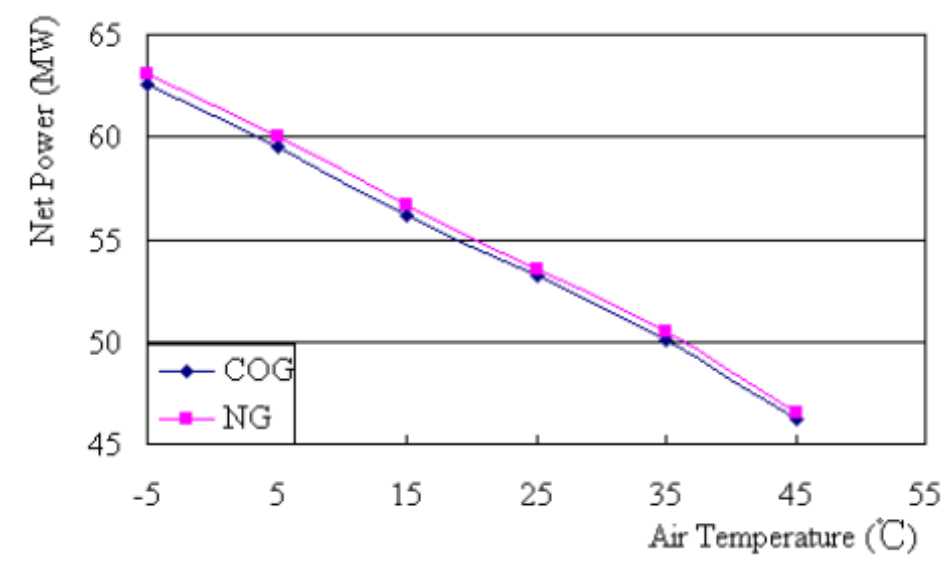

Figura 2 - Influência da variação da temperatura ambiente na potência produzida por um ciclo combinado [5]. 
Assato, [6], realizou a simulação de uma caldeira de recuperação com dois níveis de pressão para ponto de projeto e off-design. As quedas de pressão, superfícies de troca e os coeficientes globais de troca de calor dos trocadores são calculados através do valor no ponto de projeto ajustado por coeficientes de correção calibrados de acordo com dados de operação off-design do fabricante.

O modelo foi validado contra dados de uma caldeira de recuperação com dois níveis de pressão, sendo os desvios obtidos inferiores a 2,5\%. A Figura 3 mostra os desvios obtidos para a condição de $75 \%$ de carga da turbina a gás.

\begin{tabular}{|c|ccc|c|c|c|}
\cline { 2 - 7 } \multicolumn{1}{c|}{} & \multicolumn{6}{c|}{$75 \%$ LOAD } \\
\cline { 2 - 8 } \multicolumn{1}{c|}{} & \multicolumn{3}{c|}{ Plant } & \multicolumn{3}{c|}{ Deviation ${ }^{*} \%$} \\
\hline Point & $\mathrm{P}[\mathrm{kPa}]$ & $\left.\mathrm{T}^{\circ} \mathrm{C}\right]$ & Flow [kg/s] & $\mathrm{P}[\mathrm{kPa}]$ & $\left.\mathrm{T}^{\circ} \mathrm{C}\right]$ & Flow [kg/s] \\
\hline 1 & 2,10 & 547,20 & 230,10 & 0,00 & 0,00 & 0,00 \\
2 & 2,01 & 532,80 & 230,10 & 0,00 & 0,00 & 0,00 \\
3 & 1,93 & 509,70 & 230,10 & 0,00 & $-0,02$ & 0,00 \\
4 & 1,85 & 471,50 & 230,10 & 0,00 & $-0,10$ & 0,00 \\
5 & 1,42 & 307,40 & 230,10 & 0,00 & $-0,01$ & 0,00 \\
6 & 1,39 & 304,10 & 230,10 & 0,00 & 0,00 & 0,00 \\
7 & 1,17 & 269,30 & 230,10 & 0,00 & $-0,18$ & 0,00 \\
8 & 0,95 & 234,70 & 230,10 & 0,11 & $-0,03$ & 0,00 \\
9 & 0,74 & 218,90 & 230,10 & 0,00 & $-0,19$ & 0,00 \\
10 & 0,70 & 211,40 & 230,10 & 0,00 & $-0,22$ & 0,00 \\
11 & 0,51 & 174,00 & 230,10 & 0,20 & $-0,68$ & 0,00 \\
12 & 0,42 & 147,30 & 230,10 & 0,24 & $-0,78$ & 0,00 \\
13 & 0,38 & 126,70 & 230,10 & 0,26 & $-1,20$ & 0,00 \\
14 & 240,00 & 44,80 & 33,93 & 0,00 & $-0,87$ & $-0,57$ \\
15 & 240,00 & 79,90 & 33,93 & 0,00 & $-0,43$ & $-0,57$ \\
16 & 240,00 & 125,40 & 33,93 & 0,00 & $-0,44$ & $-0,57$ \\
21 & 3860,00 & 128,80 & 4,68 & 0,00 & 1,11 & $-2,44$ \\
24 & 3860,00 & 217,80 & 4,68 & 0,47 & 0,57 & $-2,44$ \\
25 & 2630,00 & 217,90 & 4,68 & 0,00 & 0,58 & $-2,44$ \\
26 & 2630,00 & 226,60 & 4,68 & 0,00 & $-0,03$ & $-2,44$ \\
27 & 2550,00 & 289,10 & 4,68 & $-0,02$ & 0,11 & $-2,44$ \\
28 & 12350,00 & 125,40 & 29,25 & 0,00 & $-2,35$ & $-0,27$ \\
29 & 12280,00 & 199,20 & 29,25 & 0,00 & $-0,80$ & $-0,27$ \\
30 & 12210,00 & 229,20 & 29,25 & 0,01 & $-0,42$ & $-0,27$ \\
31 & 12150,00 & 290,90 & 29,25 & 0,01 & $-0,04$ & $-0,27$ \\
32 & 8400,00 & 298,40 & 29,25 & 0,00 & $-0,01$ & $-0,27$ \\
33 & 8360,00 & 298,10 & 29,25 & 0,00 & 0,00 & $-0,27$ \\
34 & 8310,00 & 388,40 & 29,25 & 0,00 & 0,09 & $-0,27$ \\
35 & 8260,00 & 466,50 & 29,25 & 0,00 & 0,12 & $-0,27$ \\
36 & 8160,00 & 450,20 & 29,25 & 0,00 & 0,07 & $-0,27$ \\
37 & 7930,00 & 502,00 & 29,25 & 0,00 & 0,10 & $-0,27$ \\
\hline
\end{tabular}

Figura 3 - Comparação dos resultados obtidos com os dados de operação para diferentes pontos de operação (Turbina a gás com $75 \%$ da carga total) [6].

Manassaldi, Mussati e Scena, citam em [7] a forte dependência que o a caldeira de recuperação de calor tem sobre o desempenho do ciclo combinado. E, devido a esse fato, propõe um programa para a otimização da HRSG. Um programa matemático integral não linear é utilizado, sendo resolvido por um sistema algébrico. 
No artigo são apresentadas as equações do modelo matemático dos trocadores de calor, assim como correlações para queda de pressão e cálculo dos coeficientes de troca de calor.

O modelo da caldeira permite a variação de parâmetros tais como o design geométrico, a seleção do diâmetro das tubulações e características das aletas dos trocadores de calor.

A estratégia de solução/otimização consiste de duas etapas:

1. Focada no processo de otimização, porém considerando apenas a energia global fornecida e os balanços de massa. Essa fase é responsável por fornecer as condições iniciais da próxima etapa;

2. Um modelo completo e com decisões rigorosas baseadas em decisões lógicas relacionadas à geometria é resolvido, resultando na configuração ótima do equipamento.

Diferentes casos de estudo considerando várias funções objetivo foram resolvidos com sucesso e sem dificuldades de convergência. A configuração final sugerida pelo programa depende fortemente da função objetivo utilizada na otimização.

Kim, Lee e Ro, em [8], desenvolveram um programa capaz de prever as características do transiente de caldeiras de recuperação e o comportamento dos componentes envolvidos no sistema de alta pressão (HP) da HRSG durante a partida. A ênfase no sistema de HP é dada devido às tensões térmicas no tubulão durante a partida do equipamento. Três tipos de partida da caldeira (turbina a gás em regime permanente sem bypass, turbina a gás em regime permanente com bypass e partida da turbina a gás) são simulados. Além disso, duas formas de saída da turbina a gás são analisadas. A primeira, sequencial, se caracteriza pela passagem do gás de exaustão pela HRSG após a turbina alcançar o regime. O segundo tipo consiste na partida simultânea, isto é, a caldeira começa a operar juntamente com a turbina a gás.

Para o desenvolvimento do trabalho, os autores consideraram que o fluxo do gás é muito rápido em relação à resposta térmica do metal, dessa forma a inércia do gás foi desconsiderada, assim como a inércia do vapor. A inércia da mistura de água/vapor foi considerada devido à sua mudança de densidade e energia interna durante 0 processo de evaporação, dentro do evaporador o coeficiente de troca térmica da mistura água/vapor é consideravelmente maior do que a do gás, assim foi considerado que a temperatura do metal no evaporador é igual à temperatura da mistura. 
Os resultados obtidos nesse estudo, Figura 4, demonstram que a partida sequencial gera um aumento na pressão e temperatura dos componentes em geral, em um menor intervalo de tempo, isso acarreta em um maior stress térmico. Mostrando-se assim a necessidade de um bypass para evitar danos na maquina.

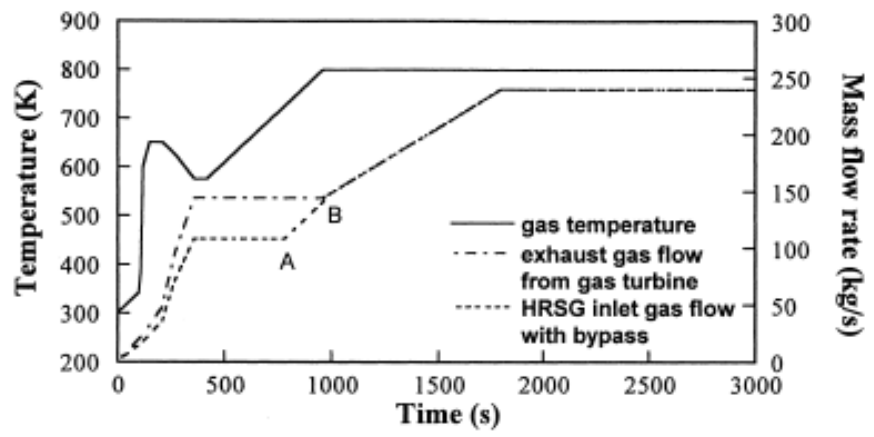

Figura 4 - Variação da condição do gás de exaustão de uma turbina a gás durante a partida [8].

Sanaye e Rezazadeh mencionam em [9] a importância de predizer condições de operações da caldeira em operações em regime e transitórias devido à grande importância da HRSG em plantas de potência. Os autores realizaram um estudo sobre o comportamento da HRSG considerando a variação da temperatura da mistura de água/vapor e do metal (efeitos de radiação também foram modelados) e mudanças de pressão dentro do tubulão.

Um programa computacional foi desenvolvido para a análise do regime permanente e transiente, sendo validado contra os dados medidos em uma planta real composta por quatro turbinas a gás (100MW) operando em ciclo combinado (HRSGs com três níveis de pressão e com damper). A Figura 5 mostra o esquema dos equipamentos presentes na caldeira e modelados no programa feito para o estudo em questão.

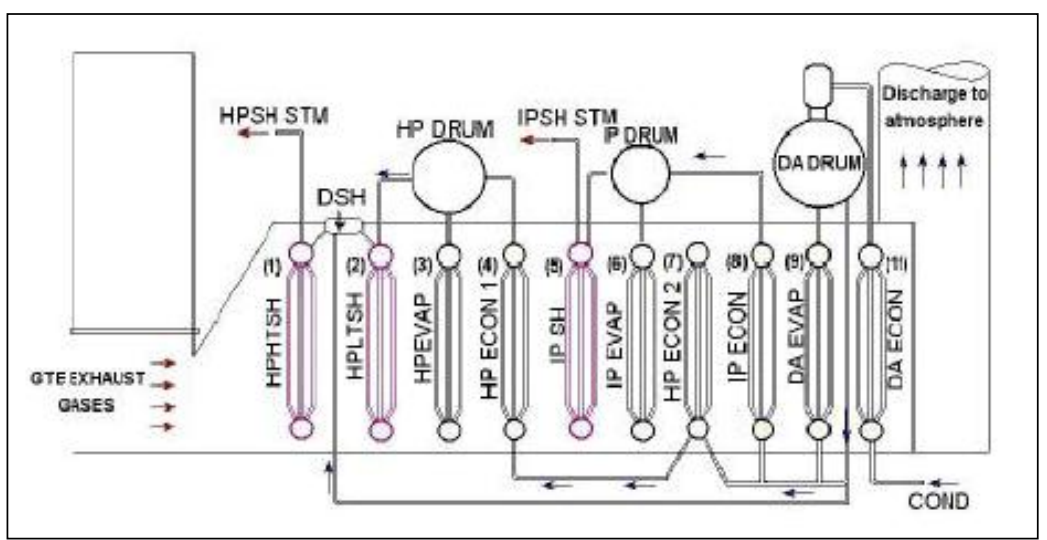

Figura 5 - Elementos do HRSG [9]. 
Os resultados gerados durante a simulação de uma partida a frio quando comparados contra os dados de uma planta real mostraram discrepâncias de $3,8 \%$ para a temperatura e 9,2\% para a pressão. A Figura 6 mostra o comportamento dos dados medidos e dos resultados do programa ao longo do tempo.

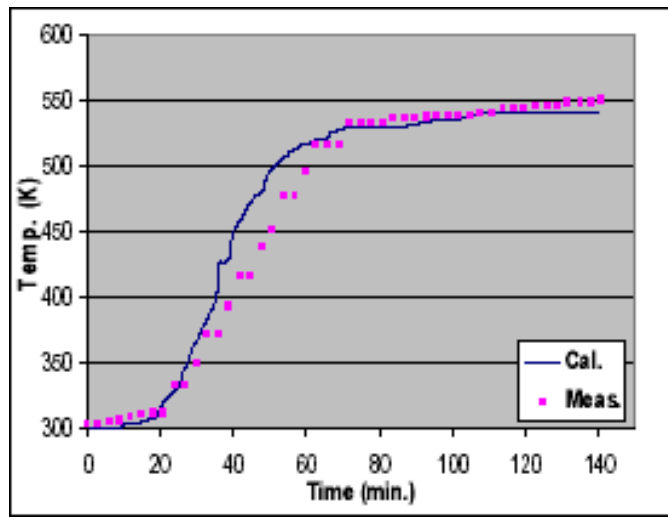

Figura 6 - Variação com o tempo da temperatura dos gases quentes no evaporador a alta pressão. [9]

Kim, Park e Ro, em [10], fizeram uma simulação do transiente de uma planta de potência operando em ciclo combinado utilizando sistema bottoming de dois níveis de pressão, conforme mostrado na Figura 7. Os autores descrevem a modelagem dos componentes, utilizando as equações de conservação. A ideia do estudo é analisar como o ciclo vapor reage às mudanças na saída da turbina a gás.

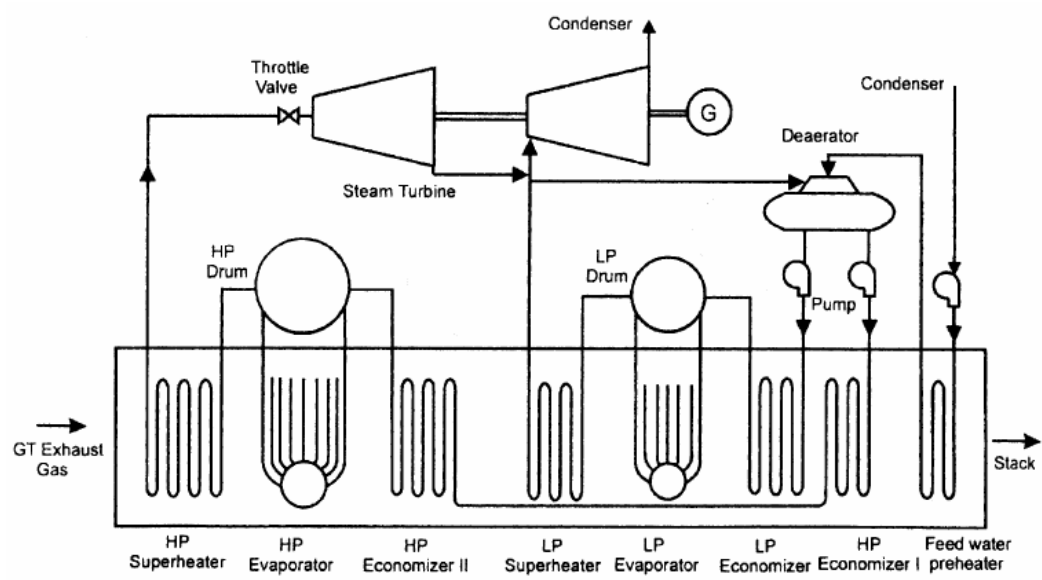

Figura 7 - Diagrama do sistema bottoming de dois níveis de pressão [10].

Um programa computacional foi desenvolvido para a análise do regime permanente e transiente, sendo validado contra os dados medidos em uma planta real composta por quatro turbinas a gás (100MW) operando em ciclo combinado (HRSGs com três níveis de pressão e com damper).

A vazão em massa e temperatura dos gases na entrada da caldeira utilizada é mostrada na Figura 8. Uma análise da resposta transiente da HRSG foi feita 
considerando a operação com e sem controle da potência do eixo para as seguintes variações:

1. Comportamento do vapor na entrada da turbina a vapor. Condições de pressão, temperatura e vazão em alta e baixa pressão. Conforme a Figura 9.

2. Variação das taxas de vazão da água de alimentação, nível do tubulão e vazão de massa no evaporador (HP e LP). Ilustrado da Figura 10.

3. Variação da Potência da turbina a vapor, como mostrado em Figura 11.

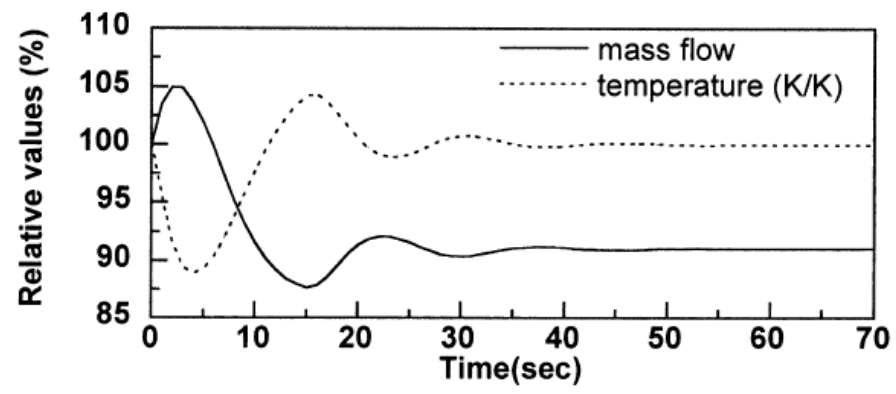

Figura 8 - Condição dos gases de exaustão na entrada da caldeira de recuperação. [10]

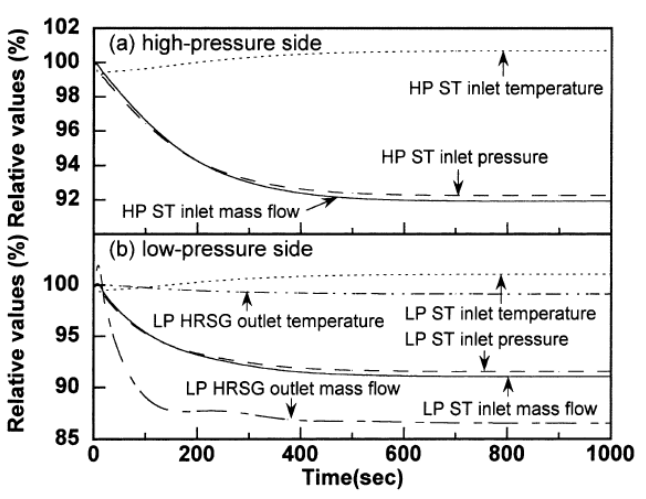

(a)

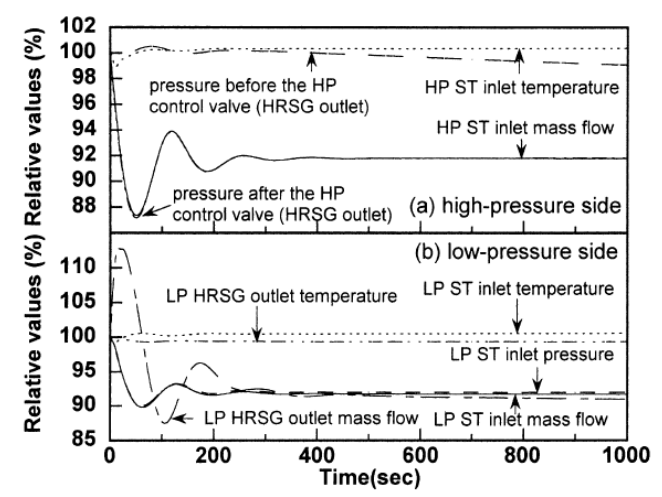

(b) 
Figura 9 - Variações nas condições de vapor em HP e LP: (a) sem controle de potência; (b) com controle de potência [10].

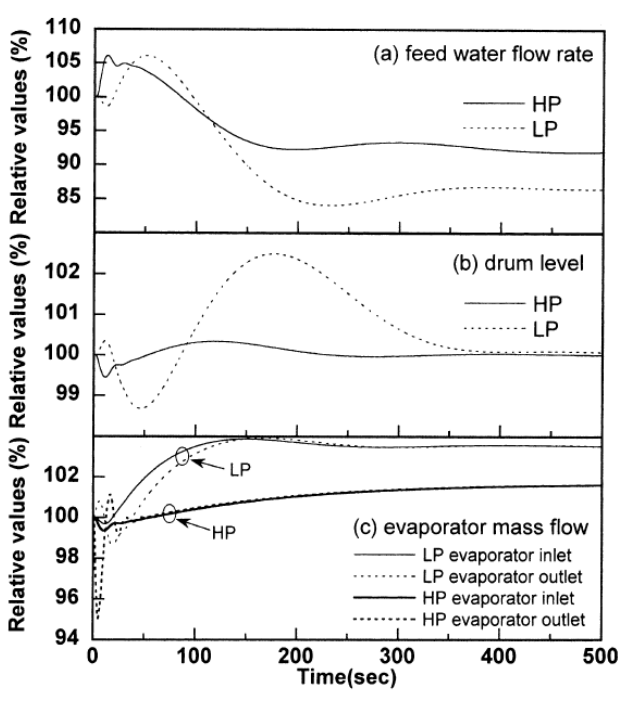

(a)

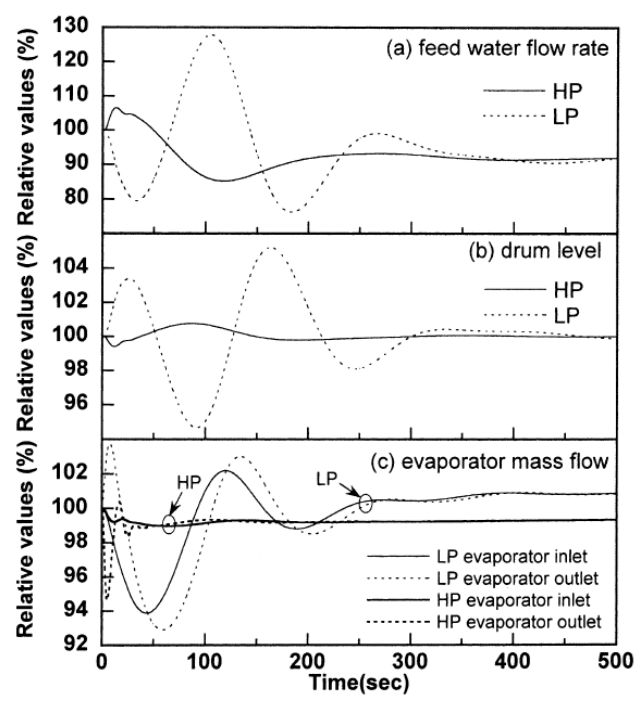

(b)

Figura 10 - Variações nas taxas nas taxas da vazão de água de alimentação, nível do tubulão e vazão em massa na entrada e saída do evaporador (de baixa e alta pressão): (a) sem controle de potência; (b) com controle de potência [10].

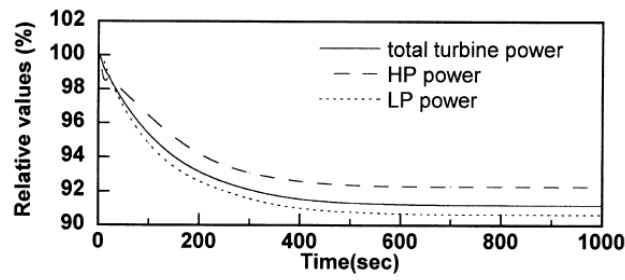

(a)

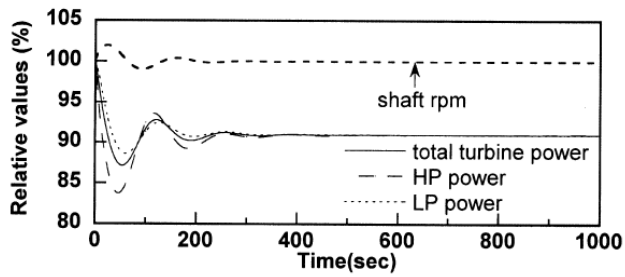

(b)

Figura 11 - Variação na potência da turbina a vapor (HP e LP): (a) sem controle de potência de eixo; (b) com controle de potência [10].

Sanaye e Moradi, em [11], apresentam resultados de uma planta operando em ciclo combinado, fazendo uso de dois programas. Um para a simulação do regime permanente da turbina a gás e outro do transiente da caldeira de recuperação de calor. Para a simulação do transiente da HRSG foi adotado o modelo de Jolly, Gurevich e Pasha [12].

O programa é capaz de simular uma partida fria, onde a vazão de gases quentes é considerada como de $25 \%$ do máximo durante os 10 primeiros minutos, depois de $50 \%$ até 45 minutos e finalmente de $100 \%$ durante o restante do tempo analisado. A Figura 12, mostra a variação do fluxo dos gases de combustão considerada. Os resultados obtidos são mostrados da Figura 12 à Figura 18. 


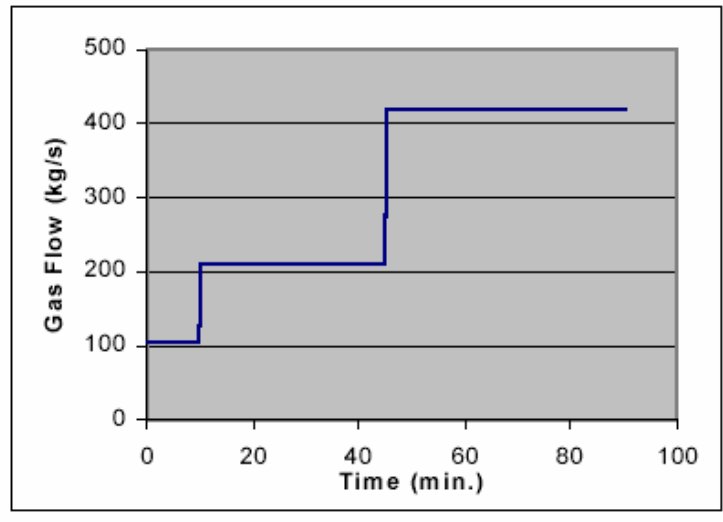

Figura 12 - Escoamento em massa dos gases quente em função do tempo [11].

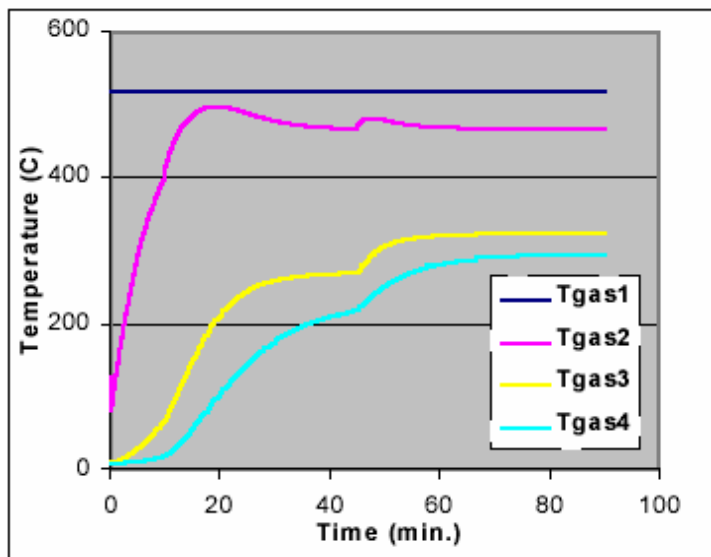

Figura 13 - Temperatura dos gases no sistema de alta pressão [11]. 


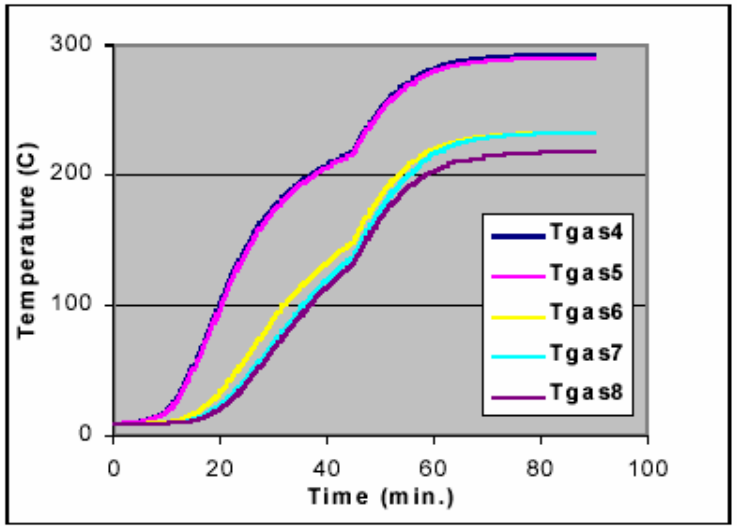

Figura 14 - Temperatura dos gases no sistema de pressão intermediária [11].

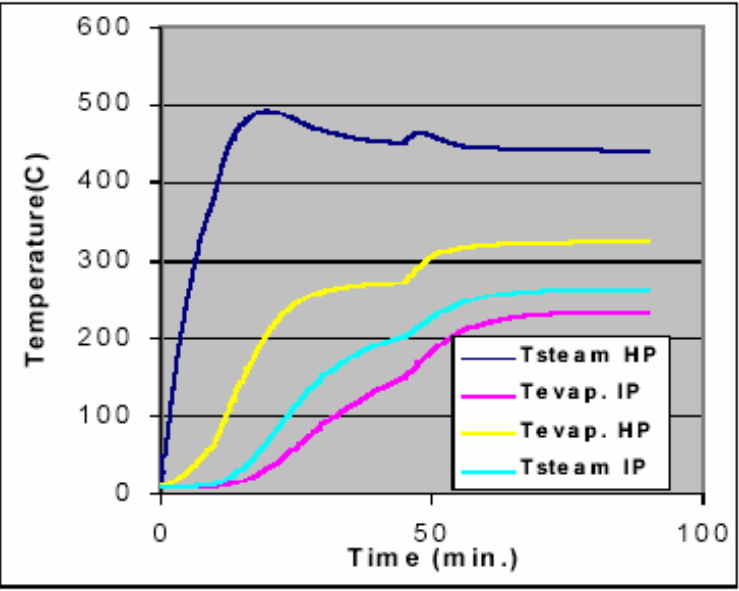

Figura 15 - Temperaturas do vapor de saída do evaporador e superaquecedor de alta e média pressão [11].

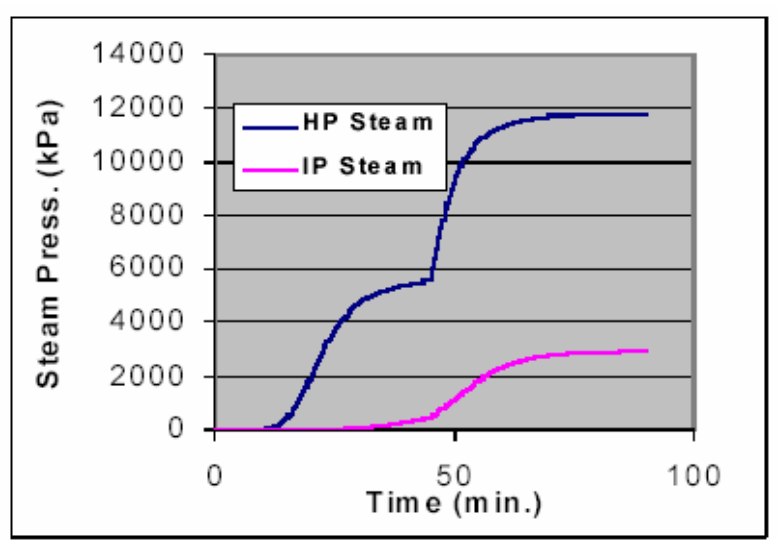

Figura 16 - Pressões do vapor no tubulão nos sistemas de HP e IP [11]. 


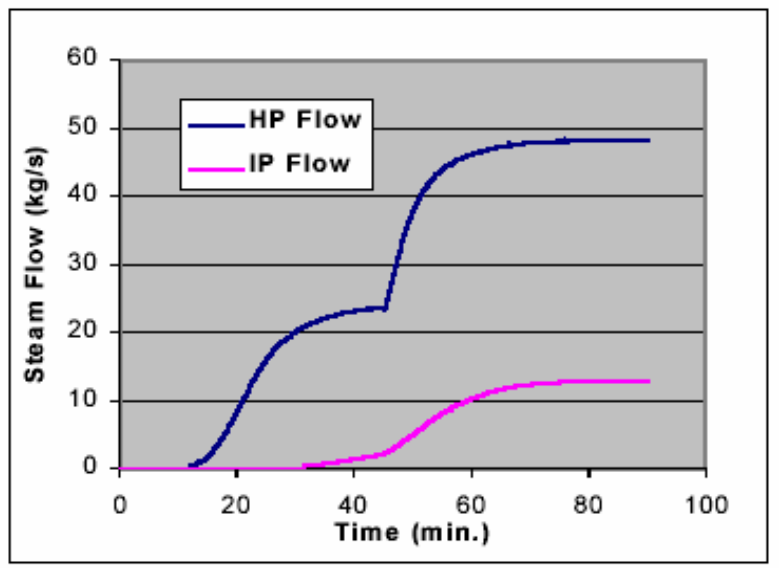

Figura 17 - Vazões de vapor nos evaporadores dos sistemas de HP e IP [11].

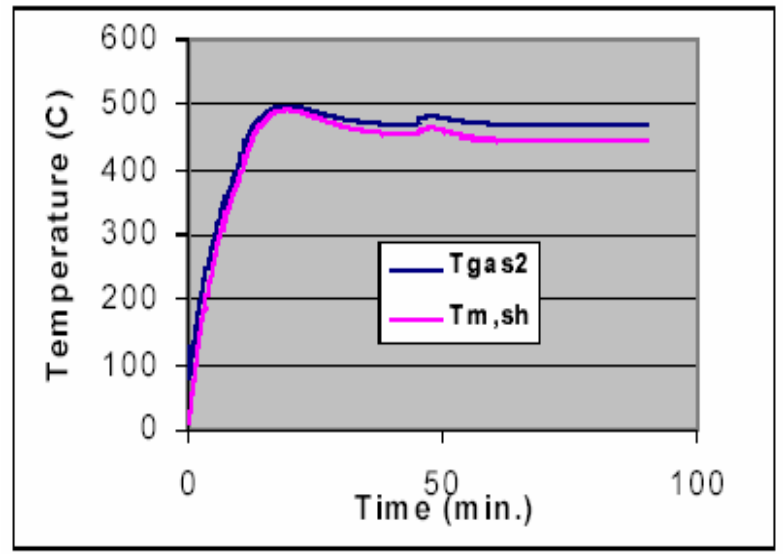

Figura 18 - Temperatura do metal do superaquecedor e dos gases quente de saída [11].

Ong'iro et al, faz uma análise detalhada em [13] visando criar uma distribuição das temperaturas, fluxos de calor nos trocadores e queda de pressão em uma HRSG com dois níveis de pressão, buscando obter ume predição acurada da performance da caldeira. Porém, sabe-se que as correlações empíricas utilizadas para a análise de trocadores de calor são baseadas em determinadas condições do escoamento, assim quando novas geometrias são adotadas a viabilidade de uso das correlações deve ser cuidadosamente estudada. Visando driblar essa dificuldade, os autores desenvolveram uma metodologia capaz de computar as características da HRSG com diferentes geometrias sem a necessidade de cálculos computacionais pesados e que sejam capazes de resolver as equações de conservação de massa energia e momentum de forma discretizada.

O modelo da caldeira foi acoplado a um modelo de turbina a gás em ASPEN PLUS e validado contra dados reais de operação. Os resultados do artigo mostraram que o programa foi capaz de: 
- Predizer a performance térmica e hidráulica de caldeiras operando em carga parcial e total;

- Avaliar o impacto de alterações no design e condições de operação no desempenho da HRSG;

- Identificar problemas de operação;

- Definir os limites seguros de operação.

A figura abaixo mostra um dos perfis de fluxo de calor obtido pelos autores, nesse caso para o superaquecedor.

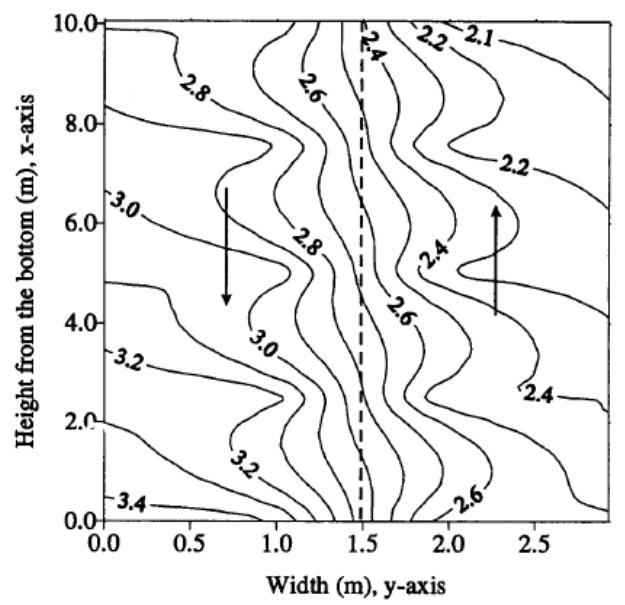

Figura 19 - Distribuição do fluxo de calor no superaquecedor $\left(\mathrm{kW} / \mathrm{m}^{2}\right)$ [13].

Busca-se, com esse trabalho mostrar um modelo de simulação de caldeiras de recuperação operando em regime permanente que não dependa diretamente dos parâmetros geométricos de um equipamento particular. Essa abordagem visa à funcionalidade do modelo para sistemas de diagnóstico, onde as variáveis de saída do modelo deverão ser somente aquelas obtidas pela instrumentação das usinas, de forma a realizar a comparação entre o medido e o previsto.

Para isso foi adotado um equacionamento semelhante ao de [6] para a modelagem dos trocadores de calor. Cada trocador de calor consiste em um módulo individual e independente, permitindo o fácil intercâmbio de posições de acordo com o arranjo da HRSG analisada.

É comum em usinas termelétricas que o caminho do vapor não esteja completamente instrumentado, assim como o perfil de queda de temperatura dos gases de exaustão o que dificulta a calibração dos trocadores de calor da caldeira. Para contornar essa dificuldade foi utilizada uma inteligência computacional baseada em algoritmos genéticos capaz de ajustar o modelo baseando-se apenas nas principais entradas e saídas da HRSG. 
3

\section{Fundamentos Teóricos}

\subsection{Introdução}

\subsubsection{Ciclo Combinado}

O ciclo combinado consiste na junção de dois ciclos termodinâmicos diferentes em uma única planta, operando sequencialmente através de uma mesma fonte de calor para a produção de energia. Quando os dois ciclos estão combinados, a eficiência que pode ser alcançada é maior do que em um daqueles ciclos operando de forma independente.

O tipo de ciclo combinado mais desenvolvido e difundido é o Brayon/Rankine, onde a produção de vapor por uma caldeira de recuperação se dá através da utilização da energia disponível nos gases quentes de exaustão da turbina a gás por de trocadores de calor. O vapor produzido é então direcionado a uma turbina a vapor para a geração de energia elétrica (Figura 20).

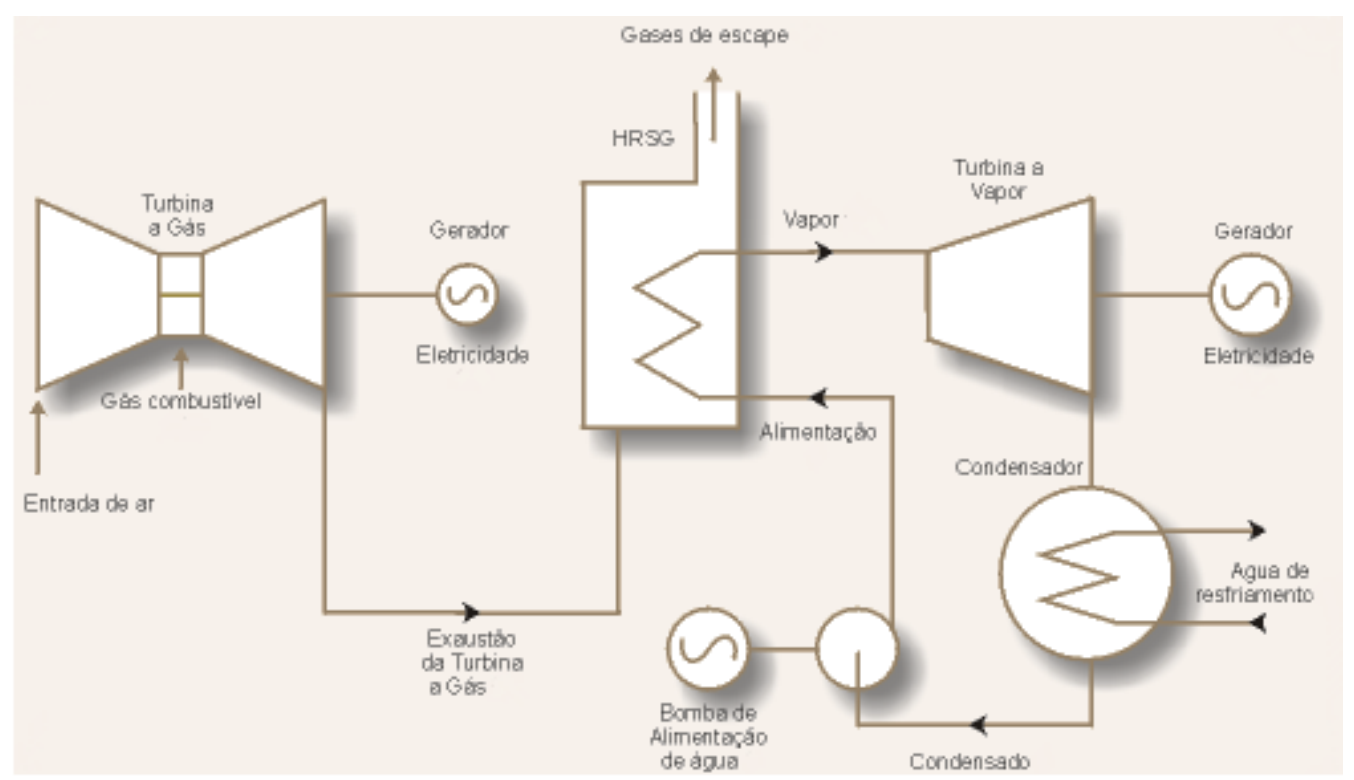

Figura 20 - Exemplo de ciclo combinado (Brayton/Rankine) para produção de energia elétrica [14]. 
A consolidação desse tipo de ciclo se deu a partir do final dos anos 1970, quando as turbinas a gás começaram a alcançar temperaturas suficientemente altas capazes de permitir a utilização de ciclos combinados com alta eficiência [15]. Atualmente, a eficiência de um sistema de geração utilizando ciclo combinado chega a cerca de $60 \%[16]$.

\subsubsection{Caldeiras de Recuperação de Calor}

O principal propósito de uma Caldeira de Recuperação de Calor (HRSG - Heat Recovery Steam Generator) é extrair energia do calor que seria desperdiçado de uma turbina a gás, ou de algum outro processo de combustão de aplicação industrial para produção de vapor. Nesse documento, HRSGs acopladas a turbinas a gás utilizadas na geração de energia são o objeto de estudo.

No passado, as HRSGs trabalhavam em conjunto com pequenas turbinas a gás, que não produziam um calor de grande potencial energético. Porém, ao longo dos anos, com a evolução das turbinas a gás, suas temperaturas de exaustão tornaram-se cada vez maiores e a melhor eficiência da queima reduziu consideravelmente a quantidade de oxigênio presente na saída do equipamento [1]. Para operar de forma eficiente com as avançadas turbinas a gás, novas caldeiras capazes de operar com altas temperaturas e pressões tiverem de ser desenvolvidas.

Atualmente, os projetos de caldeiras de recuperação de calor evoluíram para sistemas de duas e até três níveis de pressão adicionando recuperadores de forma a elevar ainda mais a eficiência do ciclo vapor.

Diferentes configurações de HRSG são possíveis, dependendo das características do calor a ser aproveitado e do intuito da usina (carga base, carga parcial, carga cíclica ou pico). Convencionalmente, as caldeiras de recuperação de calor podem ser classificadas entre horizontais e verticais, de acordo com a orientação do fluxo dos gases de combustão. Caldeiras horizontais são mais comuns na América do Norte, enquanto na Europa as HRSGs verticais são mais típicas [17], principalmente devido ao PURPA nos EUA (Public Utility Regulatory Policies Act of 1978) que permitem a viabilidade da produção de energia proveniente de térmicas na base, evitando operações cíclicas. Além disso, HRSGs verticais são mais compactas, se adequando melhor ao ambiente europeu.

As HRSGs horizontais trabalham com circulação natural, normalmente fazendo o uso de sistemas com diversas pressões, três pressões para sistemas maiores e duas pressões de operação para usinas de menor porte. 
Normalmente, esses equipamentos são instalados em linha com o eixo da turbina a gás ou perpendiculares a esse eixo, de acordo com a necessidade do projeto.

Dentre os principais benefícios de uma HRSG horizontal podem ser citados [17]:

- Design modular, o que requer menos soldas em campo, consequentemente sua construção se torna mais rápida e menos propensa a erro;

- Módulos normalmente são padronizados, facilitando a construção e conexões;

- Ligas de alta temperatura no superaquecedor e reaquecedor dão mais força, resistência à oxidação e proteção contra fadiga térmica.

Caldeiras de recuperação de calor são produzidas para operar em usinas que dependem das necessidades de produção demandadas pelo mercado, portanto, costumam experimentar rigorosos ciclos de operação, assim esses equipamentos costumam a apresentar problemas devido à [17]:

- Alta variação de temperatura do economizador durante a partida;

- Condensação no superaquecedor e reaquecedor;

- Considerável dilatação térmica em módulos muito altos;

- Diferenças de temperatura nas juntas de tubos;

- Acesso para inspeção, manutenção e reparo;

- Dificuldade para uniformizar a distribuição do gás de exaustão.

Utilizadores de HRSGs verticais afirmam que este é um equipamento mais adequado do que as caldeiras horizontais para operar ciclicamente [17]. Tal fato se dá devido às características mostradas a seguir, como redução de tensões térmicas e livre expansão térmica.

A desvantagem primária das HRSGs verticais está no fato de que elas requerem circulação forçada. Essa carga necessária para realizar a circulação reduz a eficiência do ciclo. Porém as HRSGs mais modernas já são projetadas de forma que as bombas de circulação são utilizadas apenas durante os períodos de transiente.

Podem ser citados como benefícios das HRSGs verticais [17]:

- Evita os formatos de serpentina, o que permite livre expansão térmica;

- Configuração que permite que a carcaça expanda juntamente com os conjuntos de tubos, reduzindo as tensões térmicas; 
- Menores recipientes de água que reduzem a inércia térmica;

- Mais leve devido ao menor número de módulos e aço;

- Design mais simples, com menos conexões entre tubos;

Os principais problemas enfrentados são [17]:

- O suporte dos tubos deve ser muito bem fixado, de forma a evitar o arqueamento entre os suportes;

- Um grande arqueamento pode acumular água na tubulação, caso a quantidade de condensado seja muito grande, um golpe de aríete pode ser gerado na tubulação.

Outra configuração inovadora de caldeira que também deve ser ressaltada são as Once-Through Steam Generators (OTSG), na qual a água de alimentação é convertida diretamente em vapor superaquecido (Figura 21), sem a utilização de tubulões. As OTSG eram projetadas para operar combinadas a turbinas aeroderivativas ou pequenas turbinas industriais. Atualmente, novos projetos têm surgido, capazes de lidar com configurações combinadas a uma maior gama de turbinas a gás. As OTSG se caracterizam por serem mais resistentes à fadiga térmica, uma vez que não existem componentes com paredes muito espessas. Logo, caldeiras once-through são vantajosas para operar em carga cíclica. Outra vantagem é a capacidade de funcionar a seco por longos períodos, permitindo que a caldeira parta simultaneamente à turbina a gás [17].

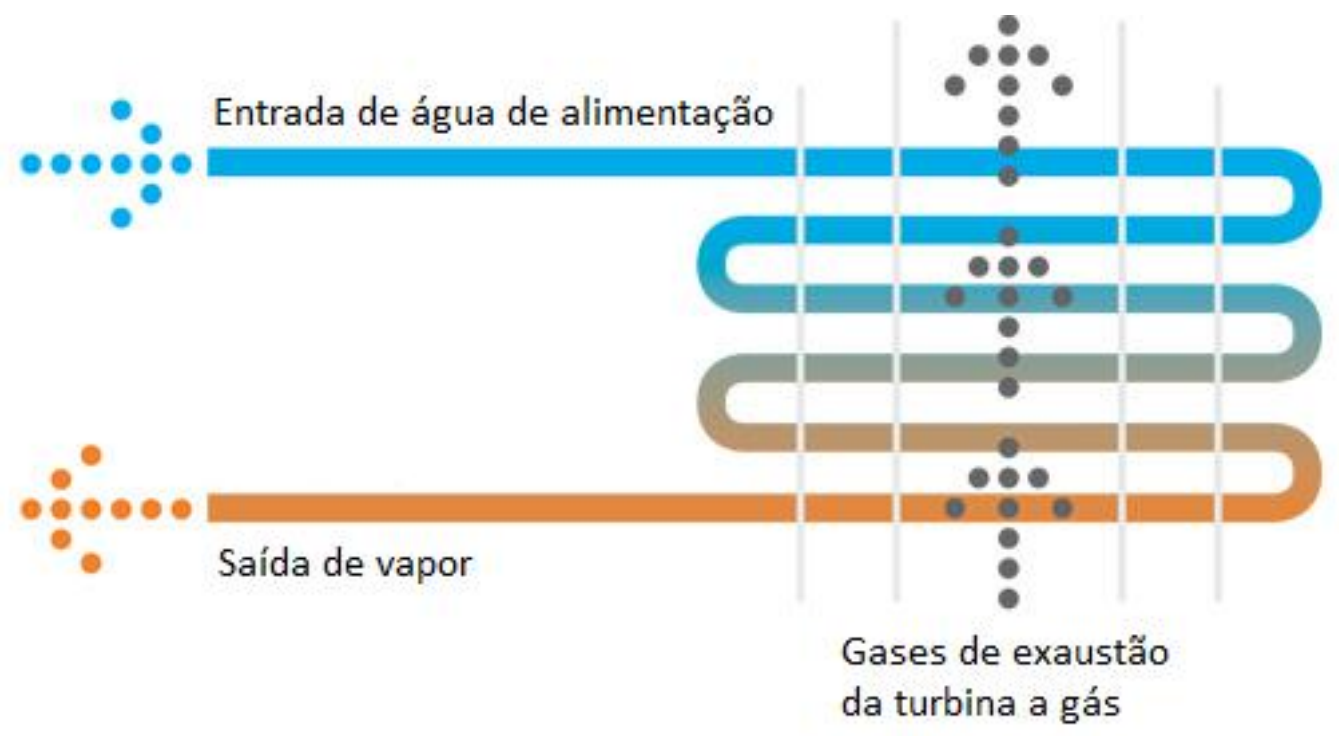

Figura 21 - Esquema do funcionamento de uma OTSG 


\subsubsection{Modelo Matemático - Ponto de Projeto}

Nesta seção são descritos os principais componentes da caldeira de recuperação de calor e os modelos matemáticos utilizados para o cálculo das condições termodinâmicas nos trocadores de calor quando os equipamentos operam no ponto de projeto (design point). Devido à configuração da instrumentação da usina, optou-se por modelar os trocadores de calor considerando como parâmetros de entrada:

- Entrada da água/vapor no equipamento;

- Saída dos gases quentes no equipamento.

Dessa forma, os estados termodinâmicos serão calculados na:

- Saída da água/vapor do equipamento;

- Entrada dos gases de exaustão no equipamento.

\subsubsection{Superaquecedores}

O superaquecedor é responsável por aquecer o vapor de água saturado até uma temperatura superior àquela de saturação da água. Este equipamento pode também ser utilizado de forma a elevar ainda mais a temperatura do vapor superaquecido proveniente de outro superaquecedor. $\mathrm{O}$ superaquecedor considerado no modelo matemático é mostrado na Figura 22, na qual 1 indica a entrada dos gases quentes e 2 a saída dos mesmos. 0 ponto 3 representa a entrada de vapor saturado e 4 a saída do vapor superaquecido.

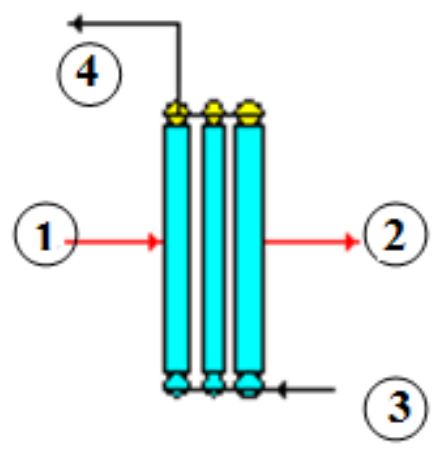

Figura 22: Esquema do superaquecedor utilizado para fins de cálculo.

A modelagem realizada consiste em blocos acoplados em série, onde cada um deles representa um equipamento. Desta forma, pode-se assumir que os parâmetros 
termodinâmicos nos pontos 2 e 3 são conhecidos pois foram calculados por algum bloco anterior ou são entradas da rotina computacional. Desta forma, as seguintes variáveis são dados de entrada do módulo:

- lado dos gases quentes: vazão mássica $\dot{m}_{2}$, temperatura $T_{2}$ e pressão $p_{2}$;

- lado de vapor: vazão mássica $\dot{m}_{3}$, temperatura $T_{3}$ e pressão $p_{3}$.

Utilizando-se relações algébricas para determinar as propriedades termodinâmicas dos fluidos foi possível calcular a entalpia dos gases quentes na saída $h_{2}$ e a entalpia do vapor na entrada $h_{3}$.

Fazendo-se uso da equação de conservação de massa em regime permanente, tem-se que toda a massa que entra no sistema deve sair e como não há mistura dos fluidos pode-se dizer que:

$$
\dot{m}_{1}=\dot{m}_{2}
$$

$$
\dot{m}_{4}=\dot{m}_{3}
$$

As pressões no superaquecedor, $P_{1}$ e $P_{4}$ podem ser calculadas através do conhecimento das perdas no lado de gás $\Delta P_{g_{S P H T R}}$ e no lado de vapor $\Delta P_{v_{S P H T R}}$, expressas em porcentuais [\%], que ocorrem nas tubulações do trocador de calor em operação no ponto de projeto. Logo:

$$
\begin{gathered}
P_{1}=P_{2} /\left(1-\frac{\left(\Delta P_{g}\right)_{S P H T R}}{100}\right) \\
P_{4}=P_{3}\left(1-\frac{\left(\Delta P_{v}\right)_{S P H T R}}{100}\right)
\end{gathered}
$$

Para determinar as propriedades do vapor superaquecido na saída do superaquecedor, foi considerado que a temperatura $T_{4}$ é um parâmetro conhecido. Como esta simulação refere-se à condição de ponto de projeto essa premissa pode ser aceita.

Uma vez conhecidos os termos $T_{4}$ e $P_{4}$ o estado termodinâmico está definido. Portanto, a entalpia $h_{4}$ pode ser determinada. 
Para obter a condição de saída dos gases quentes é utilizado o balanço de energia:

$$
\dot{Q}_{\text {gas }}=\dot{Q}_{\text {vapor }}+\Delta \dot{Q}_{S P H T R}
$$

Onde:

$$
\dot{Q}_{\text {vapor }}=\dot{m}_{3}\left(h_{4}-h_{3}\right)
$$

E $\Delta \dot{Q}_{S P H T R}$ representa a energia perdida ao ambiente, por instante de tempo, durante e troca de calor. Estipulando-se uma perda percentual, denominada Perda $\dot{Q}_{S P H T R}$, o termo $\Delta \dot{Q}_{S P H T R}$ pode ser definido como:

$$
\Delta \dot{Q}_{S P H T R}=\dot{Q}_{\text {vapor }}\left(\frac{\operatorname{Perda} \dot{Q}_{S P H T R}}{100}\right)
$$

Como o calor fornecido pelos gases quentes é dado por:

$$
\dot{Q}_{g a s}=\dot{m}_{1}\left(h_{1}-h_{2}\right)
$$

Sendo $\dot{Q}_{g a s}$ um valor conhecido e definido por 3.5, através da manipulação de 3.8 é possível calcular a entalpia dos gases quentes na entrada:

$$
h_{1}=h_{2}+\frac{\dot{Q}_{g a s}}{\dot{m}_{1}}
$$

Conhecidas a pressão $P_{1}$ e a entalpia $h_{1}$, é possível determinar a temperatura de saída dos gases de exaustão, utilizando-se uma das funções de cálculo de propriedades termodinâmicas.

Finalmente, para o cálculo da efetividade $\varepsilon$ do trocador de calor foram utilizadas as definições de [18]. Sendo:

$$
\varepsilon=\frac{\dot{Q}}{\dot{Q}_{\max }}
$$


Onde $Q$ pode ser considerado como $Q_{v a p}$ e:

$$
\dot{Q}_{\max }=C_{\min }\left(T_{1}-T_{3}\right)
$$

Lembrando que, por definição, $C_{\text {min }}$ e $C_{\text {max }}$ representam a maior e a menor taxa de capacitância térmica encontrada ou no lado do gás ou no lado do vapor. Logo, $C_{\text {min }}=\min \left(C_{g}, C_{v}\right)$ e $C_{\max }=\max \left(C_{g}, C_{v}\right)$.

Sabendo-se que:

$$
\begin{gathered}
C_{g}=\frac{\dot{Q}_{g a s}}{\left(T_{1}-T_{2}\right)} \\
C_{v}=\frac{\dot{Q}_{\text {vapor }}}{\left(T_{4}-T_{3}\right)}
\end{gathered}
$$

E, de acordo com a definição da equação 3.10 a efetividade pode ser reescrita como:

$$
\begin{aligned}
& \varepsilon=\frac{C_{v}\left(T_{4}-T_{3}\right)}{C_{\min }\left(T_{1}-T_{3}\right)} \\
& \varepsilon=\frac{C_{g}\left(T_{1}-T_{2}\right)}{C_{\min }\left(T_{1}-T_{3}\right)}
\end{aligned}
$$

O calor trocado em um trocador de calor também pode ser definido pela equação 3.16:

$$
Q=U A \Delta T_{\log }
$$

Onde $U$ é o coeficiente global de troca de calor, $A$ é a área total de troca e $\Delta T_{l o g}$ é dado por:

$$
\Delta T_{\log }=\frac{\left(T_{1}-T_{3}\right)-\left(T_{2}-T_{4}\right)}{\ln \frac{\left(T_{1}-T_{3}\right)}{\left(T_{2}-T_{4}\right)}}
$$


Então, o produto $U A$ pode ser obtido pela equação 3.16, pois $Q$ é determinado uma vez que a vazão e $\dot{Q}$ são conhecidos. Considerando que o número de unidades térmicas é definido pela equação 3.18 ,

$$
N T U=\frac{U A}{C_{\min }}
$$

E utilizando a relação para obtenção da efetividade em um trocador de calor de correntes opostas sugerido em [18], tem-se que:

$$
\varepsilon=\frac{1-e^{-\left(1+\frac{C_{\min }}{C_{\max }}\right) N T U}}{1+\frac{C_{\min }}{C_{\max }}}
$$

\subsubsection{Evaporadores}

O evaporador é o componente responsável por realizar a mudança de fase da água para o estado de vapor saturado utilizando energia proveniente dos gases quentes. De forma geral, o evaporador fornece vapor saturado a um superaquecedor $e$ recebe água de um economizador. É nesse equipamento ou, em alguns casos, em uma bomba, que a vazão de vapor que irá produzir potência na turbina é efetivamente determinada.

Este trocador de calor é acoplado a um tubulão, um tanque que armazena a mistura água/vapor. No tubulão o vapor produzido sai pelo topo e é encaminhado ao próximo equipamento, enquanto a água ainda não vaporizada pode ser encaminhada para a recirculação no trocador de calor.

É comum em algumas caldeiras que parte da água seja extraída do tubulão. Essa extração é denominada blowdown.

As principais características de desempenho do evaporador são a pressão de operação estabelecida pela bomba de alimentação, as perdas que ocorrem nos trocadores de calor, a fração de blowdown (caso existente) e a efetividade do trocador de calor. Na Figura 23 é mostrado o desenho do evaporador considerado para a modelagem matemática. 


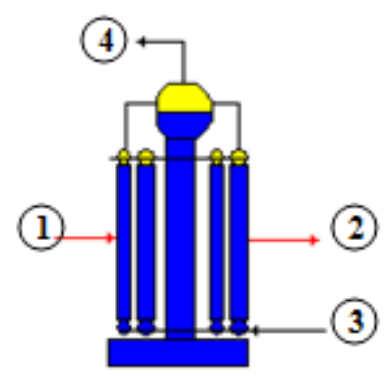

Figura 23: Esquema do evaporador utilizado para fins de cálculo

Mantendo-se a mesma convenção adotada para o superaquecedor, os pontos 2 e 3 da Figura 23 são entradas no modelo, representando a saída de gás e a entrada de água, respectivamente. Enquanto 1 e 4 são as saídas do modelo, ou seja entrada do gás quente (1) e saída do vapor (4).

Novamente, as os termos pressão, temperatura e vazão dos fluidos nas entradas 2 e 3 são consideradas conhecidas, uma vez que são calculadas pelo trocador a montante.

Portanto os termos $\dot{m}_{2}, T_{2}, P_{2}, \dot{m}_{3}, T_{3}$ e $P_{3}$, são conhecidos. Considera-se, também, que o ponto 4 representa uma saída de vapor saturado. Supondo que:

$$
P_{4}=P_{3}
$$

Então, a temperatura no ponto 4 pode ser determinada em função de $P_{4}$, pois:

$$
T_{4}=T_{\text {sat }}\left(P_{4}\right)
$$

De forma semelhante ao modelo do superaquecedor a pressão de saída dos gases quentes pode ser determinada em função de uma perda percentual de carga que ocorre nas tubulações, definida por $\left(\Delta P_{g}\right)_{E V A P}$.

$$
P_{1}=P_{2} /\left(1-\frac{\left(\Delta P_{g}\right)_{E V A P}}{100}\right)
$$

$E$, através do balanço de massa:

$$
\dot{m}_{1}=\dot{m}_{2}
$$


De acordo com as informações de projeto da usina não existe blowdown na operação em design point. Desta forma, a vazão de entrada de água deve ser igual à saída de vapor saturado, portanto:

$$
\dot{m}_{3}=\dot{m}_{4}
$$

Logo, podemos determinar o calor de evaporação $\dot{Q}_{\text {evap }}$ por 3.25 , lembrando que $h_{3}$ é um parâmetro que pode ser determinado a partir de $T_{3}$ e $P_{3}$.

$$
\dot{Q}_{\text {evap }}=\dot{m}_{4}\left(h_{4}-h_{3}\right)
$$

Pelo balanço de energia:

$$
\dot{Q}_{\text {gas }}=\dot{Q}_{\text {evap }}+\Delta \dot{Q}_{\text {evap }}
$$

Sendo $\Delta Q_{\text {evap }}$ a quantidade de calor perdida para o meio durante a troca, calculada a partir da perda percentual $\operatorname{Perda} \dot{Q}_{S P H T R}$, equação 3.27.

$$
\Delta \dot{Q}_{\text {evap }}=\dot{Q}_{\text {evap }} \frac{P e r d a \dot{Q}_{S P H T R}}{100}
$$

Determinados, então, $\dot{Q}_{\text {evap }}$ e $\Delta \dot{Q}_{\text {evap }} \cdot \dot{Q}_{\text {gas }}$ é facilmente calculado por 3.26. E permite que a obtenção da entalpia de entrada do gás de exaustão seja calculada por:

$$
h_{1}=h_{2}+\frac{\dot{Q}_{g a s}}{\dot{m}_{1}}
$$

Conhecidas a pressão $P_{1}$ e a entalpia $h_{1}$ é possível determinar a temperatura de entrada dos gases de exaustão utilizando uma das funções de cálculo de propriedades termodinâmicas.

Uma vez determinados todos os estados termodinâmicos das saídas, é possível calcular a efetividade do evaporador utilizando as mesmas definições empregadas para o superaquecedor. Primeiramente, calcula-se a média logarítmica de temperaturas $\Delta T_{\log }$ através da equação 3.17, em seguida a produto $U A$ é determinado por 3.16, sendo $\dot{Q}$ calculado por 3.25, $Q$ facilmente obtido devido ao conhecimento da vazão mássica. Então, é possível obter o número de unidades de transferência por 3.18 e assim calcular a efetividade do trocador de calor 3.19 . 
É interessante frisar que, caso a água entre no evaporador como líquido saturado, a temperatura do vapor na saída será igual à temperatura de entrada da água, isto é:

$$
T_{3}=T_{4}
$$

Portanto, o termo $C_{V}=\dot{Q}_{\text {evap }} /_{\left(T_{4}-T_{3}\right)}=C_{\max }$ tenderia a infinito, consequentemente:

$$
\frac{C_{\min }}{C_{\max }} \rightarrow 0
$$

Assim, a efetividade poderá ser escrita como:

$$
\varepsilon=1-e^{(-N T U)}
$$

\subsubsection{Economizadores}

O economizador é responsável por aquecer a água (líquido comprimido) mediante a utilização da energia proveniente dos gases quentes. Normalmente, sua entrada está conectada a outro economizador ou à bomba de alimentação. Sua saída pode ser conectada a outro economizador ou a um evaporador, de acordo com a configuração adotada na usina. A Figura 24, que mostra o esquema utilizado para modelar o economizador.

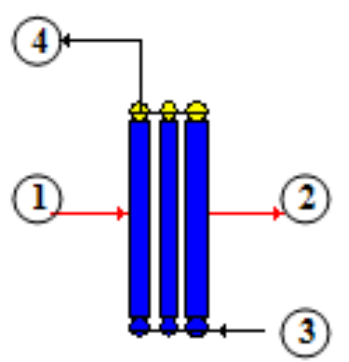

Figura 24: Esquema do economizador utilizado para fins de cálculo

Mantendo-se o padrão de nomenclatura utilizado nos modelos anteriores, é admitido que as entradas (ponto 2 e 3) são conhecidas, sendo resultados provenientes de equipamentos que estão antes do economizador, considerando o caminho da 
água/vapor. Logo, a pressão, temperatura e vazão de 2 e 3 são parâmetros conhecidos.

Realizando o balanço de massa no volume de controle (economizador) são obtidas as equações 3.32 e 3.33 .

$$
\begin{aligned}
& \dot{m}_{2}=\dot{m}_{1} \\
& \dot{m}_{4}=\dot{m}_{3}
\end{aligned}
$$

Em seguida, deve-se determinar a pressão na saída do componente, supondo que o sistema sofra perdas de carga de $\left(\Delta P_{g}\right)_{E C O N}[\%]$ no lado do gás e de $\left(\Delta P_{a}\right)_{E C O N}$ do lado da água. Então, as pressões de saída podem ser definidas como:

$$
\begin{gathered}
P_{1}=P_{2} /\left(1-\frac{\left(\Delta P_{g}\right)_{E C O N}}{100}\right) \\
P_{4}=P_{3}\left(1-\frac{\left(\Delta P_{a}\right)_{E C O N}}{100}\right)
\end{gathered}
$$

Para calcular as propriedades das saídas em ponto de projeto foi utilizado um método de calculo que considera a diferença entre a temperatura de saturação $T_{4 \text { sat }} \mathrm{e}$ $T_{4}$.

$$
\Delta T_{\text {subcool }}=T_{4 \text { sat }}-T_{4}
$$

A equação 3.36 garante que não haverá mudança de fase dentro do economizador enquanto $\Delta T_{\text {subcool }}>0$. Supondo, então, um valor conhecido de $\Delta T_{\text {subcool }}$ para o trocador de calor é possível encontrar a saída $T_{4}$, que juntamente com $P_{4}$ determina o estado termodinâmico do ponto 4 .

Utilizando-se o balanço de energia, pode-se escrever que:

$$
\dot{Q}_{g a s}=\dot{Q}_{a g u a}+\Delta \dot{Q}_{E C O N}
$$

Onde $\dot{Q}_{a g u a}$ é o calor absorvido pela água, sendo dado por: 


$$
\dot{Q}_{\text {agua }}=\dot{m}_{3}\left(T_{4}-T_{3}\right)
$$

E $\Delta \dot{Q}_{E C O N}$, equação 3.39 , é a perda de calor para o ambiente, sendo função da

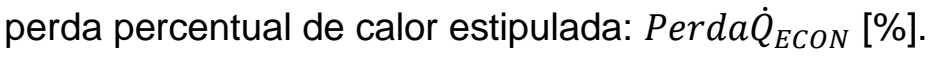

$$
\Delta \dot{Q}_{E C O N}=\dot{Q}_{a g u a} \frac{P \operatorname{erda} \dot{Q}_{E C O N}}{100}
$$

Fazendo uso 3.38 e 3.39 é possível determinar $\dot{Q}_{\text {gas }}$ por 3.37. E, assim, a entalpia de saída dos gases quentes pode ser calculada como:

$$
h_{1}=h_{2}+\frac{\dot{Q}_{g a s}}{\dot{m}_{2}}
$$

Conhecidas a pressão $P_{1}$ e a entalpia $h_{1}$ é possível determinar a temperatura de entrada dos gases de exaustão utilizando uma das funções de cálculo de propriedades termodinâmicas.

Finalmente, deve-se calcular a efetividade do trocador de calor. $\mathrm{O}$ equacionamento se dá de forma idêntica ao modelo do superaquecedor.

Primeiro a média logarítmica de temperaturas deve ser determinada utilizando a equação 3.17, então, o termo $U A$ é calculado por 3.38 , considerando que $\dot{Q}$ é dado por 3.16, $Q$ facilmente obtido devido ao conhecimento da vazão mássica. Determina-se, assim, o número de trocas térmicas por 3.18, chegando ao valor da efetividade do economizador através de 3.19 .

\subsubsection{Reaquecedores}

Os reaquecedores são trocadores de calor responsáveis por superaquecer o vapor. Operam de forma semelhante aos superaquecedores, porém se diferenciam pelo fato de sua entrada de vapor ser oriunda da turbina a vapor.

Devido ao comportamento termodinâmico semelhante ao superaquecedor, o modelo matemático utilizado para simular o reaquecedor utiliza o mesmo equacionamento discutido na seção 3.1.3.1. 


\subsubsection{Modelo Matemático - Off-design}

Como as condições de cada componente para operação em plena carga já foram modeladas, o desenvolvimento do modelo matemático do cálculo do HRSG em off-design consistiu em modificar as rotinas definidas para a operação em ponto de projeto para o ajuste às peculiaridades daquela forma de operação.

O parâmetro inicial para o modelo da caldeira tem como ponto de partida o estado termodinâmico, a vazão e composição dos gases quentes da caldeira de recuperação de calor, em sua chaminé.

Para os trocadores de calor são utilizadas correlações para determinar os coeficientes globais de troca de calor e as quedas de pressão nos componentes, baseados em [6]. Essas relações serão descritas posteriormente.

\subsubsection{Cálculo da Queda de Pressão nos Trocadores de Calor}

A fim de determinar as saídas de cada trocador de calor é necessário calcular a queda de pressão nos lados interno e externo dos tubos dos trocadores de calor, esse processo é detalhado em 3.1.4.1.1 e 3.1.4.1.2.

\subsection{Modelo de operação fora do ponto de projeto do lado interno (água ou vapor)}

A análise da operação fora do ponto de projeto do lado interno considera que o escoamento está completamente desenvolvido, já tendo alcançado seu regime permanente. Para o cálculo do fator de atrito foi considerado que o escoamento é turbulento, assim, utiliza-se a formulação de [19], mostrada na equação 3.41 .

$$
f=-\frac{\Delta P_{v} / \rho g}{\left(\frac{l}{D}\right)\left(\bar{V}^{2} / 2 g\right)}
$$

Sendo:

$\Delta P_{v}$ : queda de pressão nas tubulações do trocador de calor fora do ponto de projeto;

L: comprimento da tubulação;

D: diâmetro da tubulação;

$\rho$ : massa específica do fluido;

$g$ : aceleração gravitacional; 
$\bar{V}$ : velocidade média do fluido no interior do tubo.

Sabe-se, ainda, que:

$$
\bar{V}=\dot{m} / \rho A
$$

Onde $\dot{m}$ a vazão mássica no tubo e A é a área transversal ao escoamento dentro do tubo.

Dividindo-se a queda de pressão em off-design pela queda de pressão no ponto de projeto $\left(\Delta P_{D P}\right)$ e utilizando a relação 3.42 , é obtida a equação 3.43 .

$$
\frac{\Delta P_{v}}{\Delta P_{D P}}=\left(\frac{f}{f_{D P}}\right)\left(\frac{\dot{m}^{2} / \rho}{\left(\dot{m}^{2} / \rho\right)_{D P}}\right)
$$

Sendo $\dot{m}$ a vazão mássica no tubo e A é a área transversal ao escoamento dentro do tubo.

Para determinar o fator de atrito existem inúmeras expressões desenvolvidas, porém em sua grande maioria são implícitas em $f$ e, assim, são resolvidas iterativamente. A fim de simplificar o estudo, a equação de Karman-Nikuradse [20] foi usada para o fator de atrito, sendo mostrada em 3.44,

$$
f=0,046 R e^{-0,2}
$$

Onde Re é o número de Reynolds.

Então, é possível substituir a equação 3.44 em 3.43, obtendo-se:

$$
\Delta P_{v}=\Delta P_{D P}\left(\frac{\dot{m}}{\dot{m}_{D P}}\right)^{x}\left(\frac{T}{T_{D P}}\right)^{y}\left(\frac{P}{P_{D P}}\right)^{z}\left(\frac{v}{v_{D P}}\right)^{a}
$$

Sendo:

$\mathrm{T}:$ a temperatura do fluido na condição off-design;

P: a pressão do fluido na condição off-design;

v: o volume específico do fluido na condição off-design;

Os valores em ponto de projeto são caracterizados pelo índice DP. Os expoentes $x, y, z$ e a são cruciais para a modelagem e deverão ser ajustados de acordo com dados de operação em carga parcial da usina termelétrica. 


\subsection{Modelo de operação fora do ponto de projeto do lado externo (gás quente)}

O modelo utilizado para o cálculo da queda de pressão do lado dos gases de exaustão quando o sistema opera fora do seu ponto de projeto baseou-se em [21], fazendo uso da relação 3.46 .

$$
\Delta P_{g}=\frac{2 f V_{\max }^{2} N}{\rho}\left(\frac{\mu_{w}}{\mu_{b}}\right)^{0,14}
$$

Onde:

$V_{\text {max }}$ : velocidade máxima, na menor área do escoamento;

$N$ : número de feixes de tubos;

$\mu_{w}$ : viscosidade do gás na proximidade da parede;

$\mu_{b}$ : viscosidade do gás no centro do escoamento.

A viscosidade foi eliminada da equação 3.46 , devido à sua pequena influência [6].

Conforme o efetuado para o caso anterior, divide-se a queda de pressão fora do ponto de projeto pela queda de pressão no ponto de projeto, de forma que a seguinte relação é obtida:

$$
\frac{\Delta P_{\mathrm{g}}}{\Delta P_{\mathrm{DP}}}=\left(\frac{f}{f_{D P}}\right)\left(\frac{\dot{m}^{2} / \rho}{\left(\dot{m}^{2} / \rho\right)_{D P}}\right)
$$

Considerando novamente [21], para a determinação do fator de atrito, no lado dos gases de exaustão a expressão adotada foi:

$$
f=\lambda R e_{\max }^{-0.16}
$$

Sendo $\lambda$ dependente da geometria,

Substituindo-se 3.48 em 3.47 e adotando características de gases perfeitos para os gases de exaustão da turbina a gás, após o cancelamento dos termos comuns é obtida a seguinte equação:

$$
\Delta P_{g}=\Delta P_{D P}\left(\frac{\dot{m}}{\dot{m}_{D P}}\right)^{\alpha}\left(\frac{T}{T_{D P}}\right)^{\beta}\left(\frac{P}{P_{D P}}\right)^{\gamma}
$$

Onde: 
$\dot{m}$ : vazão mássica de gás na condição off-design;

$T$ : temperatura do gás na condição off-design;

$P$ : pressão temperatura do gás na condição off-design.

Novamente, o índice DP indica os parâmetros de ponto de projeto. Os expoentes $\alpha, \beta$ e $\gamma$ são variáveis que devem ser ajustadas de acordo com os dados de operação da usina, de forma a deixar a equação 3.49 devidamente calibrada. Cabe ressaltar que a inexistência do termo contendo a razão de volumes específicos (como na equação 3.45) se dá devido à utilização da hipótese de gás perfeito.

\subsubsection{Cálculo do Coeficiente Global de Transferência de Calor}

Uma vez determinadas as quedas de pressão em ambos os lados do trocador de calor, outro parâmetro ainda é necessário para permitir o cálculo em condições de funcionamento em carga parcial, o coeficiente global de transferência de calor $\mathrm{U}$.

Os cálculos da troca de calor foram modelados de acordo com a equação 3.17, considerando que $T_{1}$ é a temperatura de entrada dos gases quentes, $T_{2}$ é a temperatura de saída dos gases quentes no trocador. Enquanto $T_{3}$ é a temperatura de entrada da água/vapor e $T_{4}$ é a temperatura de saída da água/vapor no trocador de calor.

O termo A é uma constante definida nas condições de projeto. Uma área de troca é calculada e fixada para cada trocador de calor da HRSG.

Para os cálculos em cargas parciais foi considerada a dominância das resistências convectivas do lado do gás sobre o coeficiente global de troca de calor. Assume-se, também, que o escoamento dos gases quentes sobre os tubos é sempre turbulento [6]. Logo, a relação utilizada para número de Nusselt foi [18]:

$$
N u=C R e^{n} \operatorname{Pr}^{m}
$$

Onde, Re é o número de Reynolds calculado para os gases quentes e $\operatorname{Pr}$ o número de Prandtl para o mesmo gás e $C$ uma constante.

Segundo [21], um valor usual para o expoente $n$ é 0,8 , sendo válido para valores de Reynolds entre 40.000 e 400.000.

Fazendo a divisão entre os valores de off-design e os valores de design point, obtém-se a equação, 


$$
\frac{N u}{N u_{D P}}=\left(\frac{R e}{R e_{D P}}\right)^{n}\left(\frac{P r}{P r_{D P}}\right)^{m}
$$

U, em geral, pode ser descrito como:

$$
U=R_{h}+R_{k}+R_{f}
$$

Sendo:

$R_{h}$ : somatório das resistências convectivas;

$R_{k}$ : somatório das resistências condutivas;

$R_{f}$ : resistências devido à incrustação.

Com base em [6], foi considerado que apenas a resistência convectiva é importante para os casos estudados, portanto:

$$
U=\frac{1}{1 / h_{c}}=h_{c}=N u \frac{k}{L}
$$

Logo, ao realizar a divisão do coeficiente global de troca de calor fora das condições de projeto pelo coeficiente global de troca nas condições de projeto os termos comuns são eliminados, resultando em:

$$
\frac{U}{U_{D P}}=\frac{N u}{N u_{D P}}
$$

Então, por 3.51:

$$
\frac{U}{U_{D P}}=\left(\frac{R e}{R e_{D P}}\right)^{n}\left(\frac{P r}{P r_{D P}}\right)^{m}
$$

E:

$$
\operatorname{Pr}=\frac{C_{p} \mu}{k}
$$


Caso seja considerado que a variação da viscosidade e a condutividade térmica podem ser desprezadas e assumindo os gases quentes como gases perfeitos [6], os termos comuns da equação 3.55 se cancelam resultando em:

$$
U=U_{D P}\left(\frac{\dot{m}}{\dot{m}_{D P}}\right)^{n}\left(\frac{T}{T_{D P}}\right)^{k}\left(\frac{P}{P_{D P}}\right)^{p}
$$

Mais uma vez, os expoentes $\mathrm{k}$, p e $\mathrm{n}$ são ajustados usando os valores obtidos em operação em cargas parciais da turbina a gás, fornecidos pela usina termelétrica. 


\section{Algoritmos Genéticos}

\subsection{Introdução}

Os Algoritmos Genéticos são métodos adaptativos utilizados para resolver problemas de otimização e busca, como otimização de modelos de simulação, resolução de sistemas não lineares e problemas de controle [22]. Essa metodologia foi desenvolvida por Holland, J. H. em 1975 e difundida por um de seus estudantes, Goldberg D. E.

Consistem na adaptação do processo natural de "sobrevivência do mais adaptado" combinado com um sistema de trocas de informação randômicas para solução de problemas, assim, os algoritmos genéticos são capazes de evoluir as soluções de problemas matemáticos caso tenham sido programados para tal função.

O processo de otimização consiste em adaptar as entradas de um modelo de forma a encontrar o máximo (ou mínimo) valor para a solução do problema. O modelo matemático estudado utiliza uma função objetivo (fitness function), a qual representa o valor da solução.

A interpretação dos resultados consiste na análise do valor da função objetivo para um conjunto de entradas. Essa geração será alterada através de operadores genéticos (utilizando mutação de bits e características do melhor indivíduo) gerando um novo conjunto de entradas para ser analisada pela função objetivo. A população é definida como o conjunto de entradas consideradas em toda a aplicação do algoritmo. Apesar de randômico, o GA utiliza informações das gerações anteriores para evoluir as novas gerações [23].

Regras específicas são determinadas para evoluir a população de forma a maximizar (ou minimizar) a função objetivo. Podem-se citar algumas das vantagens dos algoritmos genéticos como [24]:

- Capacidade de otimizar parâmetros contínuos ou discretos;

- São bem adaptados ao processamento em paralelo;

- Capazes de otimizar parâmetros em modelos matemáticos complexos. 
É importante frisar que como os algoritmos genéticos são baseados em processos randômicos, não é possível determinar sua eficiência para um determinado problema.

Uma visão geral do funcionamento do GA pode ser explicada como um processo de quatro partes:

1. População inicial gerada randomicamente.

2. Seleção dos melhores indivíduos

3. Seleção de indivíduos para crossover.

4. Seleção de alguns indivíduos para mutação.

Ou seja, uma população inicial é aleatoriamente gerada, então alguns indivíduos são selecionados de acordo com as regras definidas na função fitness. Os melhores indivíduos são armazenados, posteriormente, indivíduos são selecionados para a operação de crossover. Então, novamente, alguns indivíduos são selecionados para a operação de mutação. Assim, uma nova geração é produzida e o processo é repetido até que o critério de convergência seja atingido.

A Tabela 1 mostra algumas características do algoritmo genético quando comparadas aos modelos clássicos de otimização:

Tabela 1 - Comparação entre algoritmos genéticos e algoritmos clássicos.

\begin{tabular}{|c|c|}
\hline Algoritmo Clássico & Algoritmo Genético \\
\hline $\begin{array}{c}\text { Gera um único ponto em cada } \\
\text { iteração. A sequência de pontos se aproxima } \\
\text { da solução ótima. }\end{array}$ & $\begin{array}{c}\text { Gera uma população de pontos em cada } \\
\text { iteração. O melhor ponto da população é utilizado } \\
\text { para a aproximação da solução ótima }\end{array}$ \\
\hline $\begin{array}{c}\text { Seleciona o próximo ponto na } \\
\text { sequencia a partir de um cálculo } \\
\text { determinado. }\end{array}$ & $\begin{array}{c}\text { Seleciona a próxima população por uma } \\
\text { computação evolutiva, a partir dos melhores } \\
\text { resultados anterior. }\end{array}$ \\
\hline
\end{tabular}




\subsection{Aplicação ao Caso Estudado}

No presente trabalho, a metodologia de otimização utilizando algoritmos genéticos foi utilizada para determinar os expoentes $x, y, z$ e a da equação 3.45 , bem como os coeficientes $\alpha, \beta$ e $\gamma$ da equação 3.49 relativos à queda de pressão do lado da água/vapor e do lado dos gases, respectivamente. Os termos $n, k$ e $p$, da equação 3.57 de cálculo do coeficiente global de troca de calor também foram otimizados.

\subsubsection{O processo de Otimização}

A otimização consistiu na calibração dos expoentes mencionados de maneira a obter o menor erro médio entre as saídas do programa e os dados de operação da usina. Nove diferentes condições de operação baseadas no percentual de carga da turbina a gás foram utilizadas. Os patamares de carga utilizados para a calibração são exibidos na Tabela 2, assim as entradas mostradas na Tabela 3 devem ser fornecidas para cada patamar de carga.

Tabela 2 - Patamares de carga usados na calibração utilizando algoritmos genéticos

\begin{tabular}{|l|c|c|c|c|c|c|c|c|}
\hline \multicolumn{7}{|c|}{ Percentual de Carga da Turbina a Gás } \\
\hline $97,00 \%$ & $95,00 \%$ & $93,00 \%$ & $88,00 \%$ & $83,00 \%$ & $80,00 \%$ & $73,00 \%$ & $67,00 \%$ & $60,00 \%$ \\
\hline
\end{tabular}

Para determinar os expoentes a serem enviado à rotina de cálculo da caldeira de recuperação foi utilizada a ferramenta de Algoritmos Genéticos do programa MATLAB (MATLAB GA Toolbox).

O resultado da função objetivo é o desvio médio das variáveis calculadas pelo programa. Isto é, o somatório dos desvios de cada parâmetro dividido pelo número total destes, consistindo a otimização na minimização desse resultado. Cabe ressaltar que os estados termodinâmicos e vazões na entrada e saída de todos os trocadores de calor da caldeira calculados, porém os únicos pontos que possuem medições para a validação são mostrados na Tabela 4.

Uma vez definidos os expoentes de acordo com as configurações do algoritmo genético, estes são enviados à rotina de cálculo da caldeira, desenvolvida em FORTRAN. A rotina calcula os resultados para cada conjunto de dados de entrada enviado, lembrando que cada conjunto é referente a um determinado percentual de carga da turbina a gás.

A Figura 25 mostra um esquema da estrutura do programa de otimização desenvolvido. 
Tabela 3 - Parâmetros de entrada do modelo computacional

\begin{tabular}{|l|c|}
\hline \multicolumn{1}{|c|}{ Entradas do Modelo } & Unidade \\
\hline Vazão de água na entrada do preaquecedor & {$[\mathrm{kg} / \mathrm{s}]$} \\
\hline Pressão da água na entrada do preaquecedor & {$[\mathrm{bar}]$} \\
\hline Temperatura da água na entrada do preaquecedor & {$[\mathrm{C}]$} \\
\hline Vazão dos gases na saída do preaquecedor & {$[\mathrm{kg} / \mathrm{s}]$} \\
\hline Pressão dos gases na saída do preaquecedor & {$[\mathrm{bar}]$} \\
\hline Temperatura dos gases na saída do preaquecedor & {$[\mathrm{C}]$} \\
\hline Vazão de água na entrada do evaporador de LP & {$[\mathrm{kg} / \mathrm{s}]$} \\
\hline Vazão de água na entrada do economizador de IP & {$[\mathrm{kg} / \mathrm{s}]$} \\
\hline Pressão da água na entrada do economizador de IP & {$[\mathrm{bar}]$} \\
\hline Vazão de água na entrada do economizador de HP & {$[\mathrm{kg} / \mathrm{s}]$} \\
\hline Vazão de vapor na entrada do recuperador 1 (Hot Reheat) & {$[\mathrm{kg} / \mathrm{s}]$} \\
\hline Pressão do vapor na entrada do recuperador 1 & {$[\mathrm{bar}]$} \\
\hline Temperatura de vapor na entrada do recuperador 1 & {$[\mathrm{C}]$} \\
\hline Pressão do vapor na entrada do recuperador 1 (Cold Reheat) & {$[\mathrm{bar}]$} \\
\hline Temperatura do vapor na entrada do recuperador 1 (Cold Reheat) & {$[\mathrm{C}]$} \\
\hline Pressão da água na entrada do entrada do economizador de HP & {$[\mathrm{bar}]$} \\
\hline Pressão de água na entrada do entrada do evaporador de LP & {$[\mathrm{bar}]$} \\
\hline
\end{tabular}

Tabela 4 - Parâmetros calculados pelo modelo computacional

\begin{tabular}{|l|c|}
\hline \multicolumn{1}{|c|}{ Entradas do Modelo } & Unidade \\
\hline Vazão de vapor na saída recuperador 2 & {$[\mathrm{kg} / \mathrm{s}]$} \\
\hline Temperatura do vapor na saída do recuperador 2 & {$[\mathrm{bar}]$} \\
\hline Pressão de vapor na saída do recuperador 2 & {$[\mathrm{kg} / \mathrm{s}]$} \\
\hline Vazão de vapor na saída do superaquecedor de HP 2 & {$[\mathrm{C}]$} \\
\hline Temperatura do vapor na saída do superaquecedor de HP 2 & {$[\mathrm{bar}]$} \\
\hline Pressão do vapor na saía do superaquecedor de HP 2 & {$[\mathrm{bar}]$} \\
\hline Pressão do vapor na saída do evaporador de HP & {$[\mathrm{bar}]$} \\
\hline Pressão do vapor na saída do evaporador de IP & {$[\mathrm{bar}]$} \\
\hline Pressão de vapor na saída do evaporador de LP & {$[\mathrm{kg} / \mathrm{s}]$} \\
\hline Vazão de vapor na saída do superaquecedor de LP & {$[\mathrm{C}]$} \\
\hline Temperatura do vapor na saída do superaquecedor de LP & {$[\mathrm{bar}]$} \\
\hline Pressão do vapor na saída do superaquecedor de LP & {$[\mathrm{bar}]$} \\
\hline Vazão de vapor na saída do superaquecedor de IP & {$[\mathrm{C}]$} \\
\hline Temperatura do vapor na saída do superaquecedor de IP & {$[\mathrm{bar}]$} \\
\hline Pressão do vapor na saída do superaquecedor de IP & {$[\mathrm{kg} / \mathrm{s}]$} \\
\hline Vazão de gás na entrada do recuperador 2 &
\end{tabular}




\begin{tabular}{|l|c|}
\hline Temperatura do gás na entrada do recuperador 2 & {$[\mathrm{C}]$} \\
\hline Pressão do gás na entrada do recuperador 2 & {$[\mathrm{mmHg}]$} \\
\hline
\end{tabular}

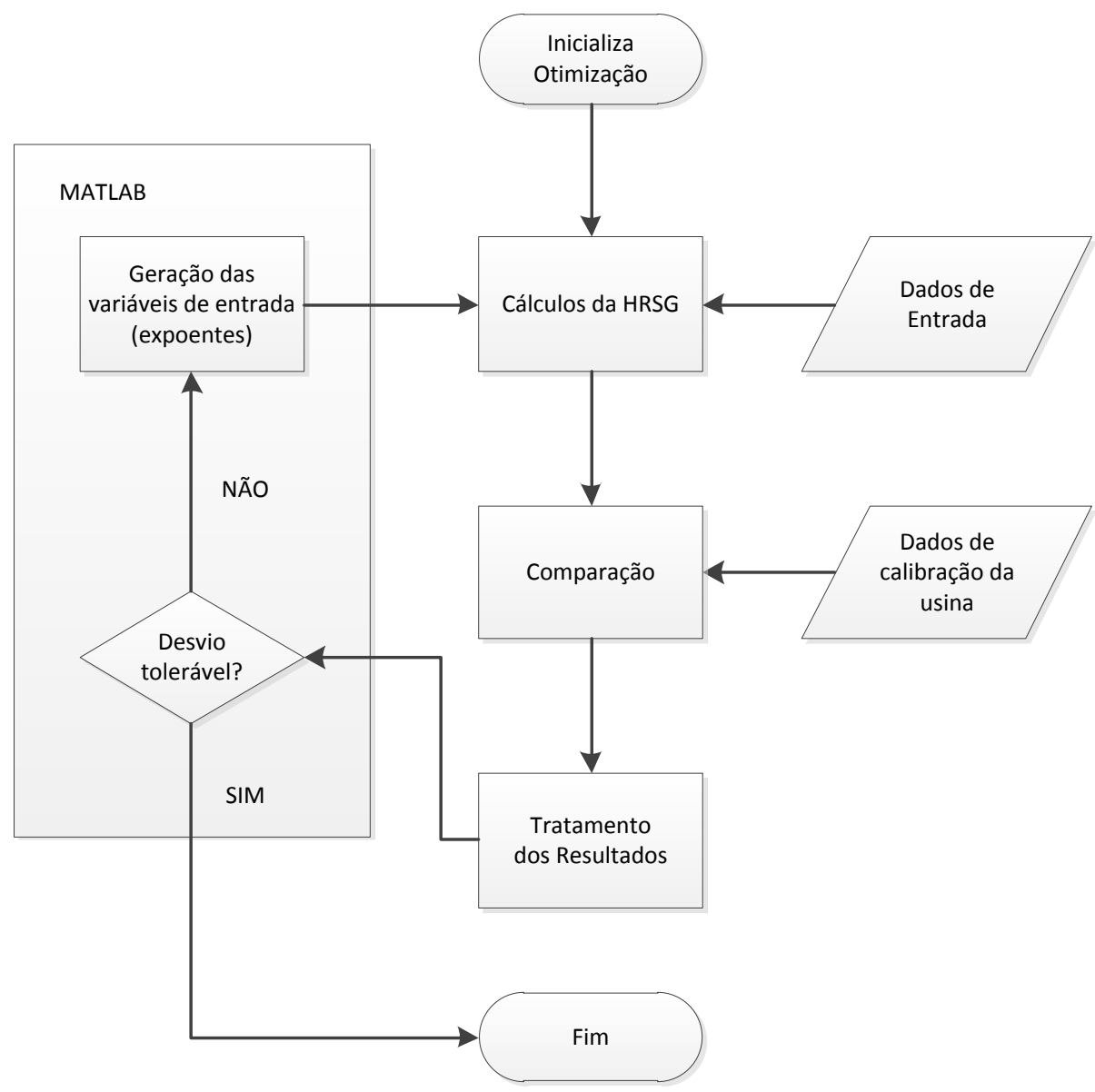

Figura 25 - Estrutura do programa de otimização dos expoentes de calibração.

Uma vez obtidos os resultados pela rotina da HRSG seus valores são comparados os dados de operação da usina, o desvio de cada variável é calculado e a média dos desvios para cada patamar de carga pode ser determinada.

$$
\begin{aligned}
& \text { Desvio }_{\text {carga } 1}=\frac{\Delta x_{1}+\Delta x_{2}+\cdots+\Delta x_{n}}{n} \\
& \text { Desvio }_{\text {carga } 2}=\frac{\Delta x_{1}+\Delta x_{2}+\cdots+\Delta x_{n}}{n} \\
& \text { Desvio }_{\text {carga } m}=\frac{\Delta x_{1}+\Delta x_{2}+\cdots+\Delta x_{n}}{n}
\end{aligned}
$$


Porém, como o número de resultados é amplo, um determinado parâmetro $x_{n}$ pode apresentar o desvio, $\Delta x_{n}$, alto enquanto os demais parâmetros possuem desvios menores. Essa situação teria por consequência um desvio pontual no parâmetro $x_{n}$ considerável, mas um desvio médio baixo para aquele patamar de carga, resultando em um valor pequeno da função objetivo a ser minimizada, o que implica em uma informação não confiável para o GA.

A fim de contornar esse problema, um sistema de penalidades foi inserido no modelo. Onde caso uma variável apresente um desvio maior do que $15 \%$ do valor de calibração o programa retorna um desvio médio elevado, fazendo com que o GA não considere o caso como uma boa solução.

O último tratamento de resultado é o cálculo do valor médio total dos desvios entre cada carga utilizada na calibração.

$$
\text { Resultado }=\frac{\text { Desvio }_{\operatorname{carga}_{1}}+\text { Desvio }_{\text {carga } 2_{2}}+\cdots+\text { Desvio }_{\text {carga } m}}{m}
$$

O GA, então, recebe o resultado e aplica as funções de seleção, reprodução e mutação nas variáveis de entrada de acordo com o valor recebido, realimentando a rotina da caldeira até que os expoentes estejam devidamente calibrados.

\subsubsection{Resultados Obtidos}

De forma a reduzir o custo computacional do processo de otimização, considerou-se que a queda de pressão dos gases de exaustão ao longo da caldeira de recuperação de calor é linear. Essa hipótese elimina a necessidade de cálculo dos expoentes determinantes da variação de pressão dos gases de exaustão (expoentes $\alpha, \beta$ e $\gamma$ ) em cada trocador de calor e pôde ser considerada uma vez que a variação da pressão ao longo da caldeira é pequena (Tabela 5 ), cerca de $0,33 \%$, não influenciando drasticamente no desempenho dos trocadores de calor.

Tabela 5 - Dados da Variação da Pressão dos Gases de Exaustão ao longo da HRSG

\begin{tabular}{|l|c|c|}
\hline Pressão de exaustão da turbina & {$[\mathrm{kPa}]$} & 101,462 \\
\hline Pressão na chaminé & {$[\mathrm{kPa}]$} & 101,132 \\
\hline & & \\
\hline Diferença de pressão total & {$[\mathrm{kPa}]$} & 0,330 \\
\hline Percentual de queda de pressão total & {$[\%]$} & 0,326 \\
\hline & & \\
\hline N. de trocadores de calor em série na HRSG & - & 12 \\
\hline Queda de pressão média & {$[\mathrm{kPa}]$} & 0,027 \\
\hline
\end{tabular}


Partiu-se então para a execução do processo de otimização visando à obtenção dos coeficientes que fossem capazes de minimizar o desvio médio, respeitando as condições impostas pelas penalidades.

Os valores obtidos para todos os expoentes calibrados foram armazenados em um arquivo para serem utilizados como entrada de dados no modelo computacional. 
5

\section{Simulação de uma Caldeira de Recuperação de Calor em uma usina de Ciclo Combinado}

\subsection{Introdução}

A HRSG da usina simulada foi desenvolvida de forma a atender a demanda de vapor da usina de acordo com parâmetros de entrada especificados, incluindo a vazão de exaustão, temperatura e queda de pressão.

A unidade é constituída por três níveis de pressão definidos como sistema de alta pressão (high pressure - HP), sistema de pressão intermediária (intermediate pressure - IP) e sistema de baixa pressão (low pressure - LP). A Tabela 6 mostra as características termodinâmicas de cada sistema de pressão presente na caldeira, de acordo com seu datasheet de fábrica.

Um sistema de reaquecimento ( $\mathrm{RHT}$ ) também foi incorporado ao conjunto, de forma a melhorar a eficiência do ciclo combinado. A água de alimentação de todos os sistemas de pressão é pré-aquecida em um conjunto comum para tal fim.

Tabela 6 - Características dos Sistemas de Vapor.

\begin{tabular}{|c|c|c|c|}
\hline Sistema & $\begin{array}{c}\text { Vazão de } \\
\text { Vapor }(\mathrm{kg} / \mathrm{h})\end{array}$ & $\begin{array}{c}\text { Pressão do } \\
\text { Vapor (barg) }\end{array}$ & $\begin{array}{c}\text { Temperatura } \\
\text { do Vapor (C) }\end{array}$ \\
\hline HP & 189828 & 135,1 & 566,1 \\
IP & 35226 & 31,7 & 270 \\
\hline LP & 31774 & 4,3 & 278,9 \\
\hline RHT & 216958 & 30,5 & 566,7 \\
\hline
\end{tabular}

Posteriormente, são apresentados os principais componentes da caldeira de recuperação de calor, conforme descritos no manual de operação do equipamento. A classificação e nomenclatura dada seguiram os padrões fornecidos pelo fabricante em seu manual. O esquema geral da HRSG pode ser visto na Figura 26. 


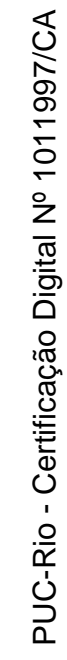

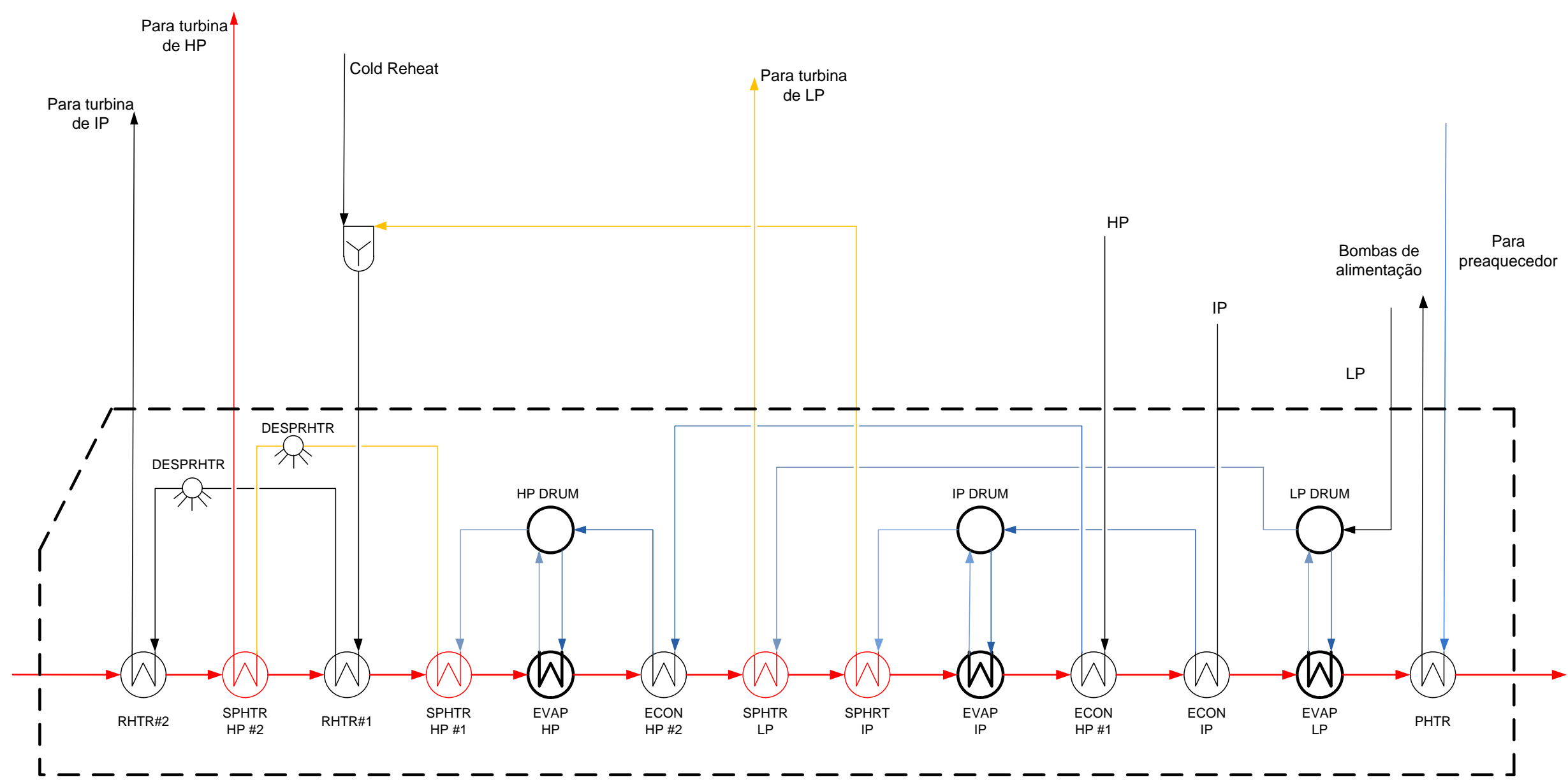

Figura 26 - Configuração da caldeira de recuperação de calor modelada 


\subsubsection{Duto de Transição da Admissão}

Essa seção é responsável por desacelerar os gases de exaustão da turbina para a altura total da HRSG, de forma a prover uma distribuição uniforme de calor para as superfícies de aquecimento.

\subsubsection{Reaquecedor \#2 / Superaquecedor HP \#2}

O aquecimento final do vapor de reaquecimento é feito no reaquecedor, enquanto o aquecimento final do vapor de HP é feito no Superaquecedor HP \#2.

O vapor presente nas trocadores é todo coletado e passado através das válvulas para a saída.

\subsubsection{Reaquecedor \#1 / Superaquecedor HP \#1}

O Reaquecedor \#1 é o responsável pelo aquecimento primário do vapor de reaquecimento, proveniente da mistura da saída da turbina de HP e do Superaquecedor de IP. O fluxo de vapor na saída de cada trocador é encanado individualmente para as entradas do Reaquecedor \#2. Cada linha contém uma estação de desuperaquecimento.

Já o Superaquecedor de HP \#1 é alimentado pelo vapor de alta pressão do tubulão de HP para que ocorra o aquecimento inicial. O fluxo de vapor na saída de cada trocador é encanado individualmente para as entradas do Superaquecedor HP \#2, e cada linha contém uma estação de desuperaquecimento.

\subsubsection{Evaporador HP}

Nesse equipamento, a água de alimentação que foi aquecida do Economizador \#2 entra na parte anterior do tubulão de vapor do Evaporador HP através de duas linhas. $O$ vapor formado sai pelo alto do tubulão através de tubos ali conectados. Esses tubos de saída conectam o tubulão ao Superaquecedor HP \#1.

\subsubsection{Economizador HP \#2}

A água nesse trocador é aquecida até um valor próximo à sua temperatura de saturação no tubulão de HP. As seções da linha de frente e até metade do trocador são de fluxo ascendente. Isso permite que qualquer vapor que seja gerado em condições fora do ponto de projeto seja levado na mesma direção do fluxo principal, 
reduzindo, assim, o potencial de bloqueio por vapor. A água deste módulo flui para o Tubulão de Vapor HP.

\subsubsection{Superaquecedor LP / Superaquecedor IP / Evaporador IP}

O Superaquecedor de LP é o responsável pelo aquecimento do vapor de LP. Após o aquecimento, todo o fluxo é todo coletado e passado através das válvulas para a saída.

O aquecimento final do vapor IP é feito no Superaquecedor IP. Onde, ao término da troca, todo fluxo é todo coletado e passado através das válvulas para a saída.

O Evaporador de IP recebe, em seu tubulão, a água de alimentação do Economizador IP através de duas linhas, para a evaporação do fluido. O vapor resultante sai pelo topo do tubulão através de tubos ali conectados. Esses tubos conectam o tubulão ao Superaquecedor IP \#1.

\subsubsection{Economizador HP \#1 / Economizador IP \#1 / Evaporador LP}

A água de alimentação vinda da bomba de alimentação da caldeira IP é aquecida no Economizador IP. Sendo todo o fluxo todo coletado na saída e direcionado para o Economizador HP \#2.

O Economizador de LP fornece a água de alimentação que entra no tubulão de vapor LP. O vapor gerado sai do topo do tubulão através de tubos em sua parte superior. Esses tubos conectam o tubulão com o Superaquecedor LP \#1.

\subsubsection{Preaquecedor}

A água de alimentação do condensado e as linhas provenientes do makeup são aquecidas nesse conjunto de quatorze linhas. Sendo fluxo das linhas é inteiramente coletado e unido na saída e, posteriormente, direcionado ao tubulão de vapor LP. 


\subsection{Modelo Computacional}

Inicialmente, buscou-se modelar cada trocador de calor individualmente, seguindo o sentido natural de seus fluxos, ou seja, os inputs seriam o estado termodinâmico e vazão de ambos os fluidos na entrada do trocador de calor, e os outputs a vazão e estado termodinâmico dos fluidos na saída dos trocadores de calor, conforme a Figura 27.

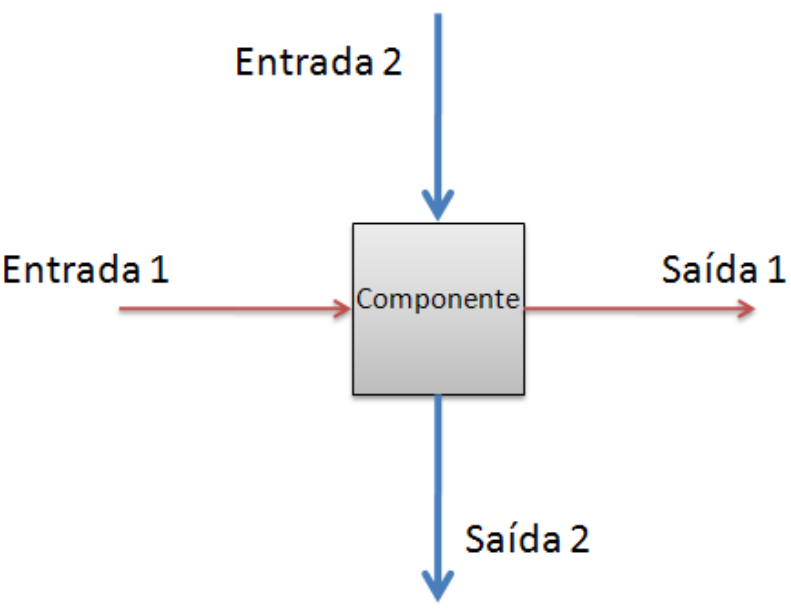

Figura 27 - Exemplo de um componente operando como trocador de calor.

Porém, as características do sistema de instrumentação da caldeira de recuperação modelada levaram à adoção da sequência de cálculo no sentido da água e contrária aos gases de exaustão.

Essa escolha ocorreu, pois não existem dados de medição de pressão entre cada trocador de calor. Portanto, para permitir a funcionalidade fidedigna do modelo computacional e possibilitar a validação dos dados e a alimentação de entradas entre os modelos de cada trocador (onde um equipamento recebe informações do equipamento à montante) a estratégia de modelagem mostrada na Figura 28 foi escolhida. Cabe ressaltar novamente que o fluxo de informações dos gases está no sentido contrário de seu escoamento 
Dado de Entrada Dado de Entrada

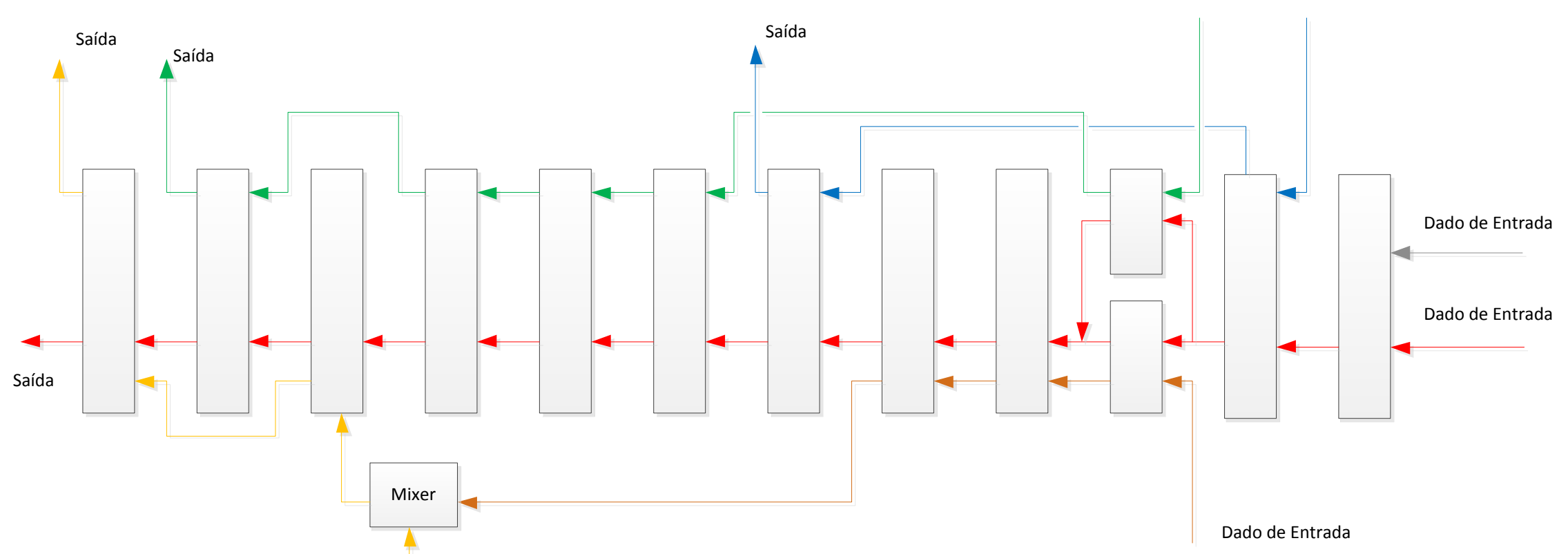

Dado de Entrada

ECON

\begin{tabular}{cccccccccccc} 
RHTR\#2 & SPHTR & RHTR\#1 & SPHTR & EVAP & ECON & SPHTR & SPHRT & EVAP & ECON & EVAP & PHTR \\
& HP\#2 & HP\#1 & HP & HP\#2 & LP & IP & IP & HP\#1 & LP & PHTR \\
\hline \multicolumn{11}{c}{ SENTIDO DO ESCOAMENTO DOS GASES } &
\end{tabular}

Figura 28 - Fluxo de informações no modelo computacional 
Foram considerados como input do modelo computacional os parâmetros numerados abaixo:

1. Vazão de água na entrada do preaquecedor;

2. Pressão da água na entrada do preaquecedor;

3. Temperatura da água na entrada do preaquecedor;

4. Vazão dos gases na saída do preaquecedor;

5. Pressão dos gases na saída do preaquecedor;

6. Temperatura dos gases na saída do preaquecedor;

7. Vazão de água na entrada do evaporador de LP;

8. Vazão de água na entrada do economizador de IP;

9. Pressão da água na entrada do economizador de IP;

10. Vazão de água na entrada do economizador de HP;

11. Vazão de vapor na entrada do recuperador 1 (Hot Reheat);

12. Pressão do vapor na entrada do recuperador 1 ;

13. Temperatura de vapor na entrada do recuperador 1 ;

14. Pressão do vapor na entrada do recuperador 1 (Cold Reheat);

15. Temperatura do vapor na entrada do recuperador 1 (Cold Reheat);

16. Pressão da água na entrada do entrada do economizador de HP;

17. Pressão de água na entrada do entrada do evaporador de LP;

Sendo os estados termodinâmicos e vazões em todos os pontos da caldeira calculados, porém os únicos que possuem medições para a validação são enumerados a seguir:

1. Vazão de vapor na saída recuperador 2;

2. Temperatura do vapor na saída do recuperador 2;

3. Pressão de vapor na saída do recuperador 2;

4. Vazão de vapor na saída do superaquecedor de HP 2;

5. Temperatura do vapor na saída do superaquecedor de HP 2;

6. Pressão do vapor na saía do superaquecedor de HP 2;

7. Pressão do vapor na saída do evaporador de HP;

8. Pressão do vapor na saída do evaporador de IP;

9. Pressão de vapor na saída do evaporador de LP;

10. Vazão de vapor na saída do superaquecedor de LP;

11. Temperatura do vapor na saída do superaquecedor de LP;

12. Pressão do vapor na saída do superaquecedor de LP;

13. Vazão de vapor na saída do superaquecedor de IP; 
14. Temperatura do vapor na saída do superaquecedor de IP;

15. Pressão do vapor na saída do superaquecedor de IP;

16. Vazão de gás na saída do recuperador 2;

17. Temperatura do gás na saída do recuperador 2 ;

18. Pressão do gás na saída do recuperador 2 .

\subsubsection{Metodologia Geral para o Cálculo dos Trocadores de Calor}

De maneira a determinar todas as temperaturas em cada trocador de calor foi utilizado um processo iterativo, ilustrado na Figura 29, onde são arbitrados dois valores para a temperatura de saída dos gases de exaustão (Tguess $1_{\text {g,out }} \mathrm{e}$ Tguess $2_{\text {g,out }}$ ), que posteriormente serão ajustados utilizando o método da secante.

Logo, o calor fornecido pelos gases pode ser calculado como:

$$
\begin{aligned}
& \dot{Q 1} 1_{g}=\dot{m}_{g} C p_{g}\left(\text { Tguess } 1_{g, \text { out }}-T_{g, \text { in }}\right) \\
& \dot{Q} 2_{g}=\dot{m}_{g} C p_{g}\left(\text { Tguess } 2_{g, \text { out }}-T_{g, \text { in }}\right)
\end{aligned}
$$

Supondo então que o calor do gás será passado à água integralmente:

$$
\begin{aligned}
& \dot{Q} 1_{w}=\dot{Q} 1_{g} \\
& \dot{Q} 2_{w}=\dot{Q} 2_{g}
\end{aligned}
$$

Assim a entalpia de saída da água será obtida pelas seguintes relações:

$$
\begin{aligned}
& h 1_{w, \text { out }}=\frac{\dot{Q} 1_{w}}{\dot{m}_{w}}+h_{w, \text { in }} \\
& h 2_{w, \text { out }}=\frac{\dot{Q} 2_{w}}{\dot{m}_{w}}+h_{w, \text { in }}
\end{aligned}
$$

Logo, as temperaturas são facilmente obtidas uma vez que pressão e entalpia são conhecidas. 


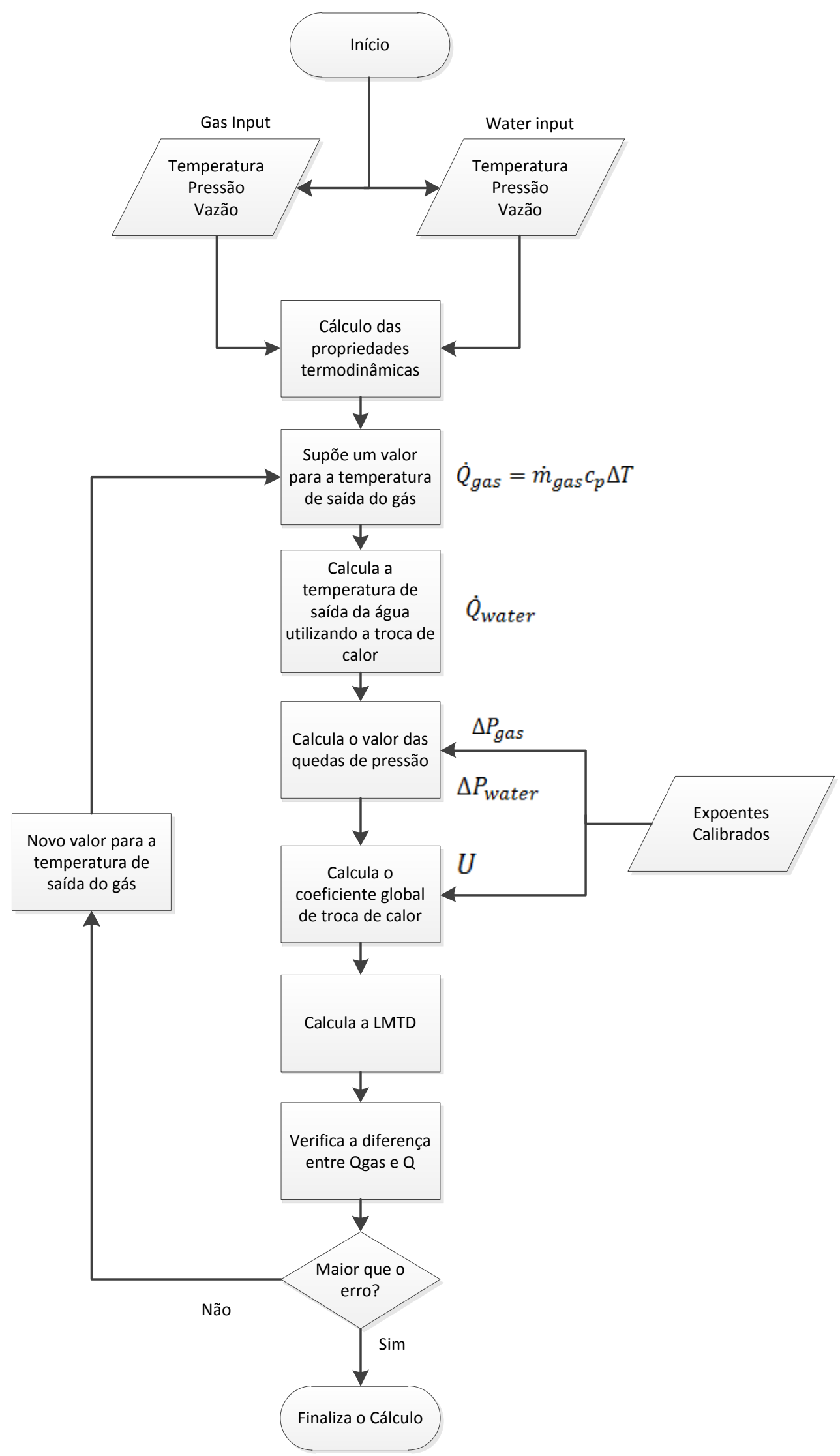

Figura 29 - Método de cálculo do trocador de calor 
Como existem duas temperaturas de saída da água, devido aos dois valores arbitrados para a temperatura de saída do gás o cálculo dos coeficientes de troca de calor deve ser feito para cada caso, bem como a diferença média logarítmica de temperaturas. Assim, dois coeficientes globais de troca de calor serão obtidos $\left(U_{1} \mathrm{e}\right.$ $\left.U_{2}\right)$.

$$
\begin{aligned}
& \dot{Q}_{1}=A U_{1} \Delta T_{\log 1} \\
& \dot{Q}_{2}=A U_{2} \Delta T_{\log } 2
\end{aligned}
$$

Os valores de $\dot{Q}_{1}$ e $\dot{Q}_{2}$ podem então ser compadrados com $\dot{Q} 1_{g}$ e $\dot{Q} 2_{g}$, respectivamente:

$$
\begin{aligned}
& f_{0}=\dot{Q} 1_{g}-\dot{Q}_{1} \\
& f_{1}=\dot{Q} 2_{g}-\dot{Q}_{2}
\end{aligned}
$$

Caso o termo $f_{1}$ seja menor do que a tolerância estabelecida pelo método o programa sai do loop e retorna os valores calculados. Porém, caso a convergência ainda não tenha ocorrido, os valores de $T$ gues $1_{\text {g,out }}$ e $T$ gues $2_{\text {g,out }}$ serão testados novamente através do seguinte cálculo:

$$
\begin{aligned}
& \Delta T=\frac{-f_{1}\left(\text { Tguess } 2_{\text {g,out }}-\text { Tguess } 1_{\text {g,out }}\right)}{\left(f_{1}-f_{0}\right)} \\
& \text { Tguess } 1_{\text {g,out }}=\text { Tguess } 2_{\text {g,out }} \\
& \text { Tguess } 2_{g, o u t}=\text { Tguess }_{1, \text { out }}+\Delta T
\end{aligned}
$$

Esse processo é repetido até que o termo $f_{1}$ atinja um valor abaixo da tolerância estabelecida, verificando a convergência do método. 


\subsubsection{Metodologia de Cálculo para os Trocadores de Calor Paralelos (ECON HP\#1 e EVAP IP)}

A configuração dos trocadores de calor dentro da caldeira da caldeira estudada mostra que o economizador de alta pressão 1 (ECON HP \#1) e o evaporador de pressão intermediária (EVAP IP) encontram-se montados em paralelo, conforme a Figura 30.

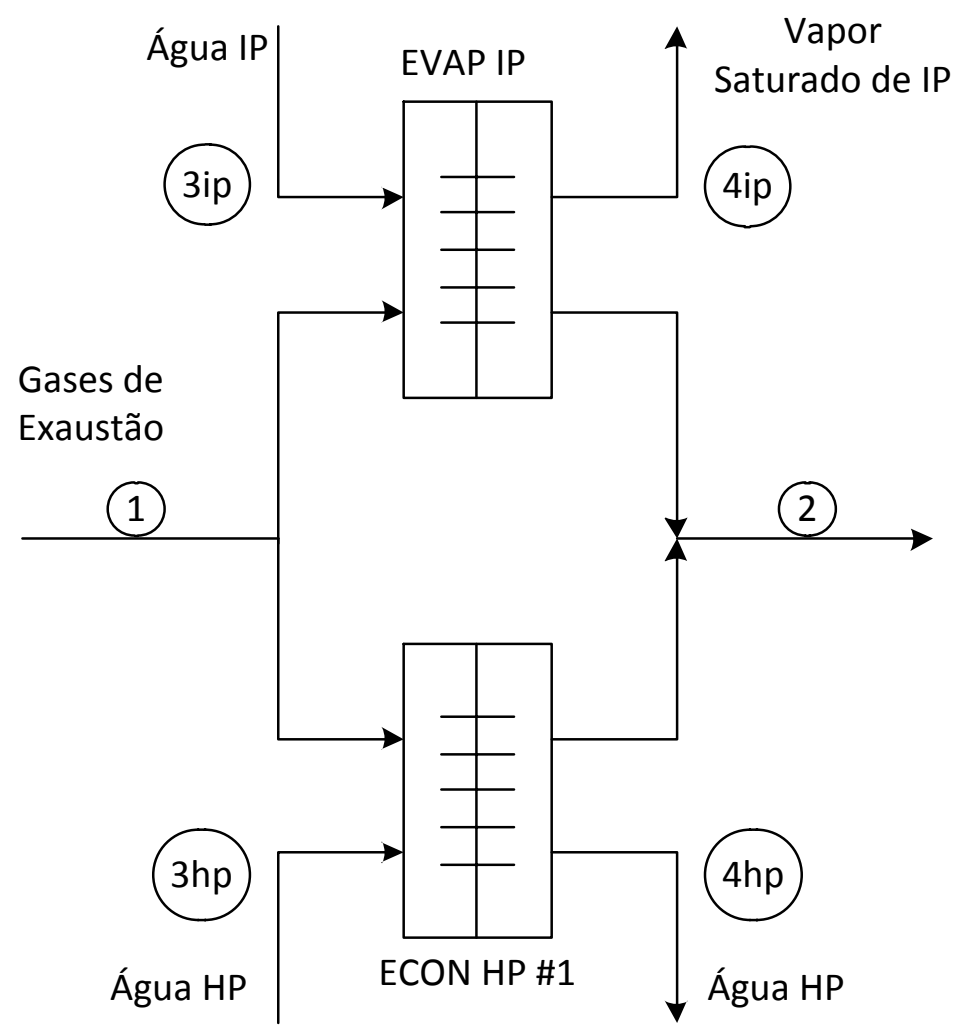

Figura 30 - Trocadores de calor em paralelo

Essa configuração merece uma atenção especial, uma vez que o conjunto de equações que descreve seu comportamento não pode ser resolvido de maneira sequencial, como os demais trocadores de calor. E sim através da solução de um sistema de equações.

De forma a resolver as peculiaridades desse conjunto, foi mantida à convenção das entradas adotada nos demais blocos da caldeira. Ou seja, são dados como conhecidos as condições de entrada da água nos trocadores de calor (3ip e 3hp) e a saída dos gases de exaustão (2).

As equações que regem a troca de calor no conjunto são: 


$$
\begin{gathered}
\dot{Q}_{I P}-U A_{I P}\left(\Delta T_{\log _{I P}}\right)=0 \\
\dot{Q}_{H P}-U A_{H P}\left(\Delta T_{\log _{H P}}\right)=0 \\
\dot{Q}-\dot{Q}_{I P}-\dot{Q}_{H P}=0 \\
\dot{Q}-\dot{m}_{1} c_{p}\left(T_{1}-T_{2}\right)=0 \\
\dot{Q}_{I P}-\dot{m}_{I P}\left[h_{4 I P}-h_{3 I P}\right]=0 \\
\dot{Q}_{H P}-\dot{m}_{H P}\left[h_{4 H P}-h_{3 H P}\right]=0
\end{gathered}
$$

Lembrando que,

$$
\begin{gathered}
\Delta T_{\log _{H P}}=\frac{\left(T_{1}-T_{3 H P}\right)-\left(T_{2}-T_{4 H P}\right)}{\ln \frac{\left(T_{1}-T_{3 H P}\right)}{\left(T_{2}-T_{H P 4}\right)}} \\
\Delta T_{\log _{I P}}=\frac{\left(T_{1}-T_{3 I P}\right)-\left(T_{2}-T_{4 I P}\right)}{\ln \frac{\left(T_{1}-T_{3 I P}\right)}{\left(T_{2}-T_{4 I P}\right)}}
\end{gathered}
$$

As entalpias são calculadas a partir das temperaturas e pressões, utilizando as correlações da IAPWS [25]. Assim, as equações 5.79 e 5.80 podem ser reescritas como:

$$
\begin{gathered}
\dot{Q}_{I P}-\dot{m}_{I P}\left[f\left(P_{4 I P}, T_{4 I P}\right)-f\left(P_{3 I P}, T_{3 I P}\right)\right]=0 \\
\dot{Q}_{H P}-\dot{m}_{H P}\left[f\left(P_{4 H P}, T_{4 H P}\right)-f\left(P_{3 H P}, T_{3 H P}\right)\right]=0
\end{gathered}
$$


As pressões são conhecidas através do cálculo da queda de pressão, logo para definir o estado termodinâmico na saída dos trocadores apenas as temperaturas devem ser calculadas.

Portanto as incógnitas do sistema de equações proposto são: $\dot{Q}_{I P}, \dot{Q}_{H P}, \dot{Q}$, $T_{1}, T_{4 H P}, T_{4 I P}$. Para a resolução desse sistema foi utilizado o Método de NewtonRaphson. Deve-se ressaltar que a entalpias, descritas pelos polinômios de [26], em função das temperaturas, geram termos com alto grau de complexidade quando derivadas, para isso foi utilizado a ferramenta de matemática simbólica do MATLAB.

\subsubsection{Organização do Modelo Computacional da Caldeira de Recuperação de Calor}

Uma vez definidas as rotinas individuais de cada trocador de calor através da aplicação das equações descritas em 3.1.4 na metodologia explicada em 5.2.1 e 5.2.2, foi necessário organizar a estrutura de chamadas das rotinas mantendo o fluxo de informação esquematizado na Figura 28 e organizando a estrutura dos módulos computacionais conforme a Figura 31.

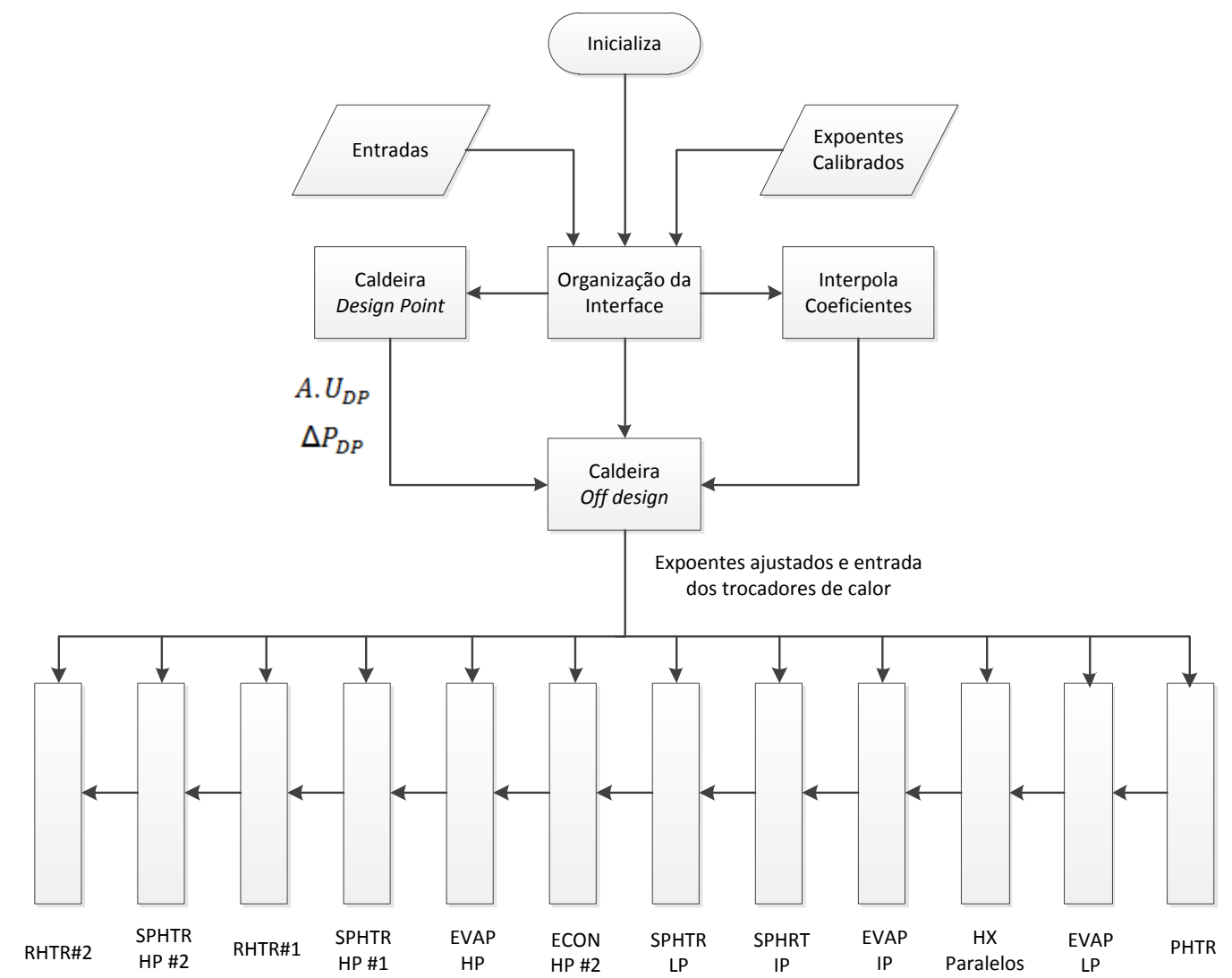

Figura 31 - Diagrama do modelo computacional da caldeira de recuperação de calor 
Quando o programa é inicializado são fornecidos como entrada os dados de entrada e os expoentes calibrados pela rotina de otimização descrita em 4.2.1. Esses dados são enviados a uma subrotina responsável por preparar a interface de entrada de cada trocador de calor da caldeira, isto é organizar as variáveis de entrada de cada modelo de trocador de calor.

A rotina de cálculos em ponto de projeto é executada e os valores de $\Delta P_{D P} \mathrm{e}$ $U A_{D P}$ são calculados.

Quando recebidos os dados de entrada e os expoentes de ajuste, uma rotina de interpolação é executada. Como os expoentes são calibrados para certos pontos de operação (patamares de carga da turbina a gás que variam de 95\% a 63\%), optou-se por interpolá-los linearmente de acordo com a entrada imposta ao modelo. Sendo a vazão dos gases de exaustão na saída da turbina o parâmetro escolhido para determinar em qual faixa de operação a entrada está.

Logo, a interpolação pode ser feita através de:

$$
x=\frac{\dot{m}_{g}-\dot{m}_{\text {inf }}}{\dot{m}_{\text {sup }}-\dot{m}_{\text {inf }}}
$$

Onde $x$ é o peso de ajuste da interpolação, $\dot{m}_{g}$ a vazão dos gases de exaustão enviada ao modelo, $\dot{m}_{\text {sup }}$ a vazão dos gases de exaustão no patamar superior do intervalo de carga onde $\dot{m}_{g}$ se encontra e $\dot{m}_{i n f}$ a vazão dos gases de exaustão no patamar inferior do intervalo de carga o qual $\dot{m}_{g}$ pertence.

Consequentemente, o coeficiente ajustado será dado por:

$$
\operatorname{coef}=\operatorname{coef}_{\text {inf }}+x\left(\operatorname{coef}_{\text {sup }}-\operatorname{coef}_{\text {inf }}\right)
$$

Sendo coef o coeficiente a ser utilizado para a entrada disponibilizada, coe $f_{\text {sup }} 0$ expoente calibrado no patamar superior do intervalo de carga e coefinf 0 expoente calibrado para o patamar inferior do intervalo de carga.

Essa interpolação é feita para todos os expoentes utilizados pelo programa.

O conjunto de dados de entrada e expoentes de ajuste interpolados é enviado à subrotina de cálculos offdesign. A subrotina da caldeira offdesign executa as chamadas de cada componente modelado, enviando os dados de entrada necessários para o equipamento e recebendo os resultados, que são armazenados e enviados ao equipamento posterior. Os resultados relativos aos gases de exaustão são repassados diretamente ao trocador de calor seguinte, enquanto os dados relativos ao lado de água/vapor são enviados ao próximo equipamento do circuito de mesma pressão (LP, 
IP ou HP), pois os equipamentos de um mesmo circuito de pressão estão dispostos de forma intercalada no interior da caldeira. 


\section{Resultados}

\subsection{Introdução}

O modelo foi validado contra nove pontos de operação em regime permanente, nos quais a carga da turbina a gás variou entre $63 \%$ a $95 \%$ de sua carga normalizada (Tabela 7), mantendo os limites usados para a calibração do modelo.

Tabela 7 - Cargas utilizadas para a validação do modelo

\begin{tabular}{|l|c|c|c|c|c|c|c|c|}
\hline \multicolumn{7}{|c|}{ Percentual de Carga da Turbina a Gás } \\
\hline $95,00 \%$ & $94,00 \%$ & $93,00 \%$ & $86,00 \%$ & $84,00 \%$ & $80,00 \%$ & $76,00 \%$ & $67,00 \%$ & $63,00 \%$ \\
\hline
\end{tabular}

Como já foi mencionado, não existem medições na entrada e saída de cada trocador de calor, portando os dados que podem ser utilizados na validação são apenas relativos aos seguintes parâmetros:

Tabela 8 - Parâmetros utilizados para validar o modelo

\begin{tabular}{|c|l|}
\hline 1 & Vazão de vapor na saída recuperador 2 \\
\hline 2 & Temperatura do vapor na saída do recuperador 2 \\
\hline 3 & Pressão de vapor na saída do recuperador 2 \\
\hline 4 & Vazão de vapor na saída do superaquecedor de HP 2 \\
\hline 5 & Temperatura do vapor na saída do superaquecedor de HP 2 \\
\hline 6 & Pressão do vapor na saída do superaquecedor de HP 2 \\
\hline 7 & Pressão do vapor na saída do evaporador de HP \\
\hline 8 & Pressão do vapor na saída do evaporador de IP \\
\hline 9 & Pressão de vapor na saída do evaporador de LP \\
\hline 10 & Vazão de vapor na saída do superaquecedor de LP \\
\hline 11 & Temperatura do vapor na saída do superaquecedor de LP \\
\hline 12 & Pressão do vapor na saída do superaquecedor de LP \\
\hline 13 & Vazão de vapor na saída do superaquecedor de IP \\
\hline 14 & Temperatura do vapor na saída do superaquecedor de IP \\
\hline 15 & Pressão do vapor na saída do superaquecedor de IP \\
\hline 16 & Vazão de gás na saída do reaquecedor 2 \\
\hline 17 & Temperatura do gás na saída do reaquecedor 2 \\
\hline 18 & Pressão do gás na saída do reaquecedor 2 \\
\hline
\end{tabular}


Porém, a pressão do vapor no evaporador de LP foi utilizada como um dado de entrada, uma vez que outros dados referentes à pressão na linha de LP após o preaquecedor não eram fornecidos.

Além disso, a vazão de vapor na saída do recuperador (reaquecedor) 2 IP é a mesma do que o parâmetro de entrada que fornece a vazão na entrada do recuperador (reaquecedor) \#1 (condição de regime permanente), portanto seu desvio é nulo. O mesmo acontece com a vazão dos gases de exaustão, a vazão dos gases na saída da turbina a gás é mesma do que na saída da chaminé (uma entrada do modelo) dada a condição de regime permanente.

Logo a comparação desses três parâmetros não será realizada, apenas das demais variáveis da Tabela 8 .

\subsection{Resultados Obtidos}

A temperatura de saída do vapor no reaquecedor \#2 calculada foi comparada com dados reais de operação da usina e os desvios obtidos foram inferiores a $5 \%$, como mostrado na Figura 32.

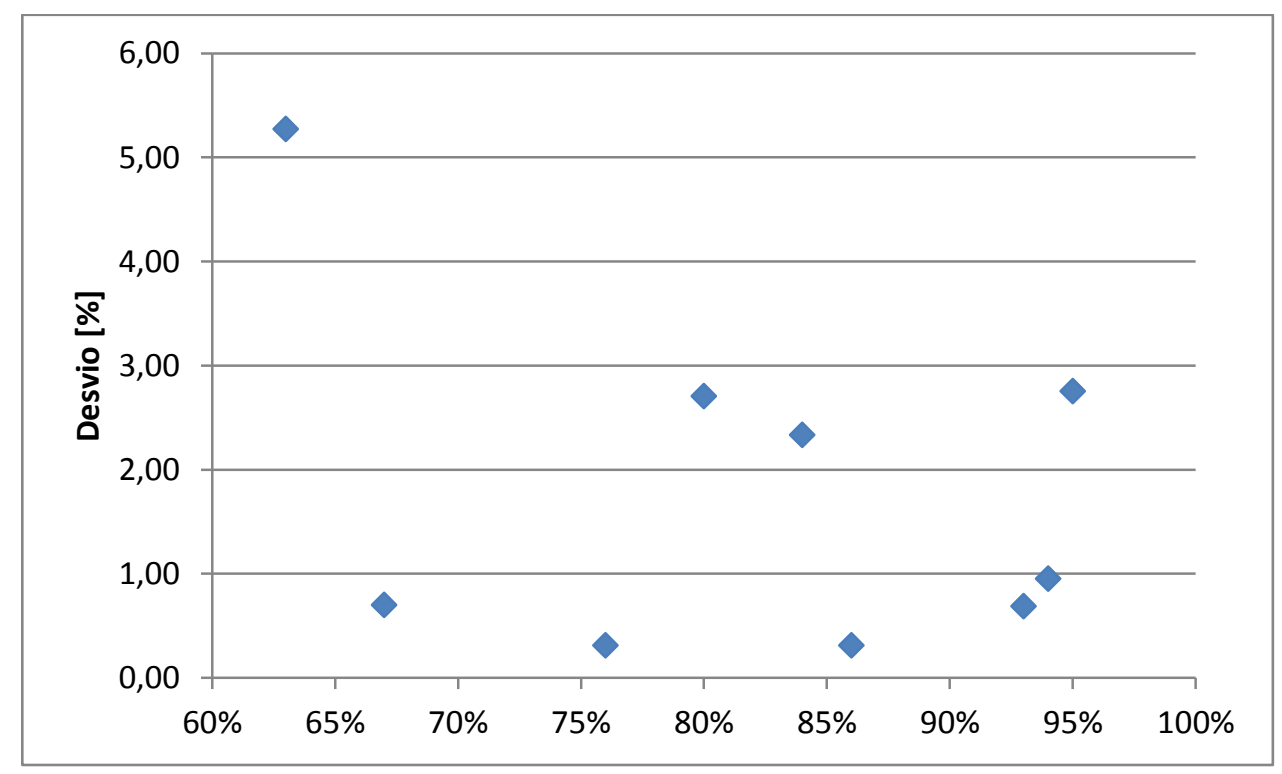

Figura 32 - Desvios obtidos para a temperatura do vapor na saída do reaquecedor de IP \#2

Ainda no reaquecedor \#2, a pressão de saída do vapor foi calculada e comparada aos dados de operação sendo os desvios obtidos variando entre $14,7 \%$ e 0,19\%, exibidos na Figura 33. Essa discrepância mostra que os coeficientes estão bem ajustados para algumas condições de operação, porém para dois patamares de carga o desvio foi superior a $10 \%$. Observou-se que a pressões calculadas onde o erro 
foi superior a $10 \%$ ( $63 \%$ e $76 \%$ de carga da turbina a gás) estavam elevadas, maiores do que as pressões calculadas percentuais cargas superiores, o que indica que o expoente de calibração da queda de pressão no lado da água não estava devidamente ajustado para essas faixas de operação.

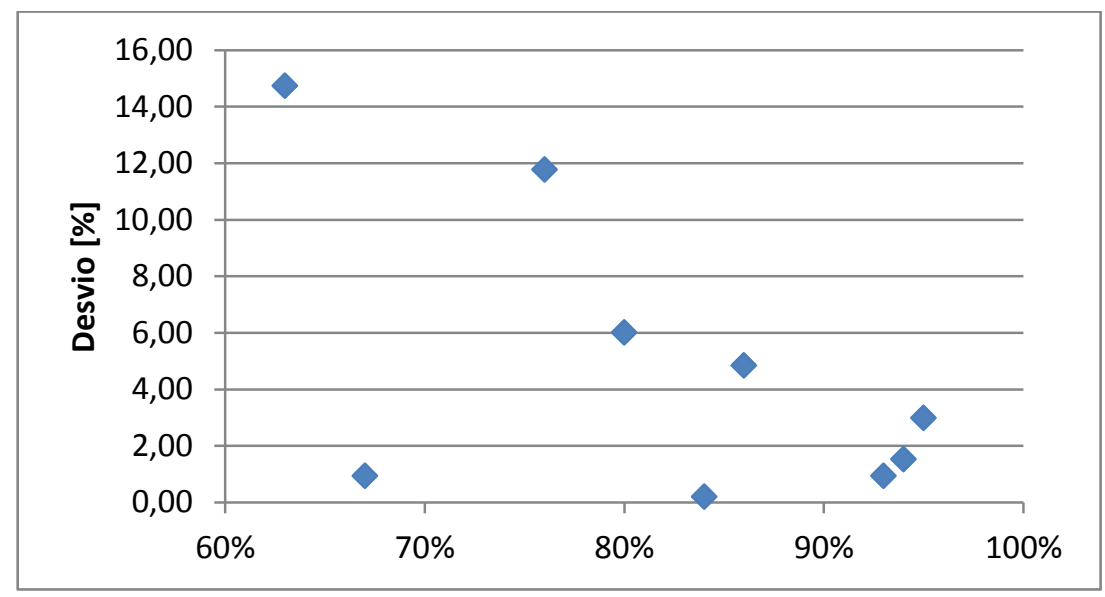

Figura 33 - Desvios obtidos para a pressão do vapor na saída do reaquecedor de IP \#2

A vazão de vapor do superaquecedor de HP \#2 calculada foi comparada com dados reais, Figura 34, resultando em desvios inferiores a $4 \%$. Cabe ressaltar que como o modelo considera que a operação se dá em regime permanente, a vazão de entrada no economizador de HP \#1 é dada como a mesma na saída do superaquecedor de HP \#2, e, como indicado pela Figura 34, na operação real tal fato não ocorre, essa diferença se dá devido a recirculações no evaporador, extrações de blowdown, controles de nível do tubulão e injeções de água pelos desuperaquecedores, que alteram a vazão em um pequeno percentual.

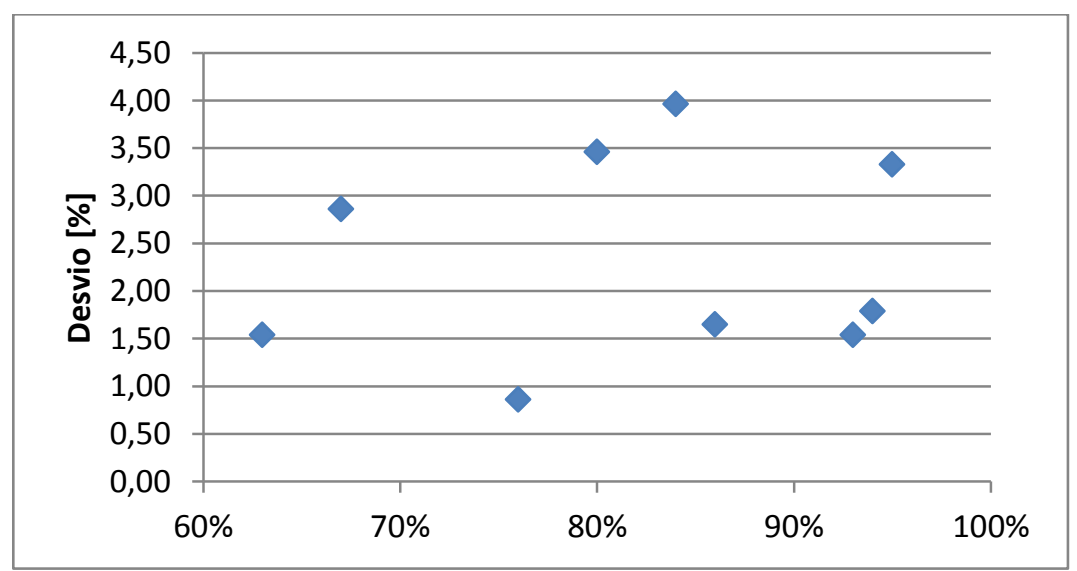

Figura 34 - Desvios obtidos para a vazão na superaquecedor de HP \#2 
O desvio da temperatura de saída do vapor no superaquecedor de HP \#2 é mostrado na Figura 35. Os valores indicam que a discrepância entre dados calculados e medidos ficou abaixo de $4 \%$ para todos os casos.

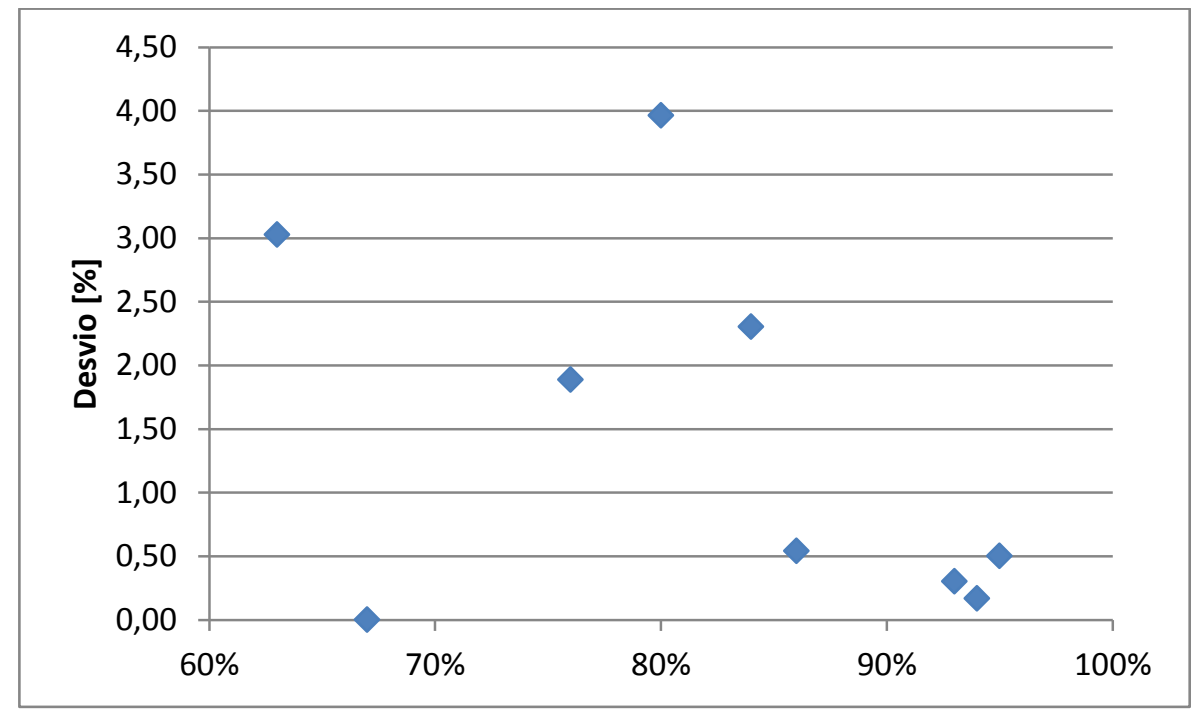

Figura 35 - Desvios obtidos para a temperatura do vapor na saída do superaquecedor de HP \#2

O desvio da pressão de saída do vapor de HP no superaquecedor \#2 também sem mostrou satisfatório, abaixo de 1\%, com um único ponto de operação apresentando $6 \%$ de erro.

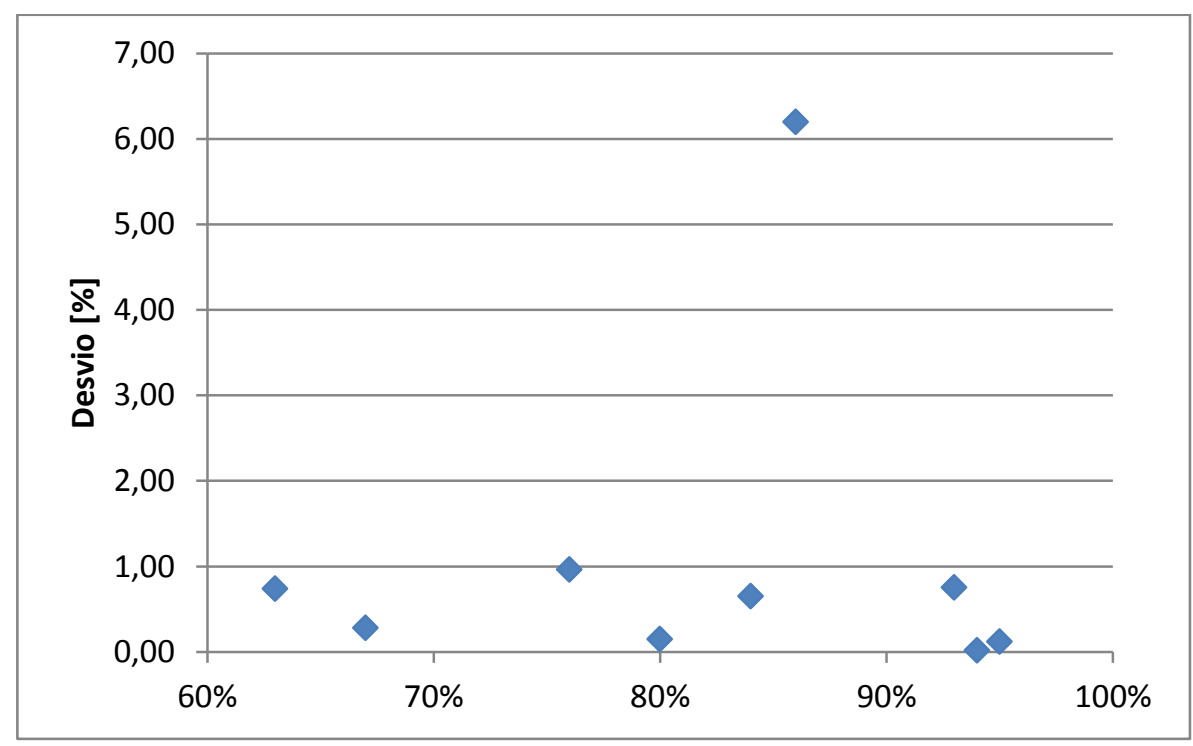

Figura 36 - Desvios obtidos para a pressão do vapor na saída do superaquecedor de HP \#2 
Foram comparadas também as pressões nos tubulões de HP e IP, Figura 37 e Figura 38, respectivamente. O tubulão de HP mostrou desvios inferiores a $5 \%$ enquanto no tubulão de IP manteve-se abaixo de $2 \%$.

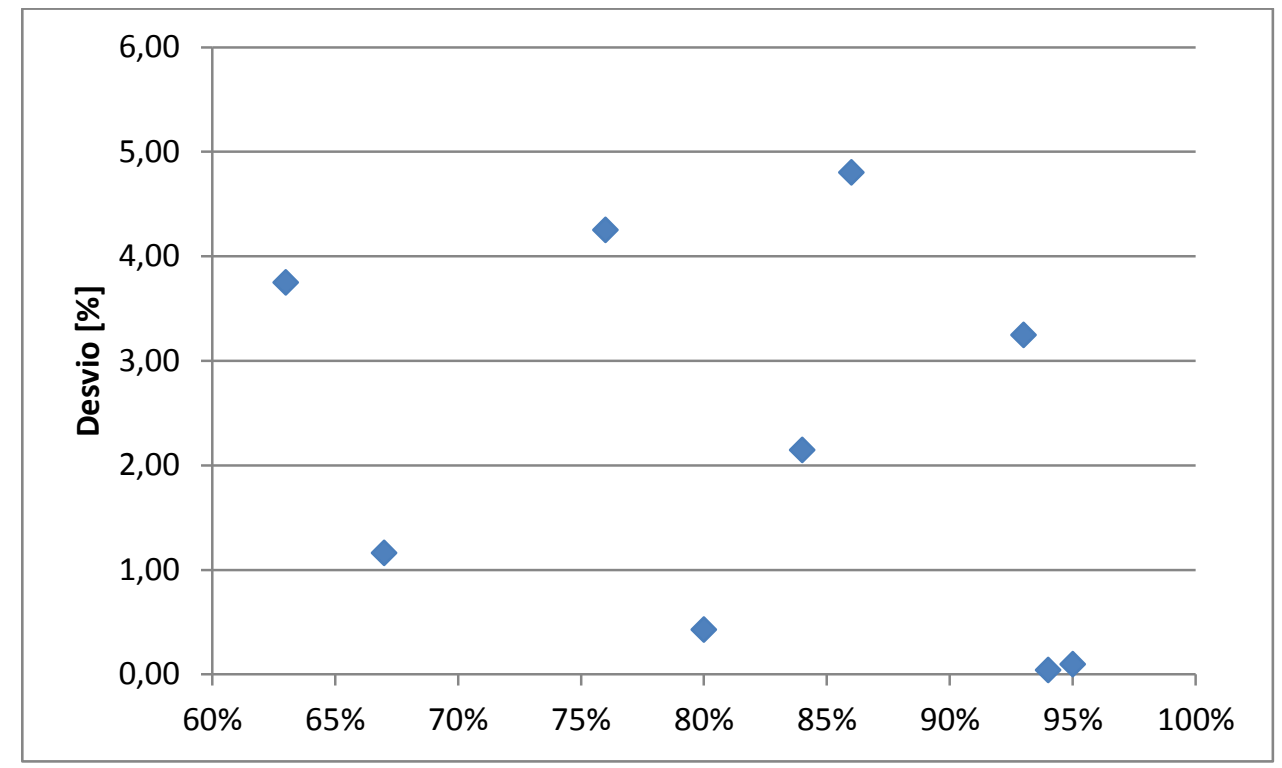

Figura 37 - Desvios obtidos para a pressão do vapor na saída do evaporador de HP

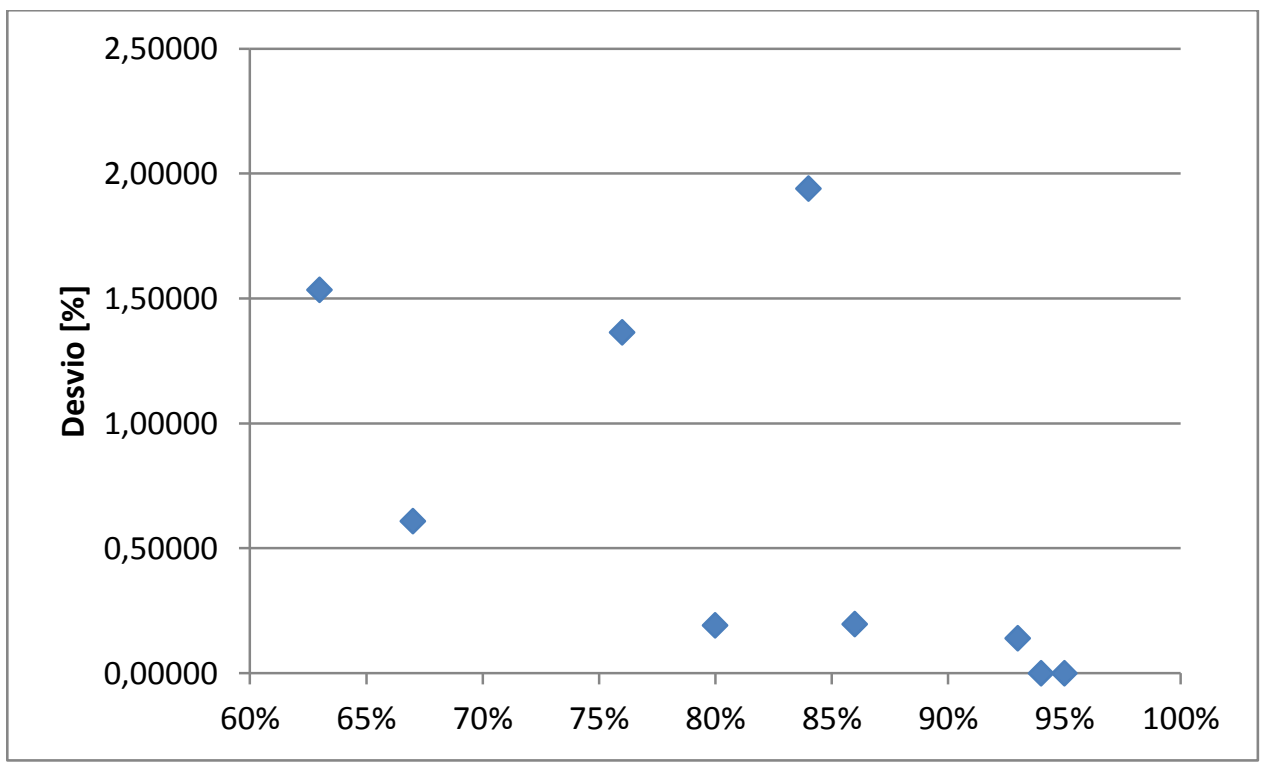

Figura 38 - Desvios obtidos para a pressão do vapor na saída do evaporador de IP

O tubulão de LP não pode ser validado, pois sua medição foi usada como alimentação do modelo, uma vez que a linha de LP não possui um economizador individual, sendo esse processo primário de aquecimento da água feito no preaquecedor. 
A vazão de vapor no superaquecedor de LP obteve o maior desvio pontual, alcançando cerca de $19 \%$ para $63 \%$ de carga da turbina a gás, Figura 39 . Tal fato ocorreu, pois a vazão de entrada na linha de LP para o patamar de carga de $63 \%$ estava muito elevada (superior à de $65 \%$ de carga), o que sugere que no momento onde os dados de input foram coletados a caldeira poderia estar sujeita à uma condição de operação não prevista pelo modelo, o que é razoável devido ao baixo valor de carga da turbina a gás.

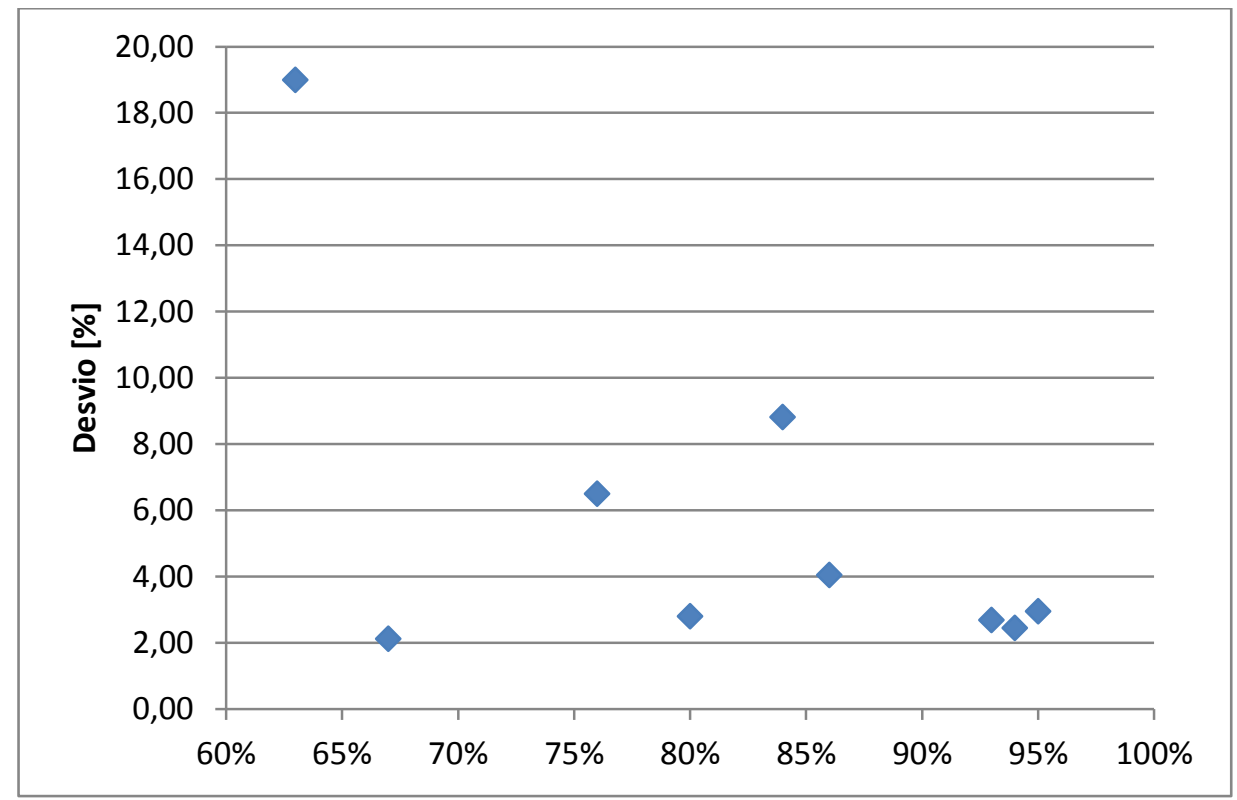

Figura 39 - Desvios obtidos para a vazão de vapor no superaquecedor de LP

Já temperatura de saída do vapor se manteve abaixo de $6 \%$ de desvio. A pressão na saída apresentou bons resultados no geral, porém ocorreu um desvio consideravelmente mais alto que os demais de em um ponto, $12 \%$ para $67 \%$ de carga na turbina a gás. Analisando os resultados, percebeu-se que a pressão calculada pelo modelo indicou um valor inferior à pressão calculada para $63 \%$ de carga, algo não esperado. E, diferentemente do alto desvio vazão (Figura 39), essa irregularidade não é proveniente de um valor de entrada inconsistente, pois a pressão na entrada da linha de LP com carga de $63 \%$ é inferior à de 67\%, mantendo a coesão física. Portanto, leva-se a crer que um expoente tenha sido mal calibrado para o patamar de cargas de $67 \%$. 


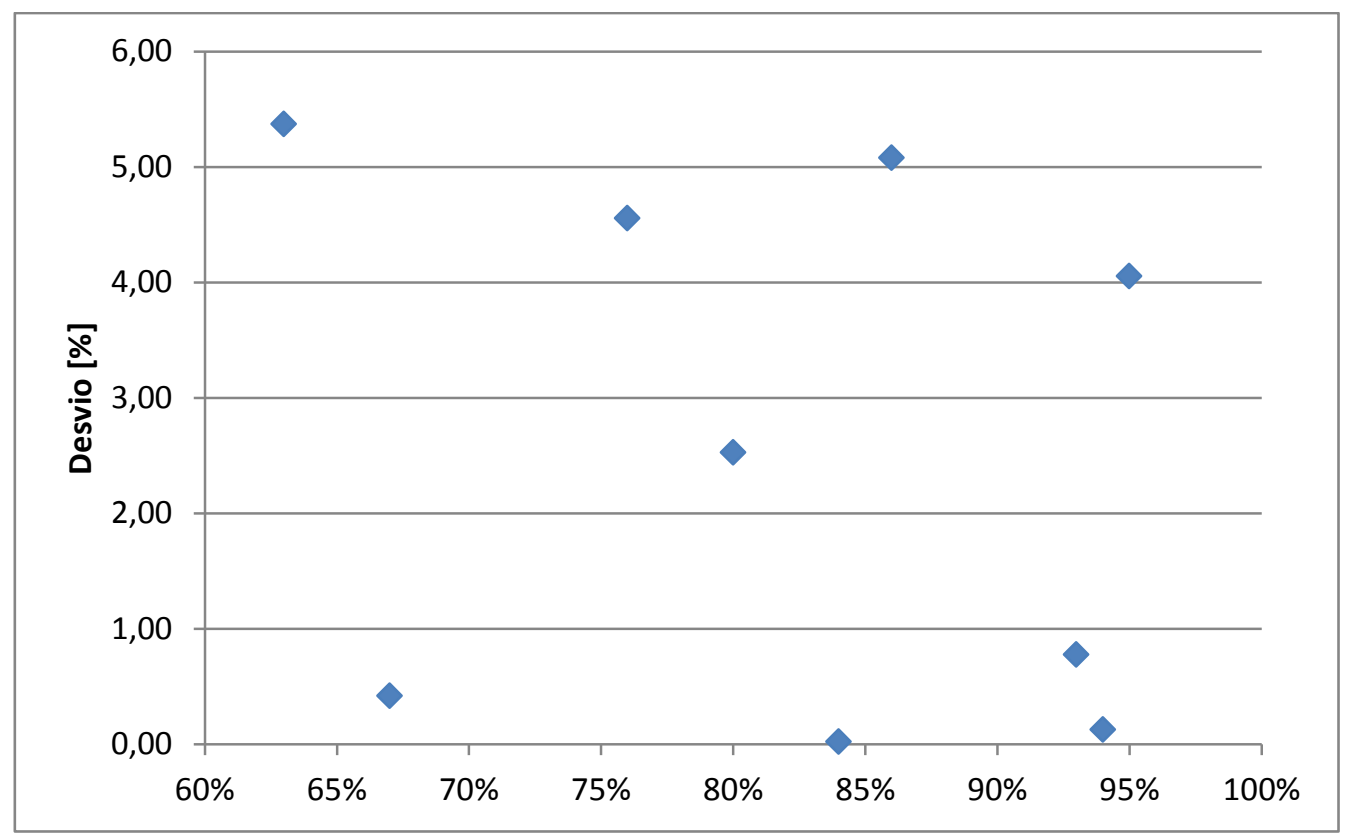

Figura 40 - Desvios obtidos para a temperatura do vapor na saída do superaquecedor de LP

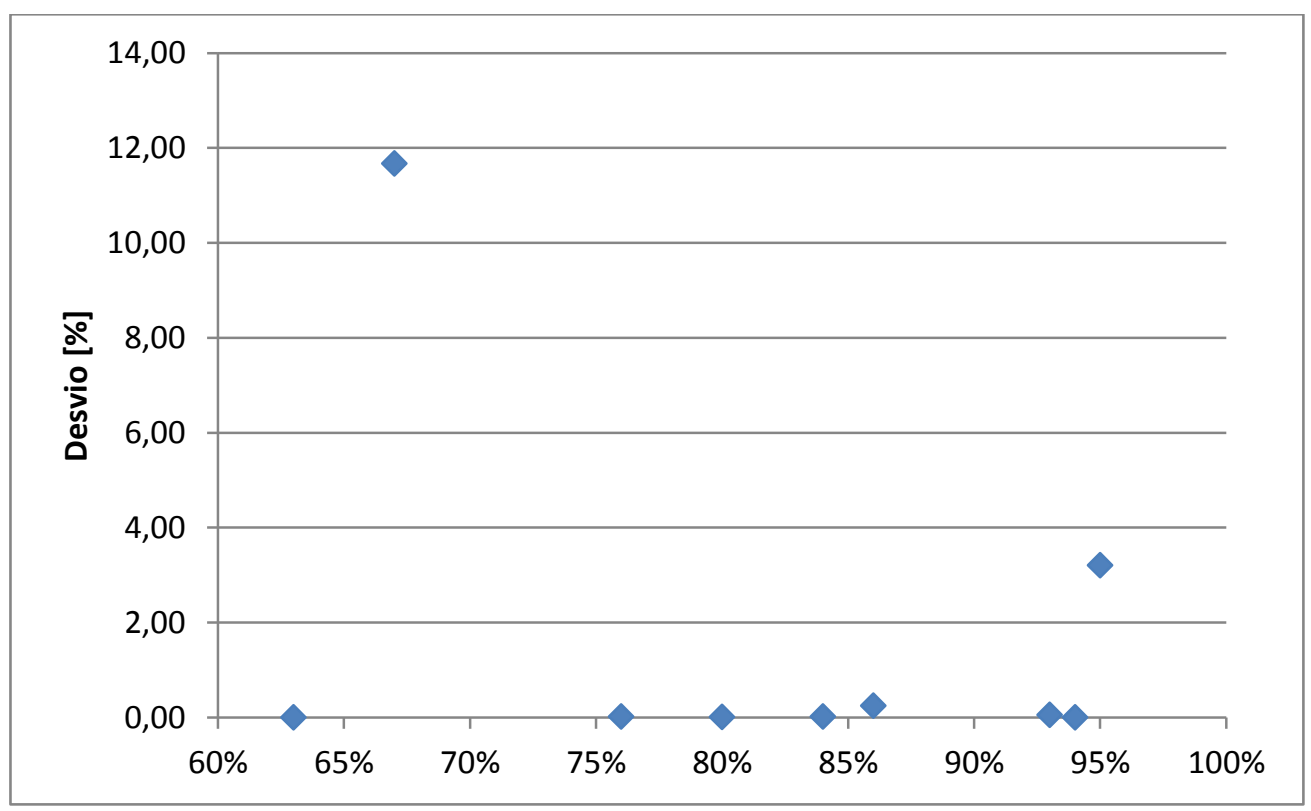

Figura 41 - Desvios obtidos para a pressão do vapor na saída do superaquecedor de LP

Os resultados obtidos para a temperatura, pressão e vazão no superaquecedor de IP são exibidos na Figura 42, Figura 43 e Figura 44 respectivamente. A temperatura e pressão apresentaram desvios inferiores a $4,5 \%$, enquanto a vazão atingiu desvios em torno de $7 \%$, aqui cabe novamente ressaltar que o modelo considera a hipótese de regime permanente, enquanto na realidade pequenas alterações no fluxo da linha podem ocorrer. 


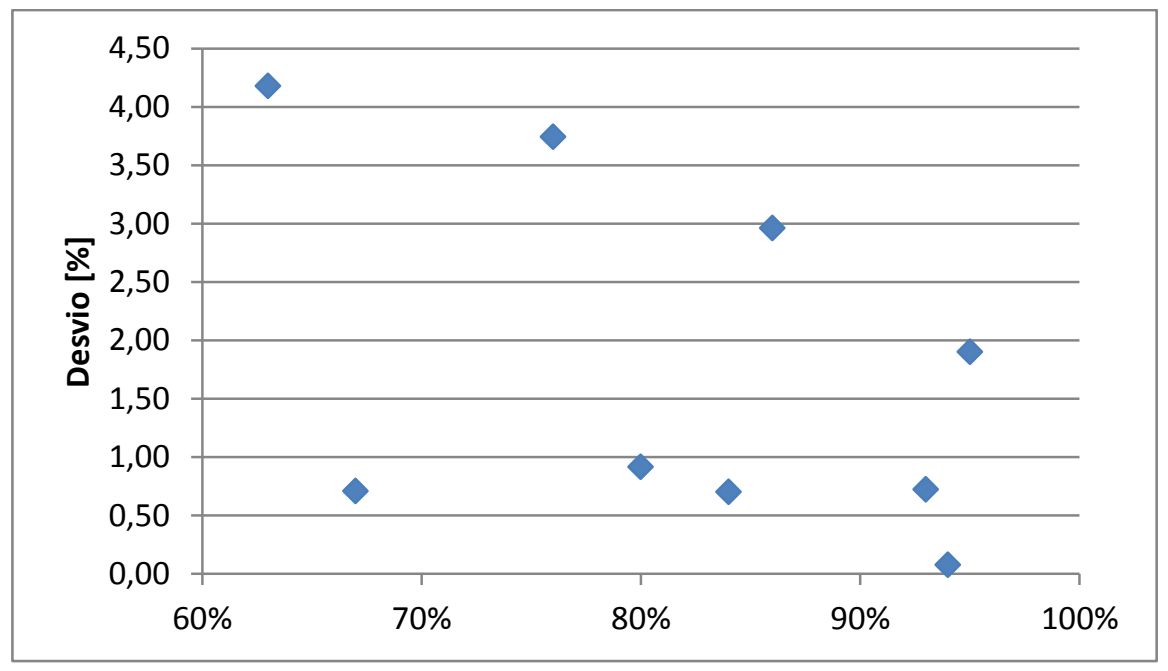

Figura 42 - Desvios obtidos para a temperatura do vapor na saída do superaquecedor de IP

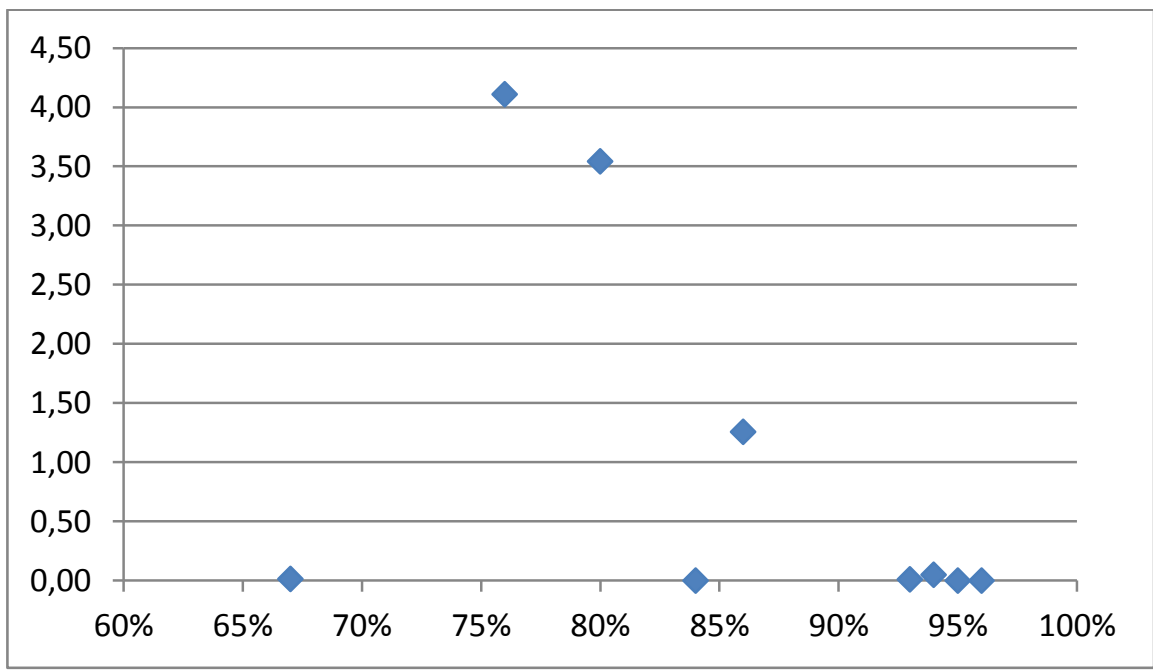

Figura 43 - Desvios obtidos para a pressão do vapor na saída do superaquecedor de IP

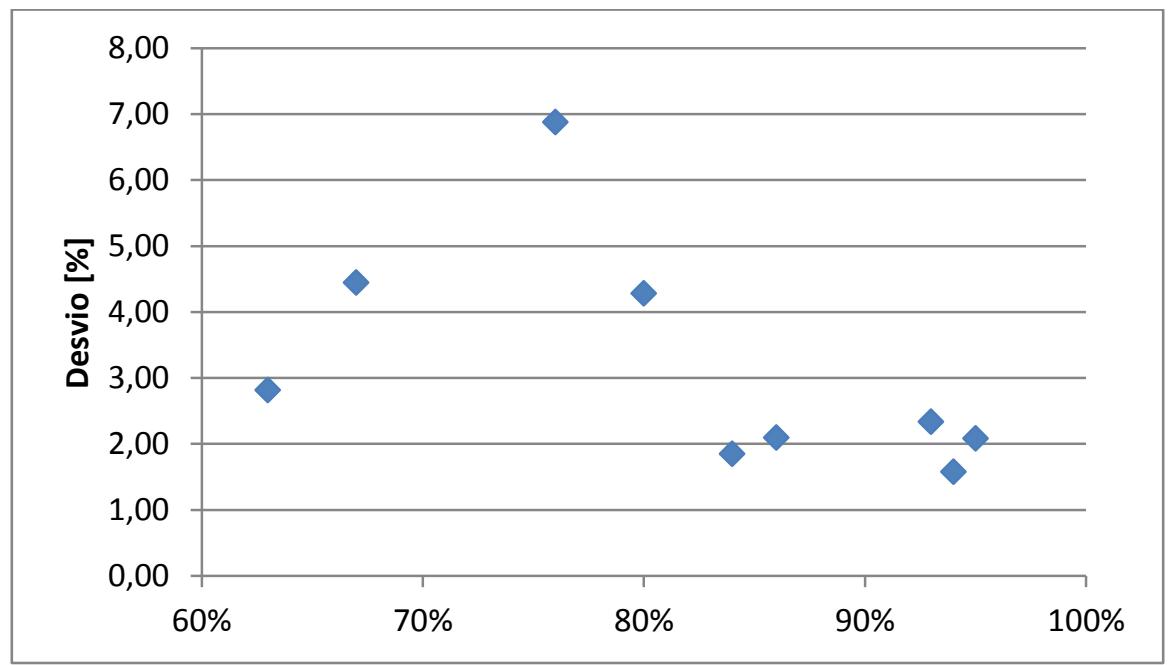

Figura 44 - Desvios obtidos para a vazão de vapor no superaquecedor de IP 
Como as medições referentes aos gases de exaustão são poucas, o estudo dos desvios só foi possível de ser feito na entrada do reaquecedor \#2, a temperatura dos gases na entrada da caldeira de recuperação de calor mostrada na Figura 45. Os desvios obtidos variaram de um máximo de 12,5\% a um mínimo de 3,5\%.

Os resultados mostraram que a temperatura de entrada dos gases quentes no reaquecedor \#2 para a carga de $63 \%$ foi maior do que em todas as demais cargas. Uma possível explicação é que o coeficiente de troca de calor global calculado esteja inferior ao valor real, necessitando assim que uma maior variação de temperatura ocorra de forma a garantir a troca de calor. Essa não conformidade se dá devido a expoentes calibrados relativos ao cálculo do termo $U$, que devem ser melhor ajustados.

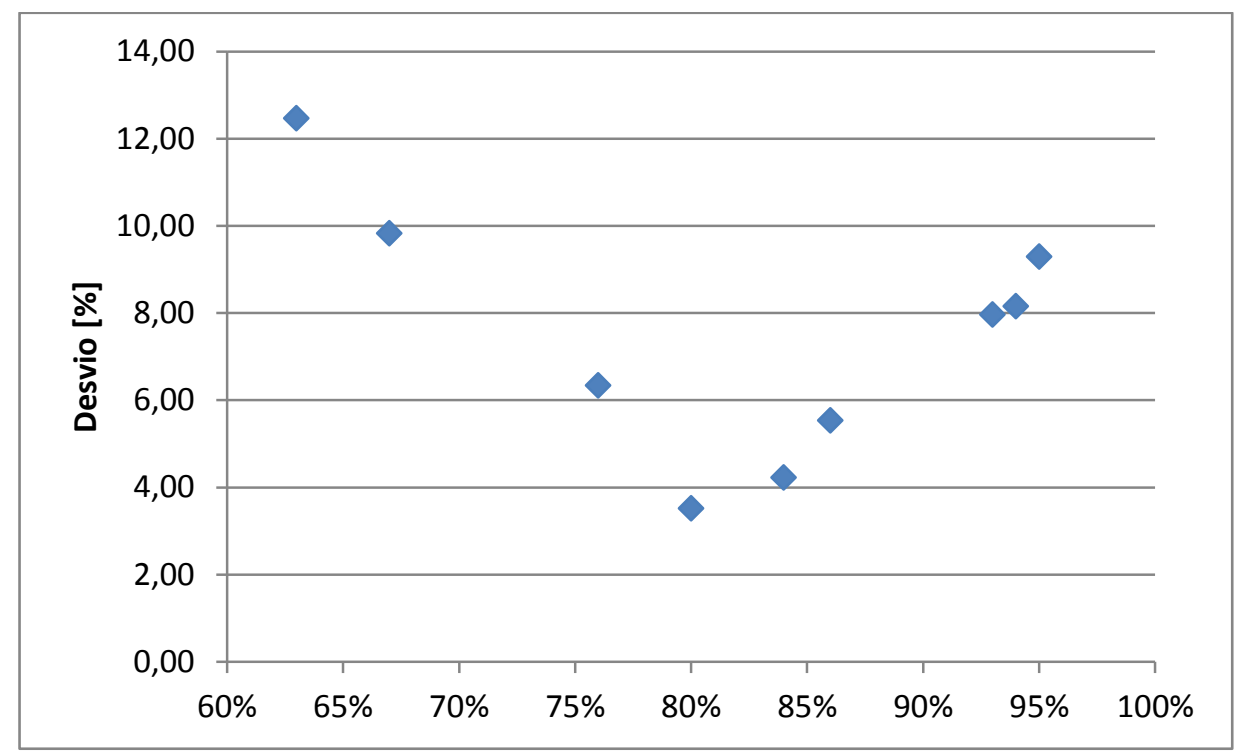

Figura 45 - Desvios obtidos para a temperatura dos gases de exaustão na entrada do reaquecedor de IP \#2

$\mathrm{Na}$ Figura 46 são mostrados os desvios obtidos para a pressão dos gases na entrada do reaquecedor \#2. Os desvios mostrados aqui foram os menores obtidos, isso ocorre, pois a queda de pressão calculada ao longo dos trocadores de calor foi considerada linear, não dependendo de expoentes de calibração. 


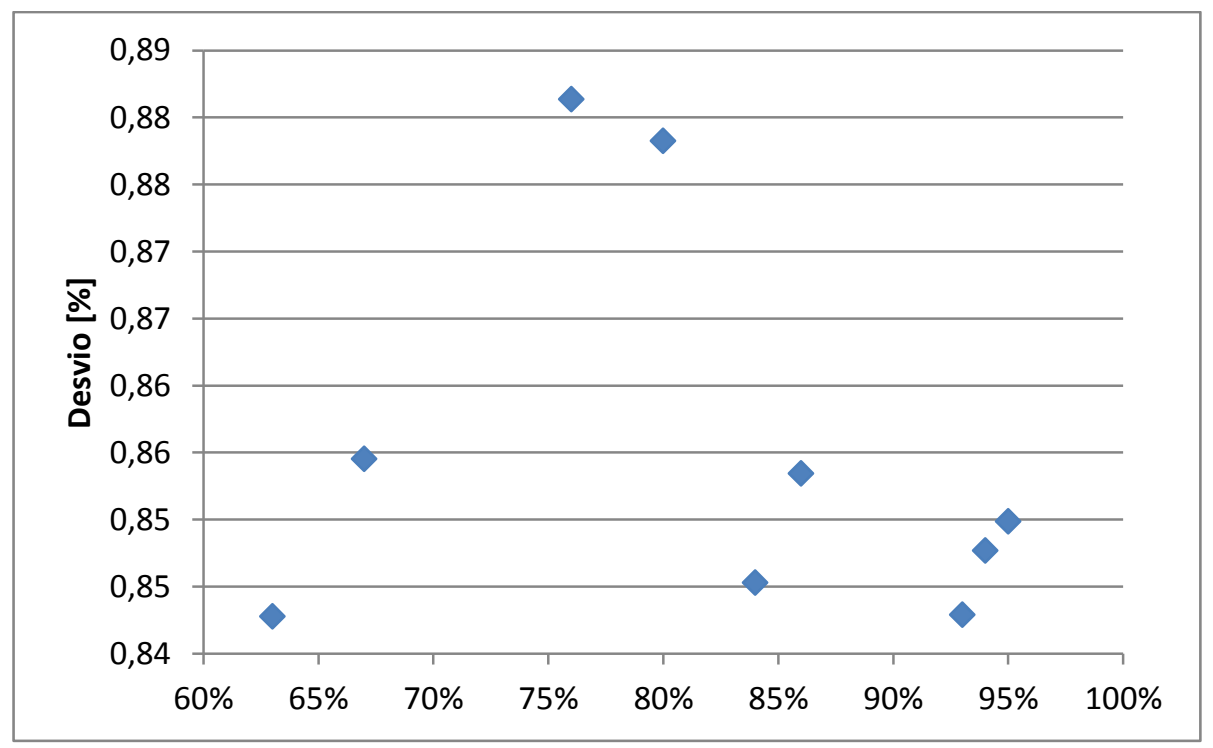

Figura 46 - Desvios obtidos para a pressão dos gases de exaustão na entrada do reaquecedor de IP \#2 


\section{7 \\ Conclusões}

O programa desenvolvido para o diagnóstico termodinâmico de caldeiras de recuperação de calor foi calibrado e posteriormente validado em nove diferentes situações de operação, mostrando-se capar de atuar como uma ferramenta de análise e apoio para uma operação real.

Para que o modelo possua uma alta confiabilidade é necessário garantir que uma ampla gama de dados de operação em diversas condições de carga estejam disponíveis para a calibração dos expoentes feita pelo algoritmo genético, pois tais parâmetros são fundamentais para o cálculo off-design.

Os resultados obtidos apresentaram o bom desempenho do modelo para o caso estudado: a simulação da operação de uma caldeira de recuperação com três níveis de pressão e reaquecimento, sem queima suplementar. Os desvios obtidos se mostraram satisfatórios e apresentaram valores ainda mais baixos quando a operação se dá próxima de algum ponto de calibração. Porém, quatro desvios pontuais atingiram valores superiores a 10\%, um deles pôde ser explicado pela inconsistência de dados de entrada, porém os outros três se deram devido à necessidade de uma melhor calibração dos expoentes utilizados para o cálculo das quedas de pressão e dos coeficientes globais de troca de calor, reafirmando a necessidade de uma grande quantidade de dados de calibração para garantir robustez ao modelo, bem como de sistemas de penalidade eficientes para os algoritmos genéticos, garantindo sempre uma calibração eficaz.

Deve-se ressaltar que o modelo foi construído de maneira a ser facilmente adaptável para simular caldeiras com outras configurações, dependendo apenas de modificações em sua rotina principal que ordena os trocadores de calor. 


\section{8 \\ Trabalhos Futuros}

O presente trabalho pode ser utilizado para gerar pesquisas futuras em diferentes tipos de caldeiras, uma vez que o modelo desenvolvido é genérico e facilmente adaptável para outras configurações de HRSGs, sejam elas horizontais ou verticais. No caso dessas últimas é importante ressaltar a necessidade de considerar bombas de circulação forçada, não necessárias em caldeiras horizontais, portanto, não previstas nesse trabalho.

A adição de efeitos que alteram a vazão ao longo das linhas de pressão, mesmo quando a operação se encontra em regime permanente, pode reduzir os desvios obtidos nas vazões calculadas. Portanto, simular os efeitos de blowdown e dos desuperaquecedores é uma evolução interessante para o atual trabalho.

Outra contribuição relevante seria a adição de um módulo responsável por simular o efeito da queima suplementar, elevando a temperatura dos gases de exaustão através da queima de combustível no interior da caldeira.

Finalmente, o modelo atual permite ser estendido para simular os fenômenos transitórios da caldeira de recuperação pela metodologia sugerida por [27], onde o cálculo do transiente é realizado por uma rotina a parte que altera as entradas dos módulos off-design, mantendo o equacionamento matemático original de cada trocador de calor mostrado nessa dissertação. Em regime transiente, a inserção do modelo dos desuperaquecedores é essencial, pois a utilização desses equipamentos é crucial para garantir transitórios não danosos à caldeira nesse tipo de operação. 
9

\section{Bibliografia}

1. GANAPATHY, V. Industrial Boilers and Heat Recovery Steam Generators. New York: Marcel Dekker, Inc., 2003.

2. GANAPATHY, V. Applications of HRSG Simulation. Abilene, Texas: ASCO Industries.

3. GANAPATHY, V. Basic Programs for Steam Plant Engineers. New York: Marcel Dekker, Inc., 1986.

4. GANAPATHY, V. Simplify Heat Recovery Steam Generetor Evaluation, Abilene.

5. SHI, W. et al. Fuel, Performance Simulation of Gas Turbine Combined Cycle with Coke Oven Gas as. North China Electric Power University, Baoding.

6. ASSATO, M. et al. Off Design Modeling and Simulation of the HRSG Components in Combined Cycle Plants. 12th Brazillian COngress of Thermal Engineering Sciences, Belo Horizonte, 10-14 November 2008.

7. MANASSALDI, J. I.; MUSSATI, S. F.; N.J., S. Optimal synthesis and design of Heat Recovery Steam Generation via mathematical programming. Energy, 2011.

8. KIM, T. S.; LEE, D. K.; RO, S. T. Analysis of Thermal Stress Evolution in the Steam Drum During Start-up of a Heat Recovery Steam Generator, 2000.

9. SANAYE, S.; REZAZADEH, M. Thermal Modeling of HRSG Behavior in Combined Cycle Power Plants, Barcelona, 2006. 
10. KIM, S. T.; PARK, H. J.; RO, S. T. Characteristics of Transient Operation of a Dual-Pressure Bottoming System for the Combined Cycle Power Plant. Energy, v. 26, p. 905-918, 2001.

11. SANAYE, S.; MORADI, A. Development of a New Simulation Program for Combined Cycle System, Amsterdam, 2002.

12. JOLLY, S.; GUREVICH, A.; PASHA, A. Modeling of Start-up Behavior of Combined Cycle HRSG's, 1994.

13. ONG'IRO, A. et al. Modeling of Heat Recovery Steam Generator Performance. Applied Thermal Engineering, 1997. 427-446.

14. GAS Net - O site do gás natural

15. KEHLHOFER, R. et al. Combine-Cycle Gas \& Steam Turbine Power Plants. 3rd. ed. Tulsa: PennWell Corporation, 2009.

16. LORA, E. E. S.; NASCIMENTO, M. A. R. Geração Termelétrica Planejamento, Projeto e Operação. 1ª. ed. Rio de Janeiro: Interciência, 2004.

17. SWANEKAMP, R. C. HRSG Users Handbook. 2nd. ed. Las Vegas: HRSG User's Group, 2006.

18. INCROPERA, F. P.; DE WITT, D. P. Fundamentals of Heat and Mass Transfer. $5^{a}$. ed. [S.I.]: [s.n.].

19. MIRONER, A. Engineering Fluid Mechanics. New York: McGraw-Hill Book Company, 1979.

20. KAYS, W. M.; CRAWFORD, M. E. Convective Heat and Mass Transfer. 2nd. ed. New York: McGraw-Hill Book Company, 1980.

21. HOLMAN, J. P. Heat Transfer. 4th. ed. New York: McGraw-Hill Book Company, 1976. 
22. GOLDBERG, D. E. Genetic Algorithms in Search, Optimization, and Machine Learning. [S.I.]: Addison-Wesley Publishing Company, Inc., 1989.

23. FERREIRA, S. B. Thermoeconomic Analysis and Optimization of Biomass Fuel Gas Turbines. [S.I.]: Cranfield University, 2002.

24. MICHALEWICZ, Z. Genetic Algorithms + Data Structures = Evolution Programs. 3rd. ed. Charlotte: Springer-Verlag, 1999.

25. INTERNATIONAL ASSOCIATION FOR THE PROPERTIES OF WATER AND STEAM. Release on the IAPWS Industrial Formulation 1997 for the Thermodynamic Properties of Water and Steam. [S.I.]. 1997.

26. MCBRIDE, G. R. Coefficients for Calcualting Thermodynamicand Transport Properties of Individual Species. [S.I.]: NASA Technical Memorandum 4513, 1993.

27. ORDYS, A. W. et al. Modeling and Simulation of Power Generation Plants. [S.I.]: [s.n.], 1994. 